\title{
REFERENCE
}

A UNITED STAIES

DEPARTMENT OF

TOMMERCE

ALILO3 074650

PUBLICATION

\section{NSRDS-NBS 41}

\section{Crystal Structure Transformations in Binary Halides}

SPARTMENT

OF COMMERCE

National

Bureau

QC $=$

100

4573

no. 41

1972 


\section{NATIONAL BUREAU OF STANDARDS}

The National Bureau of Standards ${ }^{1}$ was established by an act of Congress March 3 . 1901. The Bureau's overall goal is to strengthen and advance the Nation's science and technology and facilitate their effective application for public benefit. To this end, the Bureau conducts research and provides: (1) a basis for the Nation's physical measurement sistem, (2) scientific and technological services for industry and government. (3) a technical basis for equity in trade, and (4) technical services to promote public safety. The Bureau consists of the Institute for Basic Standards, the Institute for Materials Research, the Institute for Applied Technology, the Center for Computer Sciences and Technology, and the Office for Information Programs.

THE INSTITUTE FOR BASIC STANDARDS provides the central basis within the United States of a complete and consistent system of physical measurement; coordinates that system with measurement systems of other nations; and furnishes essential services leading to accurate and uniform physical measurements throughout the Nation's scientific community, industry, and commerce. The Institute consists of a Center for Radiation Research, an Office of Measurement Services and the following divisions:

Applied Mathematics-Electricity-Heat-Mechanics-Optical Physics-Linac Radiation²-Nuclear Radiation²-Applied Radiation²-Quantum Electronics ${ }^{3}$ Electromagnetics - Time and Frequency ${ }^{3}$ - Laboratory Astrophysics ${ }^{3}$ - Cryogenics ${ }^{3}$.

THE INSTITUTE FOR MATERIALS RESEARCH conducts materials research leading to improved methods of measurement, standards, and data on the properties of well-characterized materials needed by industry, commerce, educational institutions, and Government: provides advisory and research services to other Government agencies; and develops, produces, and distributes standard reference materials. The Institute consists of the Office of Standard Reference Materials and the following divisions:

Analytical Chemistry-Polymers-Metallurgy-Inorganic Materials-Reactor Radiation-Physical Chemistry.

THE INSTITUTE FOR APPLIED TECHNOLOGY provides technical services to promote the use of available technology and to facilitate technological innovation in industry and Government; cooperates with public and private organizations leading to the development of technological standards (including mandatory safety standards), codes and methods of test; and provides technical advice and services to Government agencies upon request. The Institute also monitors NBS engineering standards activities and provides liaison between NBS and national and international engineering standards bodies. The Institute consists of the following divisions and offices:

Engineering Standards Services-Weights and Measures-Invention and Innovation-Product Evaluation Technology-Building Research-Electronic Technology-Technical Analysis-Measurement Engineering-Office of Fire Programs.

THE CENTER FOR COMPUTER SCIENCES AND TECHNOLOGY conducts research and provides technical services designed to aid Government agencies in improving cost effectiveness in the conduct of their programs through the selection, acquisition, and effective utilization of automatic data processing equipment; and serves as the principal focus within the executive branch for the development of Federal standards for automatic data processing equipment, techniques, and computer languages. The Center consists of the following offices and divisions:

Information Processing Standards-Computer Information-Computer Services

- Systems Development-Information Processing Technology.

THE OFFICE FOR INFORMATION PROGRAMS promotes optimum dissemination and accessibility of scientific information generated within NBS and other agencies of the Federal Government; promotes the development of the National Standard Reference Data Svistem and a system of information analysis centers dealing with the broader aspects of the National Measurement System; provides appropriate services to ensure that the NBS staff has optimum accessibility to the scientific information of the world, and directs the public information activities of the Bureau. The Office consists of the following organizational units:

Office of Standard Reference Data-Office of Technical Information and Publications-I-ibrary-Office of International Relations.

Hoal quaner d Lattor.tores at Gather burg, Maryland, unless otherwise noted; mailing address Washing- 
QC 10 OUnited states department of Commerce - Peter G. Peterson, Secretary

\title{
Crystal Structure Transformations in Binary Halides
}

C. N. R. Rao and M. Natarajan

\author{
Department of Chemistry \\ Indian Institute of Technology \\ Kanpur-16, India
}

\begin{abstract}
tNSRDS-NBS 41
Nat. Stand. Ref. Data Ser., Nat. Bur. Stand. (U.S.), 41, 53 pages (July 1972) CODEN: NSRDAP

(C) 1972 by the Secretary of Commerce on Behalf of the United States Government
\end{abstract}

Issued July 1972

For sale by the Superintendent of Documents, U.S. Government Printing Office Washington, D.C., 20402 (Order by SD Catalog No. C 13.48:41)-Price 55 cents 
Library of Congress Catalog Card Number: 78-186213 


\section{Foreword}

The National Standard Reference Data System provides access to the quantitative data of physical science, critically evaluated and compiled for convenience, and readily accessible through a variety of distribution channels. The System was established in 1963 by action of the President's Office of Science and Technology and the Federal Council for Science and Technology, with responsibility to administer it assigned to the National Bureau of Standards.

The System now comprises a complex of data centers and other activities, carried on in academic institutions and other laboratories both in and out of government. The independent operational status of existing critical data projects is maintained and encouraged. Data centers that are components of the NSRDS produce compilations of critically evaluated data, critical reviews of the state of quantitative knowledge in specialized areas, and computations of useful functions derived from standard reference data. In addition, the centers and projects establish criteria for evaluation and compilation of data and make recommendations on needed improvements in experimental techniques. They are normally closely associated with active research in the relevant field.

The technical scope of the NSRDS is indicated by the principal categories of data compilation projects now active or being planned: nuclear properties, atomic and molecular properties, solid state properties, thermodynamic and transport properties, chemical kinetics, and colloid and surface properties.

The NSRDS receives advice and planning assistance from the National Research Council of the National Academy of Sciences-National Academy of Engineering. An overall Review Committee considers the program as a whole and makes recommendations on policy, long-term planning, and international collaboration. Advisory Panels, each concerned with a single technical area, meet regularly to examine major portions of the program, assign relative priorities, and identify specific key problems in need of further attention. For selected specific topics, the Advisory Panels sponsor subpanels which make detailed studies of users' needs, the present state of knowledge, and existing data resources as a basis for recommending one or more data compilation activities. This assembly of advisory services contributes greatly to the guidance of NSRDS activities.

The NSRDS-NBS series of publications is intended primarily to include evaluated reference data and critical reviews of long-term interest to the scientific and technical community.

Lawrence M. Kushner, Acting Director 


\section{Preface}

Many solids undergo transformations from one crystal structure to another. Studies of such phase transformations are of great value in understanding the nature and properties of solid materials. Recent literature abounds in information on the phase transformations of solids and it is often difficult to obtain relevant data or references on the transformations of any specific solid. We, therefore, considered it worthwhile to collect the literature on the phase transformations of various types of inorganic solids and present them in an organized manner.

In this and subsequent reviews are summarized the important data and conclusions regarding the crystal structure transformations of a few series of inorganic solids. In doing so, we have surveyed most of the material abstracted up to 1970 in Chemical Abstracts and Solid State Abstracts. We have, however, not listed references to the entire published literature on the transformations of a given solid, but have presented only the crucial ones. We believe that all the literature can be traced back through the references listed at the end of each section. In reporting the data on the transformations of a solid we have indicated the methods employed as well as the important data and conclusions from the study. For each solid we have given the crystal structure data for the stable phase around room temperature and at atmospheric pressure making use of the standard patterns of the NBS and ACA Crystal Data; we have indicated the temperature wherever data are available.

The crystal structure transformations of binary halides form the subject matter of this review. This will be followed by reviews on the transformations of binary oxides and other systems. 


\section{Contents}

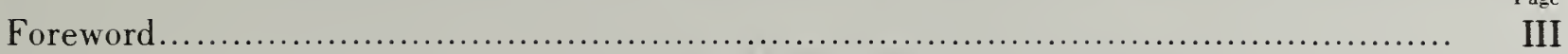

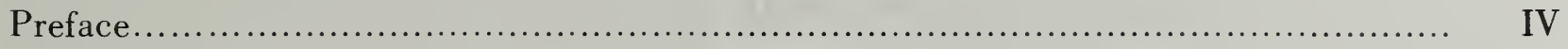

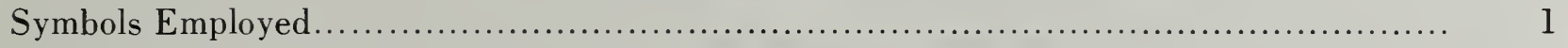

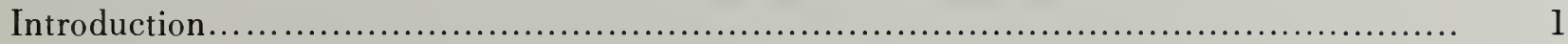

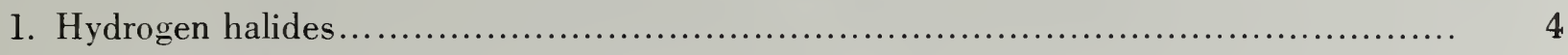

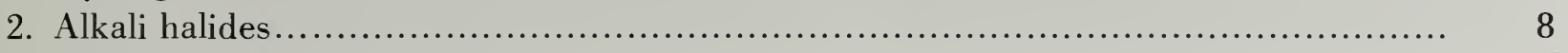

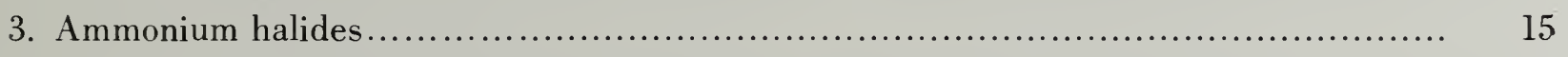

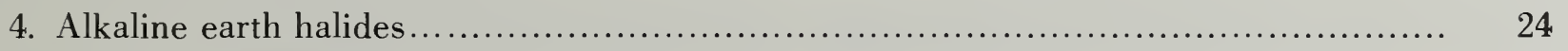

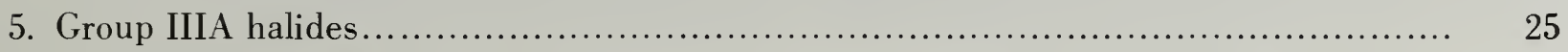

6. Group IVA halides.............................................................. 27

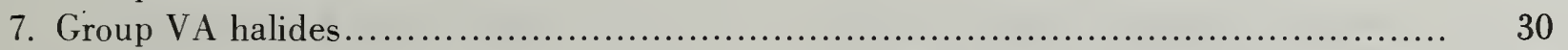

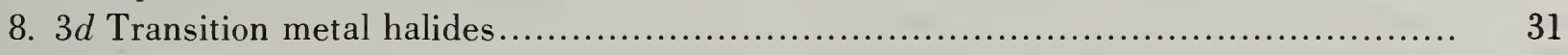

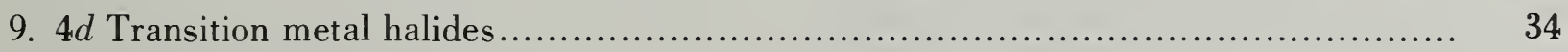

10. $5 d$ Transition metal halides ................................................. 40

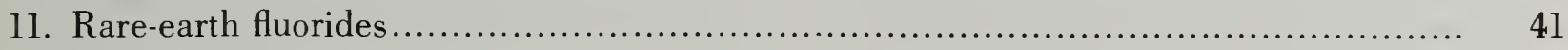

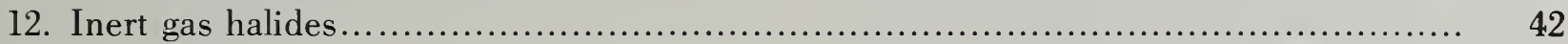

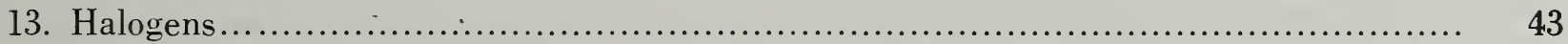





\title{
Crystal Structure Transformations in Binary Halides*
}

\author{
C. N. R. Rao and M. Natarajan
}

\begin{abstract}
A critical survey of the data describing crystal structure transformations in binary halides is compiled. Data on thermodynamic. crystallographic. spectroscopic and electronic properties are given for each transformation. Experimental techniques used to obtain the data are named and comments on the data are included in the tables. The literature is surveyed up to 1970 . References have been selected on the basis of their pertinence to the data which are cited and do not represent all the available literature.
\end{abstract}

Key words: Binary halides; crystal structure transformation: electronic data; phase transformation; spectroscopic data: thermodynamic data; x-ray diffraction data.

\section{Symbols Employed}

$P \quad=$ Pressure

$T=$ Temperature in $\mathrm{K}$

$T_{t} \quad=$ Transformation temperature

$\Delta T=$ Thermal hysteresis in a reversible transformation

$P_{T} \quad=$ Transformation pressure

$\Delta H_{t r}=$ Enthalpy change accompanying the transformation

$C_{p} \quad=$ Heat capacity at constant pressure

$\Delta S \quad=$ Entropy change

$\Delta V=$ Change in volume accompanying a transition

$\rho \quad=$ Density

$\alpha \quad=$ Volume thermal expansion coefficient

$\eta \quad=$ Linear thermal expansion coefficient

$\epsilon \quad=$ Dielectric constant

$P_{s} \quad=$ Spontaneous polarization

$E_{c} \quad=$ Coercive field

$\tan \delta=$ Dissipation factor

$\sigma \quad=$ Electrical conductivity

$E_{a}=$ Energy of activation

$E_{c}^{m} \quad=$ Cation migration energy

$E_{s}=$ Formation energy of Schottky defects

$\mathrm{atm}=$ Atmosphere

cal = Calorie

$\mathrm{eV}=$ Electron volt

DTA $=$ Differential thermal analysis

IR $=$ Infrared

$Z \quad=$ Number of molecules per unit cell

$\mathrm{NMR}=$ Nuclear magnetic resonance

$\mathrm{NQR}=$ Nuclear quadrupole resonance

$\mathrm{EPR}=$ Electron paramagnetic resonance

\section{Introduction}

There has been increasing activity in recent years in the area of crystal structure transformations in inorganic solids. A variety of experimental techniques has been employed to study these phase

*Supported by Project G-77 of the National Bureau of Standards under the Special International Programs. transformations. Valuable information has been obtained on the crystallography, thermodynamics, and kinetics as well as on the changes in optical, dielectric, magnetic and electrical properties accompanying the transformations of a large number of inorganic solids. The subject of phase transformations in inorganic solids has been reviewed by Staveley [1], ${ }^{1}$ Ubbelohde [2] and Rao [3, 4]. We shall now briefly describe the general features of crystal structure transformations.

Thermodynamics of Transformations. Classical thermodynamics gives a simple treatment of the equilibrium between two phases. The equilibrium properties of each phase are defined by the Gibbs free energy function, $G$, the pressure, $P$, and the temperature, $T$. The $G-P-T$ surfaces of two phases are considered to be independent of each other and in a first order phase transformation the surfaces intersect at the transition point. If the transformation takes place from a low-temperature to a high temperature form, there will be an entropy increase and an associated change in volume during the transformation. The classical thermodynamic approach in describing phase transformations is inadequate since a variety of systems are known to exhibit transformations occurring over a wide range of temperatures. These systems show anomalous changes in specific heats and specific volumes and show evidence of "premonitory" phenomena. The transition temperature, $T_{t}$, in these transformations is taken to be that at which the heat capacity or the coefficient of expansion shows a maximum variation. This class of transformations which is not predicted by classical thermodynamics has often been referred to as "gradual, smeared or diffuse" transformations. Essentially, the difference between these transformations and the first order transformations described by classical thermodynamics lies in the nature or/and the magnitude of the discontinuity

'Figures in bracket indicate the literature references that appear at the end of each section. 
of the thermodynamic energy functions and their derivatives.

In first order transformations, the difference in the free energies of the two phases is given by $0=\Delta C=G_{2}-G_{1}=\Delta E-T \Delta S+P \Delta V$, where $\Delta E$ is the difference in internal energies of the two phases; if $P \Delta V$ in a transformation is small, one can compare the stabilities of the two phases in terms of their Helmholtz free energies: $0=\Delta A=\Delta E-T \Delta S$. According to this equation, the transformation results from the compensation of the lattice energy difference by the entropy difference at $T_{t}$. At $T_{t}$, the free-energy curves intersect each other at $\Delta G=0$. These phase transformations involve step-wise increase in energy with increase in temperature and show discontinuity in the energy as well as in many other properties of the system at $T_{t}$.

Many instances are known where phase transformations are induced by application of pressure; in these transformations the $P \Delta V$ term is very important. Wherever there is a decrease in volume during a transformation, pressure would favor such a transformation and the thermodynamic variables are simply correlated by the Clausius-Clapeyron equation. Since the phase produced by the application of pressure will have a lower volume, the decrease in volume is compensated by an increase in the $\Delta E$ or in the coordination number.

In the second- (or higher) order transformations, energy increases gradually with temperature until the rate of increase of energy sharply falls. As a result of this, discontinuity is found in specific heats or specific volumes. Since lambda-shaped specific heat curves are generally obtained in these transformations, these are also termed lambdapoint transformations. Second- or higher-order transformations occur over a temperature interval and are generally associated with increase in disorder with rising temperature. If a solid has perfect order at absolute zero of temperature, a rise in temperature disturbs the order of the structure and with progressive increase in temperature, the structure gets more and more distorted until the transformation temperature $T_{t}$ is reached. One can introduce an order parameter $\xi$ which is equal to unity at absolute zero of temperature and becomes zero at $T_{t}$.

Although for the sake of definition one can classify transformations as first-order and second-order types, in reality 'it is difficult to find out exactly whether a transformation belongs to either of these two types. By definition first-order transformations should occur at one temperature and two phases of the same substance should not coexist at temperatures other than $T_{t}$. If a single crystal of a substance is taken through a transition point, the crystal should break up into a random assembly of one or more crystals of the other phase at $T_{t}$ (depending on the magnitude of $\Delta V$ ). If the temperature is then decreased below $T_{t}$, the first phase should reform randomly from the second phase (if the two phases are not crystallographically related). While transformations classified as first order are structurally discontinuous and involve drastic variations in energy, there are indications of higher order effects such as premonitory phenomena and thermal hysteresis in many of these transformations.

In continuous or second- (or higher) order transformations, premonitory changes are often found. Even though in these transitions there should be no discontinuity of structure, $x$-ray studies have shown that the two structures coexist over a narrow region of temperature. In some cases, transformations are found to proceed through the formation of "hybrid crystals" where the two structures coexist within a general pattern of orientation.

There are many phase transformations which strictly belong to neither first order nor to second order. For example, the ferroelectric transformation of $\mathrm{KH}_{2} \mathrm{PO}_{4}$ should theoretically be first order but conforms more closely to second order. The transformation of $\mathrm{BaTiO}_{3}$ and related materials show lambda-like changes in properties as well as small changes in latent heat. There is superposition of second-order behavior on many first order transformations as in the transformation of alkali sulphates. It often happens that transformations have observable heat effects and yet the approach to the transformation is evidenced by a gradual change of properties. Even the order-disorder change in second order transformations may be seen as an abrupt change towards the termination.

Irreversible crystal structure transformations are found in many systems where one of the polymorphs is metastable in a particular temperature (or pressure) range. In such transformations, a polymorph transforms to the other form on heating above a particular temperature and remains in the new transformed structure even after cooling. It is not possible to assign any critical transformation temperature in an irreversible transformation and the transformation will be a function of time as well as temperature. One can only define a temperature below which a transformation does not take place. Typical examples of irreversible transformations are anatase-rutile (of $\mathrm{TiO}_{2}$ ), aragonite-calcite (of $\left.\mathrm{CaCO}_{3}\right)$ and cubic-hexagonal or cubic-monoclinic transitions of rare-earth sesquioxides. Many of these systems showing irreversible transformations are associated with small changes in internal energy, but large energies of activation may involve the breaking of the primary coordination or change in bond type.

Simple thermodynamic considerations indicate that one polymorph of a solid can be more stable under a specified set of conditions than the other. It should be realized, however, that it is difficult to strictly define the thermodynamic stability of a polymorph since a variety of physical factors as well as compositional differences affect the stability of polymorphs markedly. Thus, if there is any difference in the stoichiometry between two poly- 
morphs, one cannot really classify them as belonging to the same polymorphic set. Similarly, if different samples of a solid contain different quantities of impurities, the regions of thermodynamic stability will vary.

A better insight into the nature of phase transformations can be obtained by correlating structural changes and the thermodynamics of transformations. The thermodynamics of transformations gives some indication as to the nature of structural changes accompanying transformations, but a better understanding can be obtained by considering the geometrical or crystallographic mechanisms. Since phase transformations in solids are associated with increase in entropy, one can visualize the structural origin of the entropy increases. For example, in first-order transformations, the phases with high internal energy and low density will have high entropy as well because of the greater magnitude of voids in the structure. In second-order or continuous transformations, the entropy changes have been related in many systems with the potential barrier to rotation. While going from the lowto the high-temperature forms in these systems, there will be some randomization of the structure. Ubbelohde [2] has discussed the structural origins of entropy increase in phase transformations in solids.

Structural Changes Accompanying Transformations. Buerger [5] has classified various types of thermal transformations based on structural changes involving the primary or higher coordination. Transformations where there are changes in the primary coordination will involve a more drastic change in energy and structure rather than those where there are changes only in the higher coordination. This can be visualized in the case of ionic crystals, where the energies of the ionic bonds vary inversely as the distance and the energies of the van der Waals bonds vary inversely as the sixth power of distance. Accordingly, one can classify transformations of the first order into two categories: first coordination transformations and higher coordination transformations.

Changes in primary coordination can take place by a reconstructive transformation, where the first coordination bonds are broken and reformed. Such transformations will involve high energies of activation and will be sluggish. Further, there may be no symmetry relation between the two phases. Reconstructive transformations give rise to large discontinuities such as cell dimensions, symmetry, internal energy, specific heat, etc. Changes in primary coordination may also take place through a dilatational mechanism as in the thermal transformation of cesium chloride $\left(479^{\circ} \mathrm{C}\right)$ or ammonium chloride $\left(184{ }^{\circ} \mathrm{C}\right)$. Dilatational transformations are likely to be rapid compared to reconstructive transformations.

There are some transformations where only a part of the structure may undergo a change in the primary coordination. The ferroelectric transfor- mations of barium titanate and lead titanate are likely to belong to this category since the coordination of titanium goes from 6 to 5 due to the shifting of the position of titanium from the center of the octahedron towards the vertex.

Many of the transformations involving changes in higher coordination may also have to proceed through the breaking of the primary bonds and for this reason, the energy changes and other features of the reconstructive transformations involving higher coordination may resemble those of the reconstructive first order transformations. In some transformations changes in higher coordination can be effected by a distortion of the primary bond. Such transformations may be called distortional or displacive transformations. These transformations will involve considerably smaller changes in energy and are usually fast. In the displacive transformations, the high temperature form is usually more open and has higher specific volume, specific heat and symmetry. In addition to the transformations discussed above, Buerger also discusses disorder transformations of two types: rotational and substitutional transformations.

Experimental Techniques Employed to Study Phase Transformations. A variety of techniques have been employed for the study of phase transformations in addition to $x$-ray diffraction which is an essential part of the study of any crystal structure transformation. Once a phase transition is identified in a solid by any technique, one has to investigate the same by other methods depending on the particular properties of interest. For example, the ferroelectric transformation of barium titanate has been investigated by the anomalies in heat capacity, breaks in thermal expansion curves and variations in optical properties (including vibrational spectra) in addition to changes in crystal structure and dielectric properties. The semiconductor-to-metal transitions in $\mathrm{VO}_{2}$ and $\mathrm{V}_{2} \mathrm{O}_{3}$ have been studied by measurements of changes in magnetic susceptibility, heat capacity, electrical conductivity in addition to methods like nuclear magnetic resonance spectroscopy, Mössbauer spectroscopy, neutron diffraction, and differential thermal analysis. The transformation of $\mathrm{KNO}_{2}$ provides another interesting example where a variety of methods of relevance have been employed to study the transformation. The reversible transition of $\mathrm{KNO}_{2}$ was established by differential thermal analysis; $\mathrm{x}$-ray diffraction was utilized to prove that the change was from monoclinic to cubic structure. Based on the crystal structures and also analogy with $\mathrm{NaNO}_{2}$, it was suspected that the transformation was associated with a change from a ferroelectric to a paraelectric state. In fact, the dielectric hysteresis loop disappeared around $40{ }^{\circ} \mathrm{C}$ (Curie temperature, $T_{c}$ ); the dielectric anomaly was also observed at this temperature. A plot of electrical conductivity against temperature indicated a break at $40{ }^{\circ} \mathrm{C}$. A study of the temperature-dependent infrared spectrum of $\mathrm{KNO}_{2}$ showed 
that the absorbance of the $\mathrm{NO}_{2}$ deformation frequency $\left(830 \mathrm{~cm}^{-1}\right)$ showed a marked increase in intensity at the Curie temperature. This is similar to the behavior observed in the ferroelectric-paraelectric transformation of $\mathrm{KNO}_{3}$. The literature has many such examples where several techniques have been employed to examine phase transformations in solids.

X-ray diffraction methods are by far the most important tools for the study of crystal structure transformations. Identification of structures of various phases by x-ray diffraction is very essential irrespective of what other techniques one employs to identify or examine the changes in the system accompanying the transformation. Single crystal work with Laue and Weissenberg photographs are particularly useful for a detailed knowledge of the mechanism of a phase transformation. Neutron diffraction has been employed effectively as a tool to examine the positions of light atoms as well as to study magnetic structures.

Both electronic and infrared spectroscopy are useful tools, provided a characteristic absorption band of the substance shows variations during a transformation. Wide-line NMR spectroscopy has been useful in the study of transformations containing suitable nuclei.

Measurements of (a.c. or d.c.) conductivity and dielectric constant are important techniques for the study of phase transformations. The transformations are generally indicated by a break in the conductivity versus temperature curves. Magnetic transitions (paramagnetic $\rightleftharpoons$ ferromagnetic or paramagnetic-antiferromagnetic) are generally studied by employing magnetic susceptibility measurements. Changes of magnetic anisotropy as a function of temperature has also been used to study polymorphic changes. Mössbauer spectroscopy containing (or doped with) the appropriate muclei provides valuable information on such transitions if the spectra are recorded at different temperatures.

Measurements of heat capacities as a function of temperature are valuable in the study of phase transformations (particularly in the case of second or higher order transitions). Differential thermal analysis is another powerful tool in the study of phase transformations. This technique has been employed to study the enthalpy change, activation energy and thermal hysteresis in transformations.

In principle, any technique that can measure a property of the substance which undergoes marked change during the transformation can be employed for the study of phase transformations. Dilatometric measurements, change in Young's modulus, thermal expansion of solids are some of the classical methods for the study of phase transformations.

\section{References}

[1] Staveley, L. A. K., Quart. Rev. (London) 3, 64 (1949).

[2] Ubbelohde, A. R., Quart. Rev. (London) 1 1, 246 (1957).

[3] Rao, C. N. R., and Rao, K. J., in Progress in Solid State Chemistry, Ed. H. Reiss, Vol. 4, (Pergamon Press, Oxford, 1967).

[4] Rao, C. N. R., in Modern Aspects of Solid State Chemistry, Ed. C. N. R. Rao (Plenum Press, New York, 1970).

[5] Buerger, M. J., in Phase Transformations in Solids, Ed. R. Smoluchowski (John Wiley, New York, 1957) also see Fortschr. Mineral. 39, 9 (1961).

\section{Hydrogen Halides}

Phase transitions of solid hydrogen halides have been investigated by many workers with a variety of experimental methods. The transitions generally take place at low temperatures. Dielectric relaxation, dielectric anomalies, specific heat, NMR and calorimetric measurements are some of the methods employed for these studies in addition to $\mathrm{x}$-ray and neutron diffraction. While in $\mathrm{HCl}$ there is only one transition at $\sim 98.36 \mathrm{~K}$, in $\mathrm{HBr}$ and $\mathrm{HI}$ there are two transitions.

The transformation in $\mathrm{HCl}$ involves a change from the face centered cubic structure to a low symmetry structure (face centered orthorhombic); the transition is of first order. $\mathrm{HBr}$ undergoes two transitions, one at $\sim 89 \mathrm{~K}(\mathrm{III} \rightarrow \mathrm{I})$ and the other at $\sim 114 \mathrm{~K}$ $(\mathrm{II} \rightarrow \mathrm{I})$. Phases III, II, and I are encountered successively when liquid $\mathrm{HBr}$ is cooled. The transition at $89 \mathrm{~K}$ is first order while the one at $114 \mathrm{~K}$ is a second order transition. Two transitions in $\mathrm{HI}$ are known at $\sim 70.1 \mathrm{~K}(\mathrm{III} \rightarrow \mathrm{I})$ and at $\sim 125.7 \mathrm{~K}$ $(\mathrm{II} \rightarrow \mathrm{I})$; these are similar to the transitions in $\mathrm{HBr}$. A third transition at $25 \mathrm{~K}$ has been reported in HI from infrared studies. The theory of phase transitions in hydrogen halides has been studied by Pauling and others. Some of these iransitions are recently found to be associated with a change from a ferroelectric to a paraelectric state.

The gradual transitions in hydrogen halides were examined by Pauling [24] who attributed the transitions in $\mathrm{HBr}$ and $\mathrm{HI}$ to the incipient rotation about one crystal axis and the expansion of the crystal only along this axis. The difference between the low $(\alpha)$ and high $(\beta)$ forms of $\mathrm{HCl}$ has been likened by Hettner [13], to that between liquids and solids. Molecules in the $\alpha$-state vibrate about fixed and regularly oriented equilibrium positions while in the $\beta$-state only the equilibrium positions of several temporary groups are oriented with respect to one another. On the basis of classical mechanics, Kirkwood [17] accounts for the transitions in hydrogen halides, in terms of hindered rotation. The effects of dielectric relaxation during phase changes in hydrogen and deuterium halides have been discussed by Bauer [2]. Powels [28] has discussed the mechanism of transitions from a knowledge of the experimental results including those from calorimetric, dielectric, structural and thermal expansion measurements.

Krieger and James [19] proposed a model for a crystal exhibiting successive orientational or rota- 
tional transitions as in hydrogen halides. The model consists of an array of classical rotors with next neighbor coupling. The nature of transitions in $\mathrm{HCl}, \mathrm{HBr}, \mathrm{HI}, \mathrm{DCl}, \mathrm{DBr}$ and DI have been successfully explained with this model. Recently, Kobayashi and co-workers [18] have suggested that the phase transitions in hydrogen halides can be understood qualitatively on the basis of a two dimensional rotational transition model with two sublattices.

The deuterium analogues of $\mathrm{HCl}, \mathrm{HBr}$ and $\mathrm{HI}$ also exhibit transitions corresponding to those in hydro- gen halides. Thus, $\mathrm{DCl}$ exhibits the $\mathrm{II} \rightarrow \mathrm{I}$ transition at $\sim 105 \mathrm{~K}$ with an enthalpy of $320 \mathrm{cal} \cdot \mathrm{mol}^{-1}$; both $\mathrm{DBr}$ and DI exhibit the III $\rightarrow$ I transition at $\sim 93.5 \mathrm{~K}$ $\left(\Delta H_{\mathrm{tr}} \sim 169 \mathrm{cal} \cdot \mathrm{mol}^{-1}\right)$ and $\sim 77.3 \mathrm{~K}\left(\Delta H_{\mathrm{tr}} \sim 175\right.$ $\mathrm{cal} \cdot \mathrm{mol}^{-1}$ ) respectively and the $\mathrm{II} \rightarrow \mathrm{I}$ transition at $\sim 120 \mathrm{~K}\left(\Delta H_{\mathrm{tr}} \sim 303 \mathrm{cal} \cdot \mathrm{mol}^{-1}\right)$ and $\sim 128 \mathrm{~K}\left(\Delta H_{\mathrm{tr}}\right.$ $\left.\sim 386.0 \mathrm{cal} \cdot \mathrm{mol}^{-1}\right)$ respectively. The $T_{t}$ and $\Delta H_{\mathrm{tr}}$ are higher compared to those in the respective hydrogen analogues. Just as in hydrogen halides, phase transitions in the deuterium halides have been investigated by a variety of experimental methods.

Hydrogen Halides

\begin{tabular}{|c|c|c|c|}
\hline $\begin{array}{l}\text { Substances and } \\
\text { measurement techniques }\end{array}$ & Data & Remarks & References \\
\hline \multicolumn{4}{|l|}{ Hydrogen Chloride, $\mathrm{HCl}$} \\
\hline $\begin{array}{l}\text { Calorimetric measurements like } \\
\text { molar heat, specific heat etc., as a } \\
\text { function of temperature }\end{array}$ & $\begin{array}{l}T_{t} \sim 98.36 \mathrm{~K} \\
\quad \Delta H_{\mathrm{tr}} \sim 284.3 \mathrm{cal} \cdot \mathrm{mol}^{-1} \\
\quad \Delta S \sim 2.89 \mathrm{e.u} .\end{array}$ & $\begin{array}{l}\text { Transition is indicated by anomalies in } \\
\text { molar heat or in the } C_{p} \text { versus } T \\
\text { curves. The entropy of } \mathrm{HCl} \text { was } \\
\text { calculated to verify the third law. }\end{array}$ & {$[7,9]$} \\
\hline X-ray and neutron diffraction & $\begin{array}{l}\text { Cubic } \mathrm{HCl} \text { has } a=5.44 \pm 0.01 \AA \text { at } \\
98.5 \mathrm{~K} \text {. At } 85 \mathrm{~K} \text {, solid } \mathrm{HCl} \text { has a } \\
\text { tetragonal form, with } c / a=1.10 \\
\text { where } a=5.27 \AA, c=5.797 \AA \text {. At } \\
92.4 \mathrm{~K} \text {, the structure is face } \\
\text { centered orthorhombic with the } \\
\text { space group, } \mathrm{Bb}{ }_{1} \mathrm{~m} . a=5.082 \AA \text {, } \\
b=5.410 \AA, c=5.826 \AA \text {. At } \\
118.5 \mathrm{~K}, \text { the structure is FCC, with } \\
a=5.482 \AA .\left(T_{\imath} \sim 98.4 \mathrm{~K}\right)\end{array}$ & $\begin{array}{l}\text { The } \mathrm{Bb} 2{ }_{1} \mathrm{~m} \text {-space group indicates that } \\
\mathrm{HCl} \text { structure is non-centro } \\
\text { symetric in this phase. The structure } \\
\text { at } 118.5 \mathrm{~K} \text { is an average of disordered } \\
\text { structures. }\end{array}$ & {$[22,30]$.} \\
\hline NMR spectroscopy & $\begin{array}{l}\text { Linewidth is measured as function of } \\
\text { temperature. }\end{array}$ & $\begin{array}{l}\text { The transition is found to be an order- } \\
\text { disorder type. No evidence was found } \\
\text { for a rotational transition. }\end{array}$ & {$[1]$. } \\
\hline $\begin{array}{l}\text { IR spectra of crystalline } \mathrm{HCl} \text { at } \\
68 \mathrm{~K} \text {, in } \mathrm{KBr} \text { solvent }\end{array}$ & $\begin{array}{l}\text { Two fundamental vibrations at } 2704 \\
\text { and } 2746 \mathrm{~cm}^{-1} \text {, are observed. The } \\
\text { angle } \mathrm{H}-\mathrm{Cl} \ldots \mathrm{H} \text { is } \sim 107^{\circ} \text {. }\end{array}$ & $\begin{array}{l}\text { The basic structural unit in } \mathrm{HCl} \text { is a } \\
\text { zigzag hydrogen bonded chain; } \\
\text { the crystal appears to be built from } \\
\text { anti-parallel pairs of such chains, but } \\
\text { the relative position of the chains is } \\
\text { uncertain. }\end{array}$ & {$[15]$.} \\
\hline $\begin{array}{l}\text { Dielectric constant, } \epsilon \text {, and } \tan \delta \\
\text { measurements, as a function of tem- } \\
\text { perature in various frequency ranges }\end{array}$ & $T_{t} \sim 98.4 \mathrm{~K}$ & $\begin{array}{l}\text { The dielectric behavior of solid } \mathrm{HCl} \text { is } \\
\text { predicted by Pauling's theory of free } \\
\text { rotation of molecules in crystals. The } \\
\text { dielectric behavior of liquid and dis- } \\
\text { ordered phases of } \mathrm{HCl} \text { can be ex- } \\
\text { plained in terms of Onsager's } \\
\text { equation. }\end{array}$ & {$[5.35]$.} \\
\hline $\begin{array}{l}\text { Dielectric hysteresis and ferro- } \\
\text { electric behavior of solid } \mathrm{HCl} \text { at low } \\
\text { temperature }\end{array}$ & $\begin{array}{l}\text { Spontaneous polarization, } P_{s} \text {, in } \mathrm{HCl} \\
\text { is } 1.2 \mu \mathrm{c} \mathrm{cm}^{-2} \text { at } 90 \mathrm{~K} \text {. The coercive } \\
\text { field, } E_{c}, \text { is } \sim 3.3 \mathrm{kV} \mathrm{cm} \mathrm{cm}^{-1} \text {. The } \\
\text { ferroelectric loop disappears at } \\
\sim 98.4 \mathrm{~K} \text {. }\end{array}$ & $\begin{array}{l}\text { This observation seems to support } \\
\text { Kobayashi's two sublattice theory } \\
\text { of rotational transition in } \mathrm{HCl} \text {. }\end{array}$ & [16]. \\
\hline
\end{tabular}




\begin{tabular}{l}
\hline $\begin{array}{c}\text { Substances and } \\
\text { measurement techniques }\end{array}$ \\
\hline Hydrogen bromide, $\mathrm{HBr}$ \\
Calorimetric measurements like \\
molar heat, specific heat etc., as
\end{tabular}
molar heat, specific heat etc., as a function of temperature

$\mathrm{X} \cdot$ ray diffraction

NMR spectroscopy

Infrared of $\mathrm{HBr}$ crystals at $68 \mathrm{~K}$.

Measurement of $\epsilon$ as a function of frequency, $\omega$ and temperature

$\epsilon$ and $\tan \delta$ measurements

Static dielectric constant and dispersion loss measurements.

Dielectric hysteresis in $\mathrm{HBr}$ single crystals.

Effect of ultrasonic waves on thermal hysteresis of transition in $\mathrm{HBr}$.
$T_{\text {, }}(\mathrm{III} \rightarrow \mathrm{I}) \sim 90 \mathrm{~K} ;(\mathrm{II} \rightarrow \mathrm{I}) \sim 118 \mathrm{~K} ;$

The $\Delta H_{\text {tr }}$ values are in the range $150-250 \mathrm{cal} \cdot \mathrm{mol}^{-1}$. Transitions are indicated by anomalies in $C_{p}$ versus $T$ curves.

Existence of solid $\mathrm{HBr}$ in the (space group $\mathrm{V}^{\top}$ or $\mathrm{V}_{h}^{2: 3}$ i.e., $\mathrm{D}_{22}^{7}$ or $\mathrm{D}_{2 h}^{2: 3}$ structure in the $85-90 \mathrm{~K}$ range is established beyond doubt. Below $\sim 100 \mathrm{~K} a=5.76 \AA$. Below $100 \mathrm{~K}$, $\mathrm{HBr}$ exhibits rhombic symmetry with axial ratios, $a: b: c=0.985: 1$ : 1.075 , where $a=5.555 \AA, b=5.64 \AA$ and $c=6.063 \AA ; Z=4$; $\rho=2.81 \mathrm{~g} \mathrm{~cm}^{-3}$.

Line width is measured as a function of temperature.

Two fundamental vibrations at 2404 and $2438 \mathrm{~cm}^{-1}$ are observed.

$\epsilon$ varies with $\omega$ only below $95 \mathrm{~K}$. The dispersion domains are displaced towards the high frequency with $T$. One of the dispersions is of constant amplitude while the other is temperature dependent, and exists even after $T_{t}$. Definite hysteresis effects were observed in the transitions.

The sharp increase in $\epsilon$ suggests a first order transition at $\sim 89.8 \mathrm{~K}$ while a sharp increase in $\tan \delta$ suggests a second order transition at $\sim 113.6 \mathrm{~K}$.

$\epsilon_{\text {stat }}$ above $117 \mathrm{~K}$ agrees well with Onsager's equation. In phase II, $\epsilon$ rises to peak value of 200 at $89 \mathrm{~K}$ and falls to 32 at $\sim 72 \mathrm{~K}$ in phase III.

The polarization versus field curves show a ferroelectric hysteresis loop. The measured spontaneous polarization, $P_{s}$, is about $0.4 \mu \mathrm{c} \mathrm{cm}^{-2}$ and the coercive field, $E_{\mathrm{c}}$ is $\sim 4.3 \mathrm{KV} \mathrm{cm}^{-1}$.

The hysteresis is not affected by ultrasonic waves or by inoculation.
The $\Delta H_{\text {tr }}$ values are not consistent with other experimental results. The transitions are probably akin to those in $\mathrm{NH}_{4} \mathrm{Cl}$.

The $x$-ray studies of Ruhemann and Simon [29] between $82-120 \mathrm{~K}$, however, do not indicate any fundamental crystallographic changes during the transition. They propose a FCC structure throughout this temperature range.

A basic factor affecting the line width is the characteristic flipping time i.e., the average time to change its orientation. The results suggest that the phase transition in $\mathrm{HBr}$ is an order-disorder type.

The basic structural unit in $\mathrm{HBr}$ crystals is a zimzag hydrogen bonded chain.

In addition to the two dispersions mentioned, a third one was indicated at higher frequencies. A rotation tunnel effect is introduced to explain the variation of the critical frequency with temperature. Such an effect is shown to be present in $\mathrm{HBr}$.

The complex $\epsilon$ is ascribed to a skewed arc function found for the low. temperature phase. Deviations of the relaxation rates can be explained in terms of cooperative interaction effects in the disordered phase.

Phase transitions are indicated by anomalies in $\epsilon$.

The phase transition in $\mathrm{HBr}$ i.e., the second order change is thus possibly associated with a change from ferroelectric to paraelectric state thus conforming to the two sublattice model of Kobayashi.

The position of the equilibrium curve in the transition interval could not be determined.
References

[7. 10]

$[22.23,29]$.

$[1]$.

[15].

$[6,25,26,27]$.

$[12,20]$

[3].

[16].

[8]. 
Hydrogen Halides - Continued

Substances and
measurement techniques

X-ray diffraction

\section{NMR Spectroscopy}

Infrared study of a new phase transition in HI. in the range 6 to $79 \mathrm{~K}$.

\section{Deuterium chloride, DCl}

Calorimetric measurement of molar heat of DCl.

$\mathrm{X}$-ray and neutron diffraction (as well as heat capacity measurement).

\section{Deuterium bromide, $\mathrm{DBr}$}

Calorimetric measurement of molar heat as a function of temperature.

$\mathrm{X}$-ray and neutron diffraction (as well as heat capacity).

Kinetics of $\mathrm{DBr}$ transition at $93.5 \mathrm{~K}$ by $x$-ray and neutron diffraction methods.
For III $\rightarrow \mathrm{I}, T_{t}, 72 \mathrm{~K} ; \Delta H_{\mathrm{tr}} \sim 150$

$\mathrm{cal}^{-1}, \mathrm{II} \rightarrow \mathrm{I}, T_{\iota}, \sim 124 \mathrm{~K}$;

$\Delta H_{\mathrm{tr}} \sim 395 \mathrm{cal} \cdot \mathrm{mol}^{-1}$.

HI has a face centered tetraquonal structure with $c / a=1.08(a=6.10$ $\AA$ ) at $\sim 100 \mathrm{~K}$. This structure changes to a FCC structure above $127 \mathrm{~K}: a=6.19 \AA$ at $125 \mathrm{~K}$; $\rho=3.17 \mathrm{~g} \mathrm{~cm}^{-3}$.

The line width is measured as a function of temperature.

At $25 \mathrm{~K}$, HI undergoes a phase change to a phase with more molecules in the unit cell and alsc the phase below $25 \mathrm{~K}$ is one of less symmetry than the high phase above $25 \mathrm{~K}$.

$T_{t} \sim 105.03 \mathrm{~K}, \Delta \mathrm{H}_{\mathrm{tr}} \sim 320.1$

$\mathrm{cal} \cdot \mathrm{mol}^{-1}$

$T_{1} \sim 105 \mathrm{~K}$. At $92.4 \mathrm{~K}$, the structure is face-centered orthorhombic, with $a=5.0685 \AA, b=5.3990 \AA$ and $c=5.828 \AA$. At $118.5 \mathrm{~K}$. The structure is face-centered cubic with $a=5.475 \AA$ A. The space group at $77 \mathrm{~K}$ is $\mathrm{Bb} 2{ }_{1} \mathrm{~m}$ (same as $\mathrm{HCl}$ ).

$T_{\mathrm{t}} \sim 93.5 \mathrm{~K}(\mathrm{III} \rightarrow \mathrm{I})$

$\Delta H_{\mathrm{tr}} \sim 196.7 \mathrm{cal} \cdot \mathrm{mol}^{-1} . T_{t} \sim$ $120.26 \mathrm{~K} . \Delta H_{\mathrm{tr}} \sim 303 \mathrm{cal} \cdot \mathrm{mol}^{-1}$. $T_{t} \sim 128.28 \mathrm{~K}, \Delta H_{\mathrm{tr}} \sim$ $386.4 \mathrm{cal} \cdot \mathrm{mol}^{-1}$.

Two second order transitions at $\sim 93.5 \mathrm{~K}(\mathrm{III} \rightarrow \mathrm{I})$ and at $\sim 120.3 \mathrm{~K}$ $(\mathrm{II} \rightarrow \mathrm{I})$ are noticed. At $84 \mathrm{~K}$, the space group is $\mathrm{Bb} 2{ }_{1} \mathrm{~m}$ while at $107 \mathrm{~K}$ the space group is $\mathrm{Bbcm}$.

At $84 \mathrm{~K}$, the structure is orthorhombic with $a=5.44 \pm 0.02 \mathrm{~A}$, $b=5.614 \pm 0.005 \AA$, and $c=6.12$

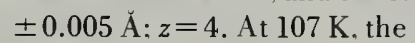
structure is orthorhombic with $a=5.559 \pm 0.005 \AA, b=5.649$ $\pm 0.005 \AA$. and $c=6.095 \pm 0.005 \AA$.

$T_{t} \sim 93.5 \mathrm{~K} \Delta V \sim 3.66 \AA^{3}$ per unit cell. $\Delta V / V_{0} \sim 1.94$ percent. A hysteresis of about 0.60 was observed.
The transitions are indicated by anomali's in the molar heat $/ C_{p}$ v'rsus temperature curves.

The transitions in HI may be similar to those in $\mathrm{NH}_{4} \mathrm{Cl}$.

[21, 22, 23. 29].

The line width is affected by the average time the molecules take to change from one orientation to another. This indicates the nature of the transition to be an order-disorder type.

The transition at $25 \mathrm{~K}$ is readily reversible and rapid. No hysteresis is evidenced in these studies.

Both $T_{\text {t }}$ and $\Delta H_{\mathrm{tr}}$ are higher than in $\mathrm{HCl}$. The transition is probably a first order one.

The FCC structure at $118.5 \mathrm{~K}$ is only an average of disordered structures, similar to that in $\mathrm{HCl}$. On the other hand the unit cell of DCl shows an anisotropic reduction in lattice constants compared to $\mathrm{HCl}$.

The $T_{t}$ and $\Delta H_{\mathrm{tr}}$ are higher than in $\mathrm{HBr}$. The second transition appears to go through a metastable state.

Below $93.5 \mathrm{~K}, \mathrm{DBr}$ is isomorphous with $\mathrm{DCl}$ (i.e.. it has an ordered crystal structure, composed of parallel zigzag chains). Between $93.5 \mathrm{~K}$ and $120.3 \mathrm{~K}, \mathrm{DBr}$ has a disordered structure where the disorder is orientational with two equilibrium orientations for each molecule.

Kinetics and the nature of the transition are discussed in terms of these experimental results.
17. 11].

|11.

[14].

$[4]$. 
Hydrogen Halides - Continued

\begin{tabular}{c|c|c|c}
\hline \hline $\begin{array}{c}\text { Substances and } \\
\text { measurement techniques }\end{array}$ & Data & Remarks \\
\hline $\begin{array}{c}\text { Deuterium iodide, D1 } \\
\text { Calorimetric measurement of molar } \\
\text { heat as a function of temperature. }\end{array}$ & $\begin{array}{c}T_{t} \sim 77.3 \mathrm{~K}(\mathrm{III} \rightarrow \mathrm{I}) ; \Delta H_{\mathrm{tr}} \sim 175.6 \\
\mathrm{cal} \cdot \mathrm{mol}^{-1} \cdot T_{t} \sim 128.28 \mathrm{~K}(\mathrm{II} \rightarrow \mathrm{I}) ; \\
\Delta H_{\mathrm{tr}} \sim 386.4 \mathrm{cal} \cdot \mathrm{mol}^{-1} .\end{array}$ & $\begin{array}{c}T_{\text {t }} \text { and } \Delta H_{\mathrm{tr}} \text { are higher than for HI } \\
\text { transitions. }\end{array}$ & {$[4,34]$.} \\
\hline
\end{tabular}

\section{References}

[1] Alpert. N. L., Phys. Rev. 75, 398 (1949).

[2] Bauer. E., compt. rend. 272 (1952).

[3] Brown, N. L., and Cole, R. H., J. Chem. Phys. 21, 1920 (1953).

[4] Clusius, K., and Wolf, G., Z. Naturforsh 2a, 495 (1947).

[5] Cone. R. M., Denison. (. H., and Kemp. J. D.. J. Am. Chem. Soc. 53, 1278 (1931).

[6] Dankïhler, G.. Ann. Physik. 31, 76 (1938).

[7] Eucken, A., and Karwat, E., Z. physik. Chem. 112, 467 (1924).

[8] Eucken, A., and Güttner, W., Math. physik., Klasse, Fachgruppe. II [N.F.] 2, 167 (1937).

[9] Giauque, W. F., and Wiebe, R., J. Am. Chem. Soc. 50, 101 (1928).

[10] Giauque, W. F., and Wiebe, R., J. Am. Chem. Soc. 50, $2193(1928)$

[11] Giauque, W. F., and Wiebe, R., J. Am. Chem. Soc. 51, 1441 (1929).

[12] Groenewegen. P. P. M., and Cole, R. H., J. Chem. Phys. 46 (3), 1069 (1967).

[13] Hettner. G., Ann. physik 32, 141 (1938).

[14] Hiebert. G. L., and Hornig, D. F., J. Chem. Phys. 26, 1762 (1957).

[15] Hornig, D. F., and Osberg, W. E., J. Chem. Phys. 23, 662 (1955).

[16] Hoshino, S., Shimaoka, K., and Nümura, N., Phys. Rev. Letters 27, 1286 (1967).
[17] Kirkwood, J. G., J. Chem. Phys. 8, 205 (1940).

[18] Kobayashi, K. K., Hanamura, E., and Shishido, F., Phys. Letters 28A, 718 (1968).

[19] Krieger, T. J., and James, H. M., J. Chem. Phys. 22, 796 (1954).

[20] Lacerda, L., and Brot, C., compt. rend. 236, 916 (1953).

[21] Mauer, F. A., Keffer, C. J., Reeves, R. B., and Robinson, D. W., J. Chem. Phys. 42 (2), 1465 (1965).

[22] Natta, G., Nature 127, 235 (1931).

[23] Natta, G., Gazz. Chim. ital, 63, 425 (1933).

[24] Pauling, L., Phys. Rev. 36, 430 (1930).

[25] Powles, J. G., compt. rend. 230, 836 (1950).

[26] Powles, J. G., Nature 165, 686 (1950).

[27] Powles, J. G., J. Phys. Radium 13, 121 (1952).

[28] Powles, J. G., Trans. Faraday Soc. 48, 430 (1952).

[29] Ruhemann. B., and Simon, F., Z. physik. B 15, 389 (1932).

[30] Sandor, E., and Farrow, R. F. C., Nature 213, 171 (1967).

[31] Sandór, E., and Johnson, M. W., Nature 21 7, 541 (1968).

[32] Sandór, E., and Johnson, M. W., Nature 223, 730 (1969).

[33] Smyth, C. P., and Hitchcock, C. S., J. Am. Chem. Soc. 55, 1830 (1933).

[34] Staveley, L. A. K., Quartr. Rev. 3, 64 (1949).

[35] Swenson, R. W., and Cole, R. H., J. Chem. Phys. 22, 284 (1954).

\section{Alkali Halides}

All the alkali halides with the exception of $\mathrm{CsCl}$, $\mathrm{CsBr}$, and $\mathrm{CsI}$ crystallize in the $\mathrm{NaCl}$ structure $(\mathrm{Fm} 3 \mathrm{~m})$, the three cesium halides crystallizing in the $\mathrm{CsCl}$ structure $(\mathrm{Pm} 3 \mathrm{~m})$. $\mathrm{CsCl}$ undergoes a first order phase transformation at $\sim 480{ }^{\circ} \mathrm{C}$ (at 1 atm pressure) from the $\mathrm{Pm} 3 \mathrm{~m}$ structure to the Fm3m structure. The transformation in $\mathrm{CsCl}$ is reversible and is associated with considerable thermal hysteresis, $\Delta T$, as well as an appreciable change in molar volume, $\Delta V$. The transformation of $\mathrm{CsCl}$ is likely to proceed by a mechanism involving dilatation along the body diagonal; the role of lattice vacancies in the mechanism of transformation is not clearly established. The phase transition in $\mathrm{CsCl}$ has been studied with the aid of a variety of experimental tools. Fm3m structures for $\mathrm{CsBr}$, and CsI have been reported in evaporated thin films at low temperatures. No other transformation data are available for $\mathrm{CsBr}, \mathrm{CsI}$, or CsF.

No phase transformations are known in lithium halides. Pressure transformation (from $\mathrm{Fm} 3 \mathrm{~m}$ to Pm3m) data have been reported for sodium, potassium and rubidium halides. The thermal transformation data on $\mathrm{CsCl}$ as well as the pressure transition data on other alkali halides have been employed to evaluate the lattice energies of the halides in the Pm3m and $F \mathrm{~m} 3 \mathrm{~m}$ phases. The Born treatment of ionic solids have been employed with fair success to explain the relative stabilities of the $\mathrm{Pm} 3 \mathrm{~m}$ and Fm3m phases.

The phase transformation in $\mathrm{CsCl}$ at $753 \mathrm{~K}$ involves a change from the $\mathrm{P}$ 'm $3 \mathrm{~m}$ structure to the $\mathrm{NaCl}$ structure. Menary, Ubbelohde and Woodward [40] suggested that a large increase in vacancies occured in the neighborhood of the transition temperature. However, Hoodless and Morrison [21] showed from electrical conductivity measurements that the transitions may not involve a disruption of the lattice and that the mechanism is likely to be dilatational as suggested by Buerger [10]. 
The Born-Mayer model [23] has been widely employed to calculate the lattice energies of ionic solids especially of alkali halides. May [38] employed a three-parameter repulsive term and a higher van der Waals contribution to account for the greater stability of the $\mathrm{Pm} 3 \mathrm{~m}$ phase of $\mathrm{CsCl}$. The use of a higher van der Waals term was criticized by Tosi and Fumi [68, 69] who employed structuredependent repulsive parameters to account for the phase transition in CsCl. Recently, Rao and co-workers [45, 60-62] have employed a four parameter repulsive term in the Born treatment to explain the phase transition in $\mathrm{CsCl}$. The model also accounts for the stabilization of the $\mathrm{Fm} 3 \mathrm{~m}$ phase by added $\mathrm{KCl}$ or $\mathrm{RbCl}$ as well as for the opposite behavior of the $\mathrm{CsCl}+\mathrm{CsBr}$ solid solutions $[45,60]$.

It is definitely established that all the potassium and rubidium halides with the likely exception of the fluorides undergo pressure transformations from the $\mathrm{NaCl}$ structure $(\mathrm{Fm} 3 \mathrm{~m})$ to the $\mathrm{CsCl}$ structure $(\mathrm{Pm} 3 \mathrm{~m})[7,25,47]$. The product of the volume change, $\Delta V$, accompanying the transition and the transition pressure, $P$, may be taken to be equal to the difference between the lattice energies of the two structures at the transition pressure [25]. Several workers have attempted to calculate the lattice energy differences between the two phases with the aid of the Born model of ionic solids. Structure-dependent $[68,69]$ as well as the fourparameter [62] repulsive terms in the Born-treatment have been employed to explain these transformations. The need for a higher van der Waals term in the Born model to account for the transition energies of $\mathrm{KX}$ and $\mathrm{RbX}(X=\mathrm{Cl}, \mathrm{Br}$ or $\mathrm{I})$ has been pointed out [62]. An atomistic formulation of compressibility has also been used to discuss the pressure transitions of alkali halides [53]. Madan and Sharma [65] have calculated the lattice energies of all the alkali halides with the Lennard-Jones (12:6) potential.

Alkali Halides

\begin{tabular}{c|c|c|c}
\hline $\begin{array}{c}\text { Substances and } \\
\text { measurement techniques }\end{array}$ & Data & References \\
\hline $\begin{array}{c}\text { Sodium fluoride, } \mathrm{NaF} \\
(\mathrm{Fm} 3 \mathrm{~m}, a=4.6344 \AA \text { at } 299 \mathrm{~K})\end{array}$ & & & \\
Volumetric investigation of high & Transition begins at $\sim 18.3 \pm 1 \mathrm{kbar}$ & Transition is reversible and incomplete & [48].
\end{tabular}
pressure transformation in $\mathrm{NaF}$.

Quantum mechanical calculation. (with nearest neighbor repulsion only) of transition pressures for $\mathrm{NaF}$ and $\mathrm{NaCl}$ for the $\mathrm{Fm} 3 \mathrm{~m}$ -

Pm3m change.

Sodium chloride, $\mathrm{NaCl}$

(Fm3m, $a=5.6402 \AA$ at $299 \mathrm{~K}$ )

X-ray investigation of the high pressure transformation employing a diamond anvil (up to $\sim 18 \mathrm{kbar}$ )

Latent heat of the Fm3m-Pm3m transformation from the temperature dependence of $P_{T}$ up to $473 \mathrm{~K}$.

Dilatometric study on $\mathrm{NaCl}$ single crystals with organosilicon liquids as the dilatometric medium.

Shear induced transition in shock loaded $\mathrm{NaCl}$ employing a piezoelectric quartz (up to $30 \mathrm{kbar}$ ).

Equation of state for $\mathrm{NaCl}$ between 0-500 kbar and 273-1773 K.

Dielectric constant and elastic constant measured as a function of pressure up to $\sim 25 \mathrm{kbar}$ at room temperature. and $430.5 \mathrm{~K} . \Delta V \sim 5 \%$.

$P_{T} \sim 280$ kbar.

$P_{T}, 17.5-18 \mathrm{kbar}$

$a(\mathrm{Pm} 3 \mathrm{~m})=3.36 \pm 0.04 \AA$ at $298 \mathrm{~K}$ and $1 \mathrm{~atm}$.

$\Delta V \sim-1.0 \pm 0.05 \mathrm{~cm}^{3} \mathrm{~mol}^{-1}$ $\Delta S \sim 1.5 \pm 0.3 \mathrm{cal} \cdot \mathrm{deg}^{-1} \cdot \mathrm{mol}^{-1}$.

$\Delta H_{\mathrm{tr}} \sim 660 \pm 370 \mathrm{cal} \cdot \mathrm{mol}^{-1}$ at $298 \mathrm{~K}$.

$P_{T} \sim 21 \mathrm{kbar}$ at $613 \mathrm{~K}$

$\sim 25$ kbar at $803 \mathrm{~K}$

$(\partial P / \partial T)$ is positive.

Fm3m-Pm3m transition occurred and conformed to a first order.

Pressure as a function of lattice constant and temperature are obtained for the equation of state.

No anomaly (characteristic of a structural change) was found in elastic or dielectric constants. even at $45 \mathrm{kbar}$.

The value is slightly different from the known experimental data.

[37].

An extreme value of $300 \mathrm{kbar}$ is also reported for $P_{T}$. Experimental and calculated transition pressures are compared for some more halides.

The $\Delta H_{\mathrm{tr}}$ is comparable to the $\Delta H_{\mathrm{tr}}$ for the thermal transition of $\mathrm{CsCl}$.

$[4,17,18,28]$.

[50].

$\mathrm{NaCl}$ is unreliable as a high-pressure $[1,33]$. gauge. 
Alkali Halides - Continued

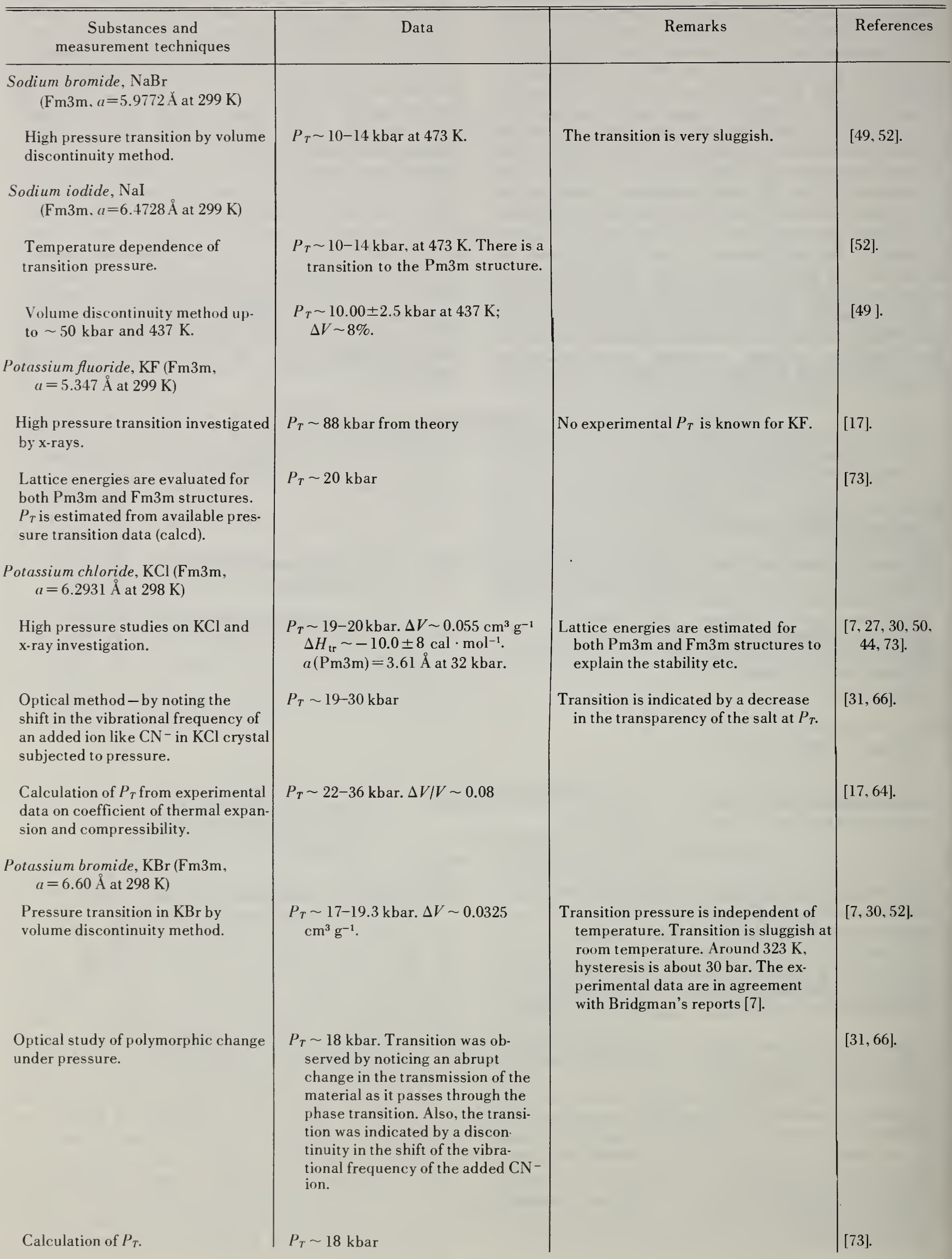




\begin{tabular}{|c|}
\hline $\begin{array}{l}\text { Substances and } \\
\text { measurement techniques }\end{array}$ \\
\hline $\begin{array}{c}\text { Potassium iodide, } \mathrm{KI}(\mathrm{Fm} 3 \mathrm{~m}, \\
\quad a=7.0655 \AA \text { at } 298 \mathrm{~K})\end{array}$ \\
\hline $\begin{array}{l}\text { High pressure studies on KI. } \\
\text { Diamond squeezers are usually } \\
\text { employed in addition to piston } \\
\text { displacement and volume discon- } \\
\text { tinuity method etc., and examined } \\
\text { by x-ray. }\end{array}$ \\
\hline
\end{tabular}

\section{Rubidium fluoride, $\mathrm{RbF}$}

(Fm3m, $a=5.64 \hat{\mathrm{A}}$ at $298 \mathrm{~K}$; a lower value of $a$ has been reported by Lew [33a]).

Pressure temperature curves for RbF.

Estimation of $P_{T}$

\section{Rubidium chloride, $\mathrm{RbCl}$}

( $\mathrm{Fm} 3 \mathrm{~m}, a=6.5810 \AA$ at $300 \mathrm{~K}$ ).

Thin layers of $\mathrm{RbCl}$ evaporated onto amorphous bases at low temperatures and examined by electron diffraction.

High pressure transition in $\mathrm{RbCl}$ and $\mathbf{x}$-ray investigation.

Investigation of pressure effects on the compressive strength and stress-strain behavior of $\mathrm{RbCl}$.

\section{Rubidium bromide, $\mathrm{RbBr}$}

(Fm3m, $a=6.889 \AA$ at $298 \mathrm{~K})$

Thin layers of $\mathrm{RbBr}$ evaporated onto amorphous bases and examined by electron diffraction at low temperatures.

Pressure transition in $\mathrm{RbBr}$ by $\mathrm{x}$-ray investigation, in the range 0-40 kbar and 273-873 K.

$\mathrm{RbBr}$ grown from aqueous solution on oriented silver films and $\mathrm{x}$-ray investigation.

\begin{tabular}{l} 
Data \\
\hline \\
$P_{T} 18-21$ kbar. Transition is almost \\
complete around 24 kbar. Internal \\
pressure in KI after the transition \\
is $\sim 20.8$ kbar as estimated from \\
$\Delta V / V_{0}$ value. $a_{\mathrm{Pm} 3 \mathrm{~m}}=4.13 \pm 0.02$ \\
$\AA$ at $298 \mathrm{~K}$.
\end{tabular}

$P_{T} \sim 22$ kbar at $\sim 973 \mathrm{~K}$.

$P_{T} \sim 11.76$ kbar.

$a_{\mathrm{P}^{\prime} \mathrm{m} 3 \mathrm{~m}}=3.97 \AA$ at $193 \mathrm{~K}$.

$P_{T} \sim 31$ kbar (calculated)

$\sim 5$ kbar at $133 \mathrm{~K}$ (observed) $\Delta H_{\mathrm{tr}} 130 \pm 20 \mathrm{cal} \cdot \mathrm{mol}^{-1}$. $P_{T}$ is $\sim 7.5 \mathrm{kbar}$ at $973 \mathrm{~K}$.

$P_{T} \sim 7.5$ kbar. A simultaneous deformation and polymorphic transformation were observed.

$a_{\mathrm{Pm} 3 \mathrm{~m}}=4.24 \AA$ at $230 \mathrm{~K}$.

$$
\begin{aligned}
P_{T} & \sim 25 \text { kbar (theory) } \\
& \sim 4.6 \text { kbar (observed). } \\
& \sim 5.5 \text { kbar at } 873 \mathrm{~K} .
\end{aligned}
$$

The films have $\mathrm{RbBr}$ with $\mathrm{Pm} 3 \mathrm{~m}$ structure where $a=4.06 \AA$. If the fil $m$ is grown from vapor, the structure is $\mathrm{Fm} 3 \mathrm{~m}$.
The value of $P_{T}$ agrees well with calculated value of 21 kbar. $P_{T}$ appears to be independent of temperature. Transition is sluggish at $298 \mathrm{~K}$ but faster at $423 \mathrm{~K}$.

Transition takes place to the $\mathrm{Pm} 3 \mathrm{~m}$ structure.

The Pm $3 \mathrm{~m}$ phase slowly disappears as the temperature is increased.

The volume contraction in $\mathrm{RbCl}$ is comparable to that in $\mathrm{CsCl}$ for the $\mathrm{Pm} 3 \mathrm{~m}-\mathrm{Fm} 3 \mathrm{~m}$ phase. Thus the high pressure phase of $\mathrm{RbCl}$ is $\mathrm{CsCl}$ type only.

The simultaneous deformation and transformation are attributed to the crack-healing effect. Cracks appear at about $1 \%$ deformation and vanish in large deformations. especially at the buckled surface of the sample. At pressures above $P_{T}$, the cracks do not disappear but transform to a system of slanted fissures.

The intensity of the Pm $3 \mathrm{~m}$ lines disappear with rise in temperature.

The experimental observations can be fitted to Simon equation.

Vapor grown $\mathrm{RbBr}$ films change to $\mathrm{Pm} 3 \mathrm{~m}$ if dissolved in water and grown from solution on silver films.
References

$[7,26,17,30$, 52. 73]

[51].

$[73]$.

[5].

$[6,17.24,47$, $50.51,68$, 69].

[34].

$[5]$.

$[6,17,47,51$. 52].

[64]. 
Alkali Halides - Continued

\begin{tabular}{l} 
Substances and \\
measurement techniques \\
\hline $\begin{array}{l}\text { Rubidium iodide, RbI } \\
\text { (Fm3m, } a=7.342 \AA \text { at } 300 \mathrm{~K})\end{array}$ \\
Thin layers of RbI evaporated ont \\
amorphous bases and examined b \\
electron diffraction. \\
Pressure-temperature curves for \\
RbI from 0-40 kbar and 273 to 873 \\
Optical investigation of the Fm3m- \\
Pm3m pressure transition in RbI \\
single crystals. A high pressure \\
vessel with a modified Vickers \\
metallographic microscope and \\
time lapse photographic technique \\
are employed.
\end{tabular}

Dilatometric studies of the Fm3m$\mathrm{Pm} 3 \mathrm{~m}$ transition in $\mathrm{RbI}$; construction of the $P-T$ diagram.

Cesium chloride, $\mathrm{CsCl}(\mathrm{Pm} 3 \mathrm{~m}$, $a=4.123 \AA$ at $298 \mathrm{~K}$ )

Calorimetric methods

Application of the Clausius-

Clapeyron relation to the transition.

DTA of pure. $\mathrm{CsCl}$ and solid solutions with other alkali halides and $\mathrm{x}$-ray diffraction studies of $\mathrm{CsCl}$ transition at various temperatures.

Temperature variable $x$-ray diffraction studies on $\mathrm{CsCl}$ powder as well as single crystals.
Electron diffraction studies of $\mathrm{Cs} \mathrm{Cl}$ transition.
$a_{\mathrm{P}^{\mathrm{m} 3 \mathrm{~m}}}=4.59 \AA$ at $193 \mathrm{~K}$.

$P_{T} \sim 4.8 \mathrm{kbar}$ at $873 \mathrm{~K}$, above which the $\mathrm{Pm} 3 \mathrm{~m}$ phase is possible

$P_{r} \sim 3.5$ kbar.

$P_{T} \sim 4.3$ kbar at $298 \mathrm{~K} .(d T / d P)$

$=1.4^{\circ} \mathrm{bar}^{-1}$ for the equilibrium curve.

$T_{t}, 743 \mathrm{~K} \Delta H_{\mathrm{tr}}, 580-707 \mathrm{cal} \cdot \mathrm{mol}^{-1}$

The relation is applicable with limited utility.

Transition $\left(T_{t}, 745-753 \mathrm{~K}\right)$ is of first order $\Delta H_{\mathrm{tr}}, 600-880 \mathrm{cal} \cdot \mathrm{mol}^{-1}$; $\Delta T \sim 33^{\circ} ; \Delta V \sim 7.34 \mathrm{~cm}^{3} \mathrm{~mol}^{-1}$. With incorporation of $\mathrm{KCl}$ or $\mathrm{RbCl}$, the $T_{t}$ and $\Delta H_{\mathrm{tr}}$ are decreased with increase in $\mathrm{KCl}$ or $\mathrm{RbCl}$. With $\mathrm{CsBr}, T_{t}$ and $\Delta H_{\mathrm{tr}}$ are increased.

$T_{t}, 742-753 \mathrm{~K}$. The lattice const. extrapolated to $298 \mathrm{~K}$ is, $a=6.91 \AA$ for the $\mathrm{Fm} 3 \mathrm{~m}$ phase (at $753 \mathrm{~K}$, $a=7.02 \AA$ ). In $\mathrm{CsCl}+\mathrm{CsBr}$ solid solutions coexistence of $\mathrm{Pm} 3 \mathrm{~m}$ and Fm3m phases is observed in the $x$-ray patterns in the neighborhood of the transition temperature.

$T_{\ell}, 753 \mathrm{~K} ; a_{\mathrm{Fm} 3 \mathrm{~m}}=6.923 \AA$ at $227 \mathrm{~K}$ and $6.940 \AA$ at $298 \mathrm{~K}$ (extrapolated values).
References

The intensity of the Pm $3 \mathrm{~m}$ lines slowly disappears as the temperature is increased.

The experimental points fit to Simon equation.

The transition was affected by the nature of the crystal surfaces. The lattice dynamics of the transition has been discussed in terms of the shifts in the optical and acoustical mode frequencies. Results of this discussion are not compatible with the experimental thermal expansion data on RbI.

Hysteresis effects are observed in the transition.

The $\mathrm{Fm} 3 \mathrm{~m}$ phase of $\mathrm{CsCl}$ gets stabilized at ordinary temperatures in solid solutions with $30 \% \mathrm{KCl}$ or $35 \%$ $\mathrm{RbCl}$. With $\mathrm{KCl}$ or $\mathrm{RbCl}$ solid solutions, first order characteristics of the $\mathrm{CsCl}$ transition are still preserved. In $\mathrm{CsBr}$ solid solutions higher order components are present in the transition and the $\mathrm{Pm} 3 \mathrm{~m}$ structure is retained at ordinary temperatures.

The lattice constants of the $\mathrm{Pm} 3 \mathrm{~m}$ as well as the $\mathrm{Fm} 3 \mathrm{~m}$ phases decrease with increasing percent of $\mathrm{KCl}$ or $\mathrm{RbCl}$. On the other hand the lattice constant increases with $\mathrm{CsBr}$ content. The molar volume change, $\Delta V$, slightly increases in $\mathrm{KCl}$ solid solutions indicating that the transitions are first order. In $\mathrm{CsBr}$ solid solutions, $\Delta V$ decreases indicating the presence of higher order components in these transitions.

The transformation is believed to proceed through a defect mechanism. Hybridization and mixed crystal (of both $\mathrm{Pm} 3 \mathrm{~m}$ and $\mathrm{Fm} 3 \mathrm{~m}$ structures) formation were noticed just below $T_{t}$.
[54].

$[2,29,32]$.

[36].

[5].

[51].

$[13,14]$.

$[45,56,59$, $60,73]$.

$[22,23,40,45$, $57,58,71$, $74,75]$.

$[5,41,63]$. 


Substances and
measurement techniques

$\mathrm{CsCl}$ and its solid solutions with $\mathrm{KCl}, \mathrm{RbCl}, \mathrm{CsBr}$ and $\mathrm{SrCl}_{2}$.

Self-diffusion and electrical conductivity measurements.

Electronographic investigation of evaporated thin films.

Study of the phase transition by $\mathrm{S}^{35}$ emanation from $\mathrm{CsCl}^{35}$ and its solid solution with $\mathrm{CsBr}$.

Kinetics of the $\mathrm{CsCl}$ transition above $733 \mathrm{~K}$, by electron diffraction studies.

Cesium bromide, $\mathrm{CsBr}$.

(Pm3m, $a=4.2953 \AA$ at $298 \mathrm{~K}$ )

X-ray diffraction up to melting point.

Thin films of CsBr evaporated on to surface of mica, $\mathrm{CaC}_{3}$ or amorphous bases at low temperatures and examined by electron diffraction.

Evaluation of $T_{t}$ and $\Delta H_{\mathrm{tr}}$ from experimental data from $\mathrm{CsCl}+\mathrm{CsBr}$ solid solutions and thermodynamic considerations.

Cesium iodide, CsI

$$
(\mathrm{Pm} 3 \mathrm{~m}, a=4.5679 \AA \text { at } 299 \mathrm{~K})
$$

X-ray diffraction of CsI up to the melting point.

Thin films of CsI evaporated on to amorphous bases or mica or $\mathrm{CaCO}_{3}$ at very low temperatures and examined by electron diffraction.
The $T_{t}$ is indicated by a break in the $\log \sigma$ versus $1 / T$ plots. The activation energies from the plot give values of cation migration energy, $E_{c}^{m} \sim 0.6 \mathrm{eV}$ and Schottky defect formation energies, $E_{s}$. $E_{s} \sim 1.4-$ $1.8 \mathrm{eV}$ in pure $\mathrm{CsCl}$ in $\mathrm{Pm} 3 \mathrm{~m}$ phase. The value of $E_{s}$ in the $\mathrm{Fm} 3 \mathrm{~m}$ phase. is $\sim 2.0 \mathrm{eV}$. The cation migration energy decreases slightly with $\mathrm{K}^{+}$ or $\mathrm{Cs}^{+}$content and increases with $\mathrm{Br}^{-}$content. Addition of $\mathrm{Sr}^{+2}$ slightly decreases the $T_{t}$ of $\mathrm{CsCl}$.

$E_{\text {" }}$ for conduction $\sim 1.26 \mathrm{eV} ; E_{\text {a }}$ for diffusion: $1.53 \mathrm{eV}$ for $\mathrm{Cs}^{127}$ $1.27 \mathrm{eV}$ for $\mathrm{Cl}^{36}$.

Both Pm $3 \mathrm{~m}$ and Fm $3 \mathrm{~m}$ structures were noticed.

$T_{t}$ is indicated by the increased radioactivity. $T_{t}$ is increased by $\mathrm{CsBr}$ addition.

The kinetics become difficult to follow because $\mathrm{CsCl}$ starts to sublime at $\sim 730 \mathrm{~K}$ and is extremely sensitive to moisture.

Some extra weak lines are observed in the x-ray spectra, which do not belong to the Pm3m structure.

Fm 3 m structure of $\mathrm{CsBr}$ was noticed $a=7.2300 \AA-7.253 \AA$ at $\sim 155 \mathrm{~K}$.

For CsBr, $T_{1} \sim 1153 \mathrm{~K}$ for $\mathrm{Pm} 3 \mathrm{~m}_{-}$ Fm $3 \mathrm{~m}$ transition: $\Delta H_{\mathrm{tr}}($ calcd $)=300$ $\mathrm{cal} \cdot \mathrm{mol}^{-1}$.

No transition was observed.

Both P $\mathrm{m} 3 \mathrm{~m}$ and Fm $3 \mathrm{~m}$ structures were observed with the intensity of Fm3m structures becoming weak with time. $a_{\mathrm{Fm} 3 \mathrm{~m}}=7.631 \AA$ at $148 \mathrm{~K}$.
The conductivity experiments on single crystals as well as polycrystalline pellets give results which do not vary much. The role of vancancies in the mechanism of the transition is not definitive. Though vancancies may aid the transition by decreasing the $T_{t}$, the mechanism would still involve dilatation along the body diagonal.

Conduction is only ionic. Schottky transformation does not involve an extensive disruption of lattice. The transformation is essentially dilatational with an increase in lattice vacancies around $T_{t}$.

Both Pm $3 \mathrm{~m}$ and $\mathrm{Fm} 3 \mathrm{~m}$ phases coexist near $T_{t}$.

The weak lines are with 2 to 4 times the basic lattice period of the stable Pm3m structure.

The Fm $3 \mathrm{~m}$ lines are of weak intensity and disappear with time.

The transition temperature is higher than the melting point of $\mathrm{CsBr}$. defects are predominant. The

$[3,42,43,46$, 46a, 72].

$20,21]$.

[19].

[35].

[70].

[71].

The intensity of the lines due to the Fm3m structure weakens slowly with increase of temperature and completely disappears at room temperature. 
Alkali Halides - Continued

\begin{tabular}{|c|c|c|c|}
\hline $\begin{array}{c}\text { Substances and } \\
\text { measurement techniques }\end{array}$ & Data & Remarks & References \\
\hline $\begin{array}{l}\text { CsI evaporated on to } \mathrm{K} \text { and } \mathrm{Rb} \\
\text { halides (as thin films) and examined } \\
\text { by electronograph. }\end{array}$ & $\begin{array}{l}\text { Microcrystals of } \mathrm{NaCl} \text { and } \mathrm{Cs} \mathrm{Cl} \text { type } \\
\text { structures were observed. With } \\
\text { increasing thickness of the CsI } \\
\text { films the lines due to } \mathrm{Pm} 3 \mathrm{~m} \\
\text { structure increase in intensity. }\end{array}$ & $\begin{array}{l}\text { Microcrystals of Fm } 3 \mathrm{~m} \text { structure were } \\
\text { unstable in air and recrystallized } \\
\text { into Pm } 3 \mathrm{~m} \text { structure. Exchange of } \\
\text { Cs and Rb cations was observed to } \\
\text { take place in the presence of } \\
\text { moisture. }\end{array}$ & [19]. \\
\hline
\end{tabular}

\section{References}

[1] Al'tshuler, L. V., Brazhnik, M. I., German, V. N., and Mirkin, L. I., Sov. Phys. Solid State 9, 2417 (1968).

[2] Arell, A., Roiha, M., and Aaltonen, M., Phys. Kondens. Materie. 6, 140 (1967).

[3] Arends, J., and Nijboer, H., physica stat. sol. 26, 537 (1968).

[4] Bassett, W. A., Takahashi, T., Mao, H., and Weaver, J. S., J. Appl. Phys. 39, 319 (1968).

[5] Blackman, M., and Khan. I. H., Proc. Phys. Soc. (London) 77,471 (1961).

[6] Bridøman, P. W., Z. Krist. 67, 363 (1928).

[7] Briduman, P. W., Phys. Rev. 48,893 (1935).

[8] Bridgman, P. W., Proc. Am. Acad. Arts Sci. 76, 1 (1945)

[9] Buckle. E. R., Diss. Faraday Soc. 30, 46 (1960).

[10] Buerger, M. J., in Phase Transformations in Solids, Ed. R. Smoluchowski (John Wiley \& Sons. Inc., New York, 1951).

[11] Corll, J. A., and Samara, G. A., Solid State Communications 4, 283 (1966).

[12] Davis, L. A., and Gordon, R. B., phys. stat. sol. 36, K133 (1969).

[13] Daniels, W. B., and Skoultchi, A. I., J. Phys. Chem. Solids. 27, 1247 (1966).

[14] Daniels, W. B., J. Phys. Chem. Solids. 28, 350 (1967).

[15] Decker, D. L., J. Appl. Phys. 36, 157 (1965).

[16] Decker, D. L., J. Appl. Phys. 37, 5012 (1966).

[17] Evdokimora, V. V., and Vereschagin, L. F., Sov. Phys. JETP 16, 855 (1963).

[18] Evdokimora, V. V., and Vereschagin, L. F., Zh. Eksperim. i. Teor. Fiz. 43, 1208 (1962).

[19] Haav, A., Trudy. Inst. Fiz. i Astron. Akad. Nauk. Eston. S.S.R.. page 123 (1961).

[20] Harvey, P. J., and Hoodless, I. M., Phil Mag. 16, 543 (1967).

[21] Hoodless, I. M., and Morrison, J. A., J. Phys. Chem. 66, 557 (1962).

[22] Hovi. V., Ann. Univ. Turkuensis, Ser. A I 26, 8 (1957); Acta. Met. 6, 254 (1958).

[23] Huggins. M. L., and Mayer, J. E., J. Chem. Phys. 1, 637 (1933).

[24] Jacobs, R. B., Phys. Rev. 54, 325 (1938).

[25] Jacobs, R. B., Phys. Rev. 54, 468 (1938).

[26] Jamieson, J. C., J. Geol. 65, 334 (1957).

[27] Jamieson, J. C., and Lawson, A. W., J. Appl. Phys. 33, $776(1962)$.

[28] Johnson, Q., Science 153,419 (1966).

[29] Kaylor, C. E., Walden, G. E., and Smith, D. F., J. Phys. Chem. 64, 276 (1960).

[30] Kennedy, G. C., and La Mori, P. N.. J. Geophys. Res. 67, 851 (1962).

[31] Klynev, Yu. A., Dokl. Acad. Nauk. S.S.S.R. 144, 538 (1962).

[32] Krogh-Moe, J.. J. Am. Chem. Soc. 82, 2399 (1960).

[33] Larson, D. B.. Keeler, R. N., Kusubov, A., and Hord, B. L.. J. Phys. Chem. Solids 27, 476 (1966).

[33a] Lew, H., Can. J. Phys. 42, 1004 (1964).

[34] Livshits, L. D.. Beresnev, B. I., Genshaft. Yu. S., and Ryabinin, Yu. N., Dokl. Acad. Nauk. S.S.S.R. 164, 541 (1965).

[35] Makarov, L. L.. Aloi, A. S.. and Stupin, D. Yu.. Radiokhimiva 11, 116 (1969).

[36] Najumdar, A. J.. and Roy, R., J. Inorg. Nucl. Chem. 27, 1961 (1965).

[37] Mansikka, K.. Ann. Univ. Turku. Ser. A I 121, 11 (1968).
[38] May, A., phys. Rev. 52, 339 (1937); ibid. 54, 629 (1938).

[39] Mayer, J. E., J. Chem. Phys. 1, 270 (1933).

[40] Menary, J. W., Ubbelohde, A. R., and Woodward, I., Proc. Roy. Soc. (London) A208, 158 (1951).

[41] Morlin, Z., and Tremmel, J., Acta. Phys. 21, 129 (1966).

[42] Morlin, Z., Acta. Phys. 21,137 (1966).

[43] Morlin, Z., Acta. Phys. 24, 277 (1968).

[44] Nagasaki, H., and Minomura, S., J. Phys. Soc. Japan 19, 1496 (1964).

[45] Natarajan, M., Rao, K. J., and Rao, C. N. R., Trans. Faraday Soc. 66, 2497 (1970).

[46] Natarajan, M., Ph.D., Thesis, 1970, Indian Institute of Technology, Kanpur, India.

[46a] Natarajan, M., Prakash, B., and Rao, C. N. R., J. Chem. Soc. A, 2293 (1971).

[47] Pauling, L., Z. Krist 69, 35 (1928).

[48] Pistorius, C. W. F. T., and Admiraal, L. J., Nature 201, 1321 (1964).

[49] Pistorius, C. W. F. T., Nature 204, 467 (1964).

[50] Pistorius, C. W. F. T., J. Phys. Chem. Solids 25, 1477 (1964).

[51] Pistorius, C. W. F. T., J. Chem. Phys. 43, 1557 (1965).

[52] Pistorius, C. W. F. T., J. Phys. Chem. Solids 26, 1003 (1965).

[53] Plendl, J. N., and Gielisse, P. J. M., physica stat. sol. 35, K151 (1969).

[54] Petrunina, T. I., and Estrin, E. I., Dokl. Acad. Nauk. S.S.S.R. 183, 817 (1968).

[55] Popov, M. M., Simanov, V. P., Skuratov, S. M., and Suzdal'tseva, M. N., Ann. Sect. anal. phys. chim. Inst. Chim. gen. (U.S.S.R.), 16, 111 (1943).

[56] Pöyhonen, J., and Mansikka, K., phys. Kondens. Materie 3, 218 (1965).

[57] Pöyhonen, J., Jaakkola, S., and Rasanen, V., Ann. Univ. Turku, Ser. AI 80, 12 (1964).

[58] Pöyhonen, J., and Ruuskanen, A., Ann. Acad. Sci. Fennicae. Ser. A VI 146, 12 (1964).

[59] Rao, K. J., and Rao, C. N. R., J. Materials Sci. 1, 238 (1966).

[60] Rao, K. J., Rao, G. V. S., and Rao, C. N. R., Trans. Faraday Soc. 63, 1013 (1967).

[61] Rao, K. J., and Rao, C. N. R., Proc. Phys. Soc. (London) 91 , 754 (1967).

[62] Rao, K. J., Rao, G. V. S., and Rao, C. N. R., J. Phys. C. (Proc. Phys. Soc.) 1, 1134 (1968).

[63] Schulz, L. G., J. Chem. Phys. 18, 996 (1950); ibid. 19, 504 (1951).

[64] Schumacher, D. P., Phys. Rev. 126, 1679 (1962).

[65] Sharma, M. N., and Madan, M. P., Ind. J. Phys. 38, 231 (1964).

[66] Slykhouse, T. E., and Drickamer, H. G., Coll. intern. centre. natl. recherche, Sci. 77, 163 (1959).

[67] Smits, A., Z. physik. Chem. B5 1, 1 (1941).

[68] Tosi, M. P., and Fumi, F. G., J. Phys. Chem. Solids 23, 359 (1962).

[69] Tosi, M. P., J. Phys. Chem. Solids 24, 1067 (1963).

[70] Tremmel, J., and Morlin, Z., Radex Rundsch., 449 (1967).

[71] Wagner, G., and Lippert, L., Z. Physik chem. B3 1, 263 (1936).

[72] Weijma, H., and Arends, J., phys. stat. solidi 35, 205 (1969).

[73] Weir, C. E., and Piermarini, G. J., J. Res. Nat. Bur. Stand. (U.S.) 68A (Phys. and Chem.), No. 1, 105 (1964).

[74] Wood, L. J., Secunda, W., and McBride, H., J. Am. Chem. Soc. 80, 307 (1958).

[75] Wood, L. J., Sweeney, Ch., and Derbes, M. T., J. Am. Chem. Soc. 81, 6148 (1959). 


\section{Ammonium Halides}

Phase transitions in ammonium halides as well as their deuterium analogues are well documented in the literature. A wide variety of experimental methods have been employed to study these transitions. While a higher order $\lambda$-transition at low temperatures is common to all the halides, a $\mathrm{Pm} 3 \mathrm{~m}(\mathrm{CsCl})-\mathrm{Fm} 3 \mathrm{~m}$ $(\mathrm{NaCl})$ transition is exhibited by ammonium chlorides, bromides and iodides and their deuterated analogues at higher temperatures. The latter is a first order transition and is accompanied by considerable thermal hysteresis. In addition to the $\lambda$ and $\mathrm{Pm} 3 \mathrm{~m}-\mathrm{Fm} 3 \mathrm{~m}$ transitions, a third transition is reported in $\mathrm{NH}_{4} \mathrm{Br}$ at $\sim 100 \mathrm{~K}$. The $\lambda$-transitions of ammonium halides are associated with a change in the rotational motion of the $\mathrm{NH}_{4}^{+}$ion about the ternary axis. Pressure transitions in $\mathrm{NH}_{4} \mathrm{X}$ have been reported. Lattice energies of all the four ammonium halides have been estimated theoretically [38] and the calculated values are in good agreement with the observed values.

Much of the theoretical work has been devoted to the $\lambda$-transitions in ammonium halides. These $\lambda$ transitions are believed to be due to the onset of $\mathrm{NH}_{4}^{+}$ ion rotation by Pauling [28a]. While the $\lambda$-changes in $\mathrm{NH}_{4} \mathrm{Cl}$ and $\mathrm{NH}_{4} \mathrm{Br}$ have been attributed to an order-disorder change in the $\mathrm{NH}_{4}^{+}$ion orientation [8a, 25], a temperature-dependent one-dimensional free rotation has been suggested in the case of $\mathrm{NH}_{4} \mathrm{I}$ [30]. The low temperature phase of $\mathrm{NH}_{4} \mathrm{Cl}$ consists of parallel oriented $\mathrm{NH}_{4}^{+}$groups while the high temperature phase is characterized by randomly oriented $\mathrm{NH}_{4}^{+}$groups [27]. In $\mathrm{NH}_{4} \mathrm{Br}$, the low temperature phase consists of an antiparallel orientation of $\mathrm{NH}_{4}^{+}$ ions and the high temperature phase is similar to that of $\mathrm{NH}_{4} \mathrm{Cl}$ [26]. Neutron diffraction studies $[22,25]$ have confirmed the $\mathrm{NH}_{4}^{+}$ion orientations in these halides. The polarization effect of the halide ions is considered to be responsible for the difference in the $\mathrm{NH}_{4}^{+}$ion orientation in the low temperature phases of $\mathrm{NH}_{4} \mathrm{Cl}$ and $\mathrm{NH}_{4} \mathrm{Br}$ [26]. NMR [10a, $15]$ and IR [36, 54] studies have been employed to investigate the problem of $\mathrm{NH}_{4}^{+}$ion rotation. Sonin [40] has discussed the possible antiferroelectricity in $\mathrm{NH}_{4} \mathrm{I}$ and $\mathrm{NH}_{4} \mathrm{Br}$ from a correlation of physical properties with structure.

The Pippard equations and the phase diagram for $\mathrm{NH}_{4} \mathrm{Cl}$ have been analyzed in terms of a compressible Ising model; the Pippard relations are completely consistent with the occurrence of a first-order transition in the immediate vicinity of a $\lambda$-point [33]. Anomalous heat capacity variations in ammonium halides at low temperatures have been ascribed to second order phase transitions [53]. However, calculations based on available data show that the behavior is described by the Clausius-Clapeyron equation for the first order transitions rather than Ehrenfest's equation for the second order transitions. An abrupt change in dielectric constant at the transition points also indicate a first order transition. A compressible Ising model has also been employed to show that the anomalous $\Delta V$ due to ordering is essentially identical with the anomalous changes in the elastic constant, $\mathrm{C}_{44}[9,9 \mathrm{a}]$.

Thermal Transitions. Ammonium fluoride is hexagonal at room temperature and belongs to B4 group (similar to hexagonal AgI or wurtzite type); this is the only ammonium halide which exists in the hexagonal structure. No transition is known in $\mathrm{NH}_{4} \mathrm{~F}$ above $298 \mathrm{~K}$. However, a $\lambda$-transition at $242 \mathrm{~K}$ and a pressure transition around $4000 \mathrm{~atm}$ have been reported.

Below $450 \mathrm{~K}$, ammonium chloride possesses the B2 structure with the $\mathrm{Pm} 3 \mathrm{~m}$ (CsCl type) space group. Phase transitions in $\mathrm{NH}_{4} \mathrm{Cl}$ have been the subject of detailed investigation by many workers. The following is the sequence of phase transitions in ammonium chloride.

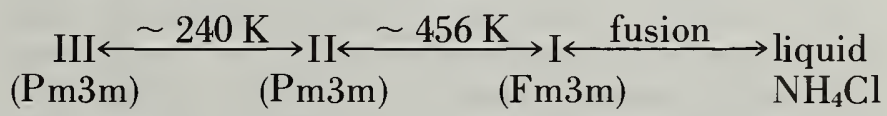

Forms III and II are both CsCl type structures, the transition between them being of $\lambda$-type. Form I is of $\mathrm{NaCl}$ type $(\mathrm{Fm} 3 \mathrm{~m})$ with $a=6.520 \AA$ at $523 \mathrm{~K}$. Thus the phase transition at $456 \mathrm{~K}$ is a $\mathrm{Pm} 3 \mathrm{~m}-\mathrm{Fm} 3 \mathrm{~m}$ transformation similar to the transition in CsCl. The Pm3m-Fm3m transition is of first order and is associated with considerable thermal hysteresis. IR, Raman and NMR spectroscopy, x-ray diffraction, DTA as well as measurements of piezoelectricity, dielectric constant, heat capacity and heat of solution have been employed for the study of the transitions.

Ammonium bromide is body centered cubic (Pm3m, CsCl type) below $411 \mathrm{~K}$. Above this temperature, the structure is face-centered cubic $(\mathrm{Fm} 3 \mathrm{~m}$, $\mathrm{NaCl}$ type). Just as in $\mathrm{NH}_{4} \mathrm{Cl}$, there are two transitions in $\mathrm{NH}_{4} \mathrm{Br}$. The $\mathrm{Pm} 3 \mathrm{~m}-\mathrm{Fm} 3 \mathrm{~m}$ transition takes place at $\sim 411 \mathrm{~K}$ with appreciable volume change and thermal hysteresis. The transition has been found to be first order. The $\lambda$-change takes place around $235 \mathrm{~K}$. In addition to these two transitions a third transition at $\sim 102 \mathrm{~K}$ has also been reported. The transitions at $235 \mathrm{~K}$ and $102 \mathrm{~K}$ are also accompanied by hysteresis effects; these transitions have been attributed to changes in the $\mathrm{NH}_{4}^{+}$ion orientation in III and IV phases.

$$
\underset{(\mathrm{Pm} 3 \mathrm{~m})}{\stackrel{102 \mathrm{~K}}{\longleftrightarrow}} \text { Tetragonal } \underset{\begin{array}{c}
\lambda \text {-change }(\mathrm{Pm} 3 \mathrm{~m}) \\
\text { (nearly } \\
\text { CsCl type) }
\end{array}}{\stackrel{235 \mathrm{~K}}{\stackrel{4}{\leftrightarrows}}}
$$


The room temperature structure of $\mathrm{NH}_{4} \mathrm{I}$ is Fm3m. This transforms to the $\mathrm{Pm} 3 \mathrm{~m}$ structure (CsCl type) at about $257 \mathrm{~K}$. A $\lambda$-transition in $\mathrm{NH}_{4} \mathrm{I}$ takes place at $\sim 231.3 \mathrm{~K}$. It is interesting to note that the stability range of phase II (CsCl-type) is narrowed down to $25^{\circ}$.

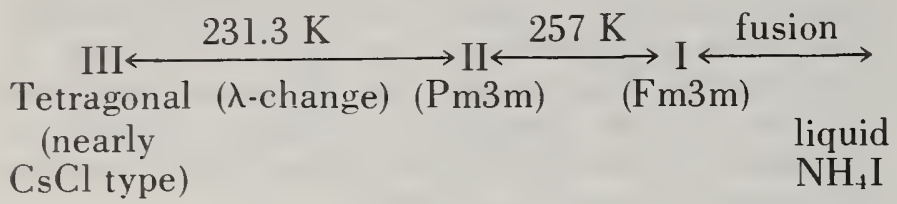

Deuteroammonium halides, $\mathrm{ND}_{4} \mathrm{X}$, exhibit the Pm3m-Fm3m phase transitions with the exception of $\mathrm{ND}_{4} \mathrm{I}$. But a $\lambda$-transition is common to all of them just as in their hydrogen counterparts. The Pm3mFm $3 m$ transitions retain their first-order characteristics in the deuterated solids. The transition temperatures of $\mathrm{ND}_{4} \mathrm{X}$ are generally lower than in the corresponding $\mathrm{NH}_{4} \mathrm{X}$, except the III-IV transition of $\mathrm{ND}_{4} \mathrm{Br}$.

The $\mathrm{Pm} 3 \mathrm{~m}-\mathrm{Fm} 3 \mathrm{~m}$ transition in $\mathrm{ND}_{4} \mathrm{Cl}$ takes place at $448 \mathrm{~K}$ while the $\lambda$-change occurs at $\sim 250$ $\mathrm{K}$. These transition temperatures are lower than the corresponding values in $\mathrm{NH}_{4} \mathrm{Cl}$. While the $\mathrm{Pm} 3 \mathrm{~m}-\mathrm{Fm} 3 \mathrm{~m}$ transition is accompanied by considerable hysteresis and volume change, the $\lambda$-change has no hysteresis effects.

There are three transitions in $\mathrm{ND}_{4} \mathrm{Br}$ corresponding to those in $\mathrm{NH}_{4} \mathrm{Br}$ :

$$
\begin{aligned}
& 164 \mathrm{~K} \\
& 215 \mathrm{~K} \\
& \text { IV } \\
& \text { (Pm3m) (nearly CsCl type; } \lambda \text { - change (Pm3m) }
\end{aligned}
$$

$\underset{(\mathrm{Pm} 3 \mathrm{~m})}{\mathrm{II}} \stackrel{393 \mathrm{~K}}{\mathrm{I}} \underset{(\mathrm{Fm} 3 \mathrm{~m})}{\stackrel{\text { fusion }}{\longrightarrow}} \underset{\mathrm{ND}_{4} \mathrm{Br}}{\stackrel{\text { liquid }}{\longleftrightarrow}}$

The III-IV transition is faster than in $\mathrm{NH}_{4} \mathrm{Br}$; $T_{t}$ is also higher in the former case. The $\Delta V$ in $\mathrm{ND}_{4} \mathrm{Br}$ transitions are comparable to those in $\mathrm{NH}_{4} \mathrm{Br}$.

No literature data seem to be available on ${ }_{1} \mathrm{ND}_{4} \mathrm{I}$ after Staveley's report [47]. The III-II transition takes place at $\sim 229 \mathrm{~K}$, with no thermal hysteresis and negligible volume change $(\sim-0.1$ $\mathrm{cm}^{3} \mathrm{~mol}^{-1}$ ). This is likely to be a higher order transformation.

Pressure Transitions. Pressure transitions in ammonium halides are not reported extensively in the literature, compared to thermal transitions. The earliest work on pressure-temperature relationships in ammonium halides seems to be that of Bridgman [7a] who reported data for $\mathrm{NH}_{4} \mathrm{Cl}$, $\overline{\mathrm{N}} \mathrm{H}_{4} \mathrm{Br}$ and $\mathrm{NH}_{4} \mathrm{I}$ between $273 \mathrm{~K}$ and $473 \mathrm{~K}$ and $12,000 \mathrm{~kg} \mathrm{~cm}^{-2}$. The only reports on the transition of $\mathrm{NH}_{4} \mathrm{~F}$ (at $\sim 3800$ atm and liquid nitrogen temperatures) are that of Stevenson [48], and Swenson and Tedeschi [50a]. Stevenson [49] also reports data on $\mathrm{NH}_{4} \mathrm{Cl}, \mathrm{NH}_{4} \mathrm{Br}, \mathrm{NH}_{4} \mathrm{I}$ and $\mathrm{ND}_{4} \mathrm{Br}$. Adams and Davis [1] report four polymorphic forms for $\mathrm{NH}_{4} \mathrm{I}$. Pressure effects on the $\lambda$-transition of $\mathrm{NH}_{4} \mathrm{Cl}$ have been investigated by Klynev [17] as well as Trappeniers and co-workers [52]. A systematic investigation of pressure transitions in ammonium halides has been carried out by Pistorius [29] recently. A brief account of phase transitions in ammonium halides has been reported recently by Hovi [1la]. This review summarizes the experimental results from di-

\begin{tabular}{|c|c|}
\hline $\begin{array}{l}\text { Substances and } \\
\text { measurement techniques }\end{array}$ & Data \\
\hline $\begin{array}{l}\text { Ammonium fluoride, } \mathrm{NH}_{4} \mathrm{~F}(\mathrm{P} 6 \mathrm{mc} \text {, } \\
\quad \begin{array}{l}a=4.44 \AA \text { and } c=7.17 \AA \text { at } \\
298 \mathrm{~K})\end{array}\end{array}$ & \\
\hline $\begin{array}{l}\text { Dielectric constant as a function } \\
\text { of temperature. }\end{array}$ & $\begin{array}{l}\text { Anomaly in } \epsilon \text { at } \sim 242 \mathrm{~K} . T_{t} \\
\sim 241.5 \mathrm{~K} .\end{array}$ \\
\hline $\begin{array}{l}\text { Ammonium chloride, } \mathrm{NH}_{4} \mathrm{Cl} \\
\quad(\mathrm{Pm} 3 \mathrm{~m}, a=3.8756 \AA \text { at } 299 \mathrm{~K})\end{array}$ & 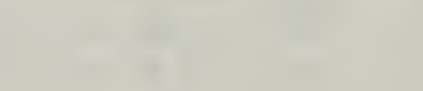 \\
\hline & $P m 3 m-F m 3 m$ transition \\
\hline $\mathrm{X}$-ray diffraction & $\begin{array}{l}a_{\mathrm{Pm} 3 \mathrm{~m}}=3.868 \AA \text { at } 291 \mathrm{~K} \\
a_{\mathrm{Fm} 3 \mathrm{~m}}=6.52 \AA \text { at } 523 \mathrm{~K} \\
T_{\imath} \sim 457.3 \mathrm{~K} .\end{array}$ \\
\hline $\begin{array}{l}\text { Specific heat as a function of } \\
\text { temperature }\end{array}$ & $\begin{array}{l}T_{1} \sim 456.1 \mathrm{~K}, \Delta H_{\mathrm{tr}} \sim 1030 \\
\quad \mathrm{cal} \cdot \mathrm{mol}^{-1}\end{array}$ \\
\hline
\end{tabular}
alatometric, x-ray, calorimetric and NMR studies; the effect of deuteration of ammonium halides is also included.

Ammonium Halides 


\section{Substances and
measurement techniques}

Thermal analysis

Differential Calorimetry

Dielectric constant as a

function of temperature

Dilatometric studies

Review articles

X-ray diffraction down to $80 \mathrm{~K}$

Thermal analysis

\section{Differential calorimetry}

Dielectric constant as a function of temperature

Dilatometric studies; with $\mathrm{CBr}_{4}$ as the dilatometric liquid.

Thermal expansion of $\mathrm{NH}_{4} \mathrm{Cl}$ and $\mathrm{x}$-ray investigation.

Temperature dependence studies of proton and deuteron spin. lattice relaxation in $\mathrm{NH}_{4} \mathrm{Cl}$.

ESR and DTA studies on doped $\mathrm{NH}_{4} \mathrm{Cl}$ samples containing a paramagnetic ion, like $\mathrm{Cu}^{+2}$, $\mathrm{Ni}^{+2}$ or $\mathrm{VO}_{2}^{+}$

$$
\begin{aligned}
& T_{t} \sim 458 \mathrm{~K} ; \Delta H_{\mathrm{tr}} \sim 1073 \mathrm{cal} \\
& \mathrm{mol}^{-1} . T 813.25 ; \Delta V 87.14 \\
& \mathrm{~cm}^{3} \mathrm{~mol}^{-1}
\end{aligned}
$$

$T_{t} \sim 456.1 \mathrm{~K} ; \Delta H_{\mathrm{tr}} \sim 1073 \mathrm{cal}$. $\mathrm{mol}^{-1}$.

$\Gamma_{t} \sim 458 \mathrm{~K}$

$T_{t} \sim 456.1 \mathrm{~K} ; \Delta V \sim 19.31 \%$ at $T_{t} \cdot\left(d T_{t} / d P\right)=0.0724^{\circ} \mathrm{atm}^{-1}$.

\section{$T_{t} \sim 456 \mathrm{~K}$ \\ $\Delta S_{\mathrm{tr}} \sim 2.2 \mathrm{cal} \mathrm{deg}^{-1} \cdot \mathrm{mol}^{-1}$ $\Delta V 85.26 \mathrm{~cm}^{3} \cdot \mathrm{mol}^{-1}$.}

\section{$\lambda$-transition}

$T_{\lambda} \sim 243 \mathrm{~K}$ $a=3.82 \AA$ at $88 \mathrm{~K}$.

$T_{\lambda} \sim 242.5 \mathrm{~K}$.

$$
\begin{aligned}
& T_{\lambda} \sim 242.1 \mathrm{~K} \\
& \Delta T \sim 0.3^{\circ} \\
& \Delta H \sim 109 \mathrm{cal} \cdot \mathrm{mol}^{-1}
\end{aligned}
$$

$T_{\lambda} \sim 242.5 \mathrm{~K}$

$\frac{d V}{d T}$ is maximum at $T_{\lambda} \sim 242.4 \mathrm{~K}$ $\Delta T \sim 0.30^{\circ}$.

$\alpha$ is maximum between $\left(T_{\lambda}\right), 242$ and $242.5 \mathrm{~K}$.

$T_{\lambda} \sim 242.8 \mathrm{~K}$; the temperature trend of the nuclear correlation time $\tau_{c}$ is in qualitative agreement with volume-temperature dependence.

$T_{\lambda}$ is indicated by a peak in DTA; in ESR, $T_{\lambda}$ is indicated where the first derivative of the hyperfine constant with respect to temperature is a maximum.
Hysteresis is shown as a difference in the $T_{t}$ in heating and cooling curves.

A detailed discussion of the possible sources of error and their corrections in evaluating the $\Delta H_{\text {tr }}$ is furnished. The data are likely to be the best for $\mathrm{NH}_{4} \mathrm{Cl}$ transition and very reliable.

For single crystals $\epsilon$ is 7.08 at $293 \mathrm{~K}$ and $2 \mathrm{MHz}$.

These results compare well with the results of other investigations. The transition conforms to first order as indicated by Clausius-Clapeyron equation.

The transition is due to a change in the rotational motion of $\mathrm{NH}_{4}^{+}$ion. Hysteresis effects are observed in the transition.

\section{in $\epsilon(T)$ curve. \\ Hysteresis was about $1^{\circ}$ if $\mathrm{CBr}_{4}$ was
used.}

Transition is indicated by an anomaly

Transition is believed to be due to an order-disorder change.

There appears to be an indirect relation between the temperature dependence of $\tau_{c}$ and the degree of order in the crystal lattice in the region of the $\lambda$-transition.

With increasing $\mathrm{Cu}^{+2}$ ion, $T_{\lambda}$ decreases. The intensity of the signal in $\mathrm{VO}_{2}^{+}$doped $\mathrm{NH}_{4} \mathrm{Cl}$ vanishes at $T_{\lambda} \sim 241 \mathrm{~K}$. In the electronic absorption spectrum of $\mathrm{Ni}^{+2}$ doped $\mathrm{NH}_{4} \mathrm{Cl}$, a blue shift of $100-150$ $\mathrm{cm}^{-1}$ observed at $\sim 235 \mathrm{~K}$ in the positions of the band maxima is attributed to the anomalous lattice contraction of the $\mathrm{NH}_{4} \mathrm{Cl}$ lattice.
$[32 \mathrm{a}, 37$,

$42,57]$.

[2].

[16].

[1]a, 24, 47, 52a].

$[46,46 \mathrm{a}]$.

$[18,19]$.

[4].

[16].

$[43,51]$.

[7].

[58a].

$[20,28,35]$. 
Ammonium Halides - Continued

\begin{tabular}{c}
\hline $\begin{array}{c}\text { Substances and } \\
\text { measurement techniques }\end{array}$ \\
Vibrational spectra of thin non- \\
scattering films of $\mathrm{NH}_{4} \mathrm{Cl}$ at
\end{tabular}
301,195 and $83 \mathrm{~K}$.

Total scattering cross section per $\mathrm{H}$ atom measured as a function of temperature by using subthermal neutrons.

Review articles

\section{Ammonium bromide, $\mathrm{NH}_{4} \mathrm{Br}$}

(Pm3m, $a=4.059 \AA$ at $299 \mathrm{~K}$ )

X-ray diffraction of $\mathrm{NH}_{4} \mathrm{Br}$ from 293 to $467 \mathrm{~K}$

Solubility as a function of temperature by a close tube method.

Dielectric constant as a function of temperature.

Thermal analysis

Dilatometric method (Kinetics of the transition, of $\mathrm{NH}_{4} \mathrm{Br}$ at $410.2 \mathrm{~K})$.

Rate of transition of supercooled high-temperature modifcation $\left(\mathrm{NaCl}\right.$ type) of $\mathrm{NH}_{4} \mathrm{Br}$ crystallizing from highly supersaturated aqueous solution into the low temperature $\mathrm{CsCl}$ phase (by oscillographic recording of the photocurrent change accompanying the I $\rightarrow$ II transition).
No indication of fine structure due to free rotation of the $\mathrm{NH}_{4}^{+}$ion was found. Evidence for the presence of a torsional lattice mode involving the $\mathrm{NH}_{4}^{+}$ions both above and below $T_{\lambda}$ was found.

An apparent change in cross section is observed at $T_{\lambda}$.

$T_{\ell}, 247.2 \mathrm{~K} ; \Delta S \sim 0.82 \mathrm{eu}$. $\Delta V \sim 0.16 \mathrm{~cm}^{3} \mathrm{~mol}^{-1}$.

\section{Pm3m-Fm3m transition}

The lattice constants are:

$$
\begin{aligned}
& \mathrm{a}_{1}=6.85187+1.38 \times 10^{-5} t+ \\
& 5.385 \times 10^{-7} t^{2} \\
& \mathrm{a}_{\mathrm{II}}=4.5409+2.116 \times 10^{-5} t+: \\
& 3.29 \times 10^{-7} t^{2} \\
& \text { where } t \text { is in }{ }^{\circ} \mathrm{C} . \\
& \Delta V_{\mathrm{I} \rightarrow \mathrm{II}}=0.0767 \mathrm{~cm}^{3} \mathrm{~g}^{-1} .
\end{aligned}
$$

$T_{\ell} \sim 410 \mathrm{~K}$

$T_{t} \sim 410 \mathrm{~K}$

$$
\begin{gathered}
T_{\imath} \sim 410.4 \mathrm{~K} ; \Delta T \sim 24^{\circ} \\
\Delta H_{\mathrm{tr}} \sim 882 \mathrm{cal} \cdot \mathrm{mol}^{-1} \\
\Delta V \sim 9.5 \mathrm{~cm}^{3} \mathrm{~mol}^{-1} .
\end{gathered}
$$

$T_{t} \sim 410.2 \mathrm{~K}$

$$
\begin{aligned}
& \Delta V \sim 18.85 \% \\
& \left(\frac{d T_{\ell}}{d P}\right) 0.0878^{\circ} \mathrm{atm}^{-1} .
\end{aligned}
$$

$E_{a}$ for the transition is $\sim 15000$ $\mathrm{cal} \cdot \mathrm{mol}^{-1}$.

The transition rate is very high and comparable to the speed of sound.
References

Low temperature modification belongs to $T_{d}^{\prime}$ sym. is which the $\mathrm{NH}_{4}^{+}$ion symmetry is $T_{d}$. Transition is probably of the order-disorder type.

The transition involves a change in the rotational motion of the $\mathrm{NH}_{4}^{+}$ ion from torsional oscillation to relatively free rotation.

$\Delta V$ calculated from $x$-ray data shows good agreement with the value from dilatometric studies.

The $T_{t}$ is indicated by the point of cross section of the solubility curves of I and II phases.

For single crystal $\mathrm{NH}_{4} \mathrm{Br}, \epsilon=7.24$ at $293 \mathrm{~K}$ and $2 \mathrm{MHz}$.

[56].

[23].

$[11 \mathrm{a}, 24,47$, 52a].

$[32,46 \mathrm{a}]$.

[41].

[16].

$[33 \mathrm{a}, 37,57]$.

Total volume changes, variation of density and thermal expansion coefficients are discussed. A discussion of thermal expansion behavior is given.

It is inferred that the transition has a martensite character.
$[8,31]$.

[21]. 


\begin{tabular}{l}
\hline $\begin{array}{c}\text { Substances and } \\
\text { measurement technique }\end{array}$ \\
\hline Measurement of specific volur \\
by hydrostatic weighing in \\
$293-413 \mathrm{~K}$ range. \\
IR spectra of $\mathrm{NH}_{4} \mathrm{Br}$ thin and \\
nonscattering films at 301,105
\end{tabular}
and $83 \mathrm{~K}$.

Review articles

X-ray diffraction between 295 and $148 \mathrm{~K}$.

DTA

Dielectric constant as a function of temperature.

Dilatometric methods with toluene as the dilatometric liquid.

Total scattering cross section per $\mathrm{H}$-atom measured as a function employing subthermal neutrons.

ESR Investigation of $\mathrm{NH}_{4} \mathrm{Br}$ single crystals doped with $\mathrm{Cu}^{+2}$ ion through $\lambda$-point.

Review articles

Ammonium iodide, $\mathrm{NH}_{4} \mathrm{I}(\mathrm{Fm} 3 \mathrm{~m}$, $a=7.2613 \AA$ at $299 \mathrm{~K}$ )
$\Delta V \sim 7.4866 \mathrm{~cm}^{3} \mathrm{~mol}^{-1}$ at $T_{t}$ for $\mathrm{NH}_{4} \mathrm{Br}$

$\Delta V \sim 7.4704 \mathrm{~cm}^{3} \mathrm{~mol}^{-1}$ at $T_{t}$ $(392.5 \mathrm{~K})$ for $\mathrm{ND}_{4} \mathrm{Br}$.

The spectra in phase II is in agreement with the symmetry, $\mathrm{D}_{\mathrm{th}}$. No evidence for free rotation at any temperature is found. $T_{\imath} \sim 414 \mathrm{~K}$

$\Delta V \sim 6.34 \mathrm{~cm}^{3} \mathrm{~mol}^{-1}$.

\section{$\lambda$-transition}

For phase II,

$$
a_{i}=4.0534+1.6 \times 10^{-4} t \text { (where } \quad a_{1}=a_{2} \neq a_{3} \text { for phase III }
$$$$
i=1,2,3)
$$$$
a_{i}=4.0539+1.34 \times 10^{-4} t(\text { where }
$$$$
i=1,2 \text { ) }
$$$$
\text { where } t \text { is in }{ }^{\circ} \mathrm{C} \text {. }
$$

For Phase III, $a_{3}=4.0537-2.72 \times 10^{-4} t$

$\bar{V}$, the molar volume (in $\mathrm{cm}^{3} \mathrm{~mol}^{-1}$ is given by

$V=40.113+4.82 \times 10^{-3} t$ for phase II

$V=40.042-2.34 \times 10^{-3} t-$ $3.64 \times 10^{-5} t^{2}$ for phase III.

Thermal expansion coefficient, $\alpha=1.24 \times 10^{-4}$ for phase II $\alpha=-6.0 \times 10^{-5}-1.8 \times 10^{-6} t^{2}$ for phase III.

$T_{\lambda} \sim 234.9 \mathrm{~K}$.

$T_{\lambda} \sim 236 \mathrm{~K}$

$T_{\text {入 }} \sim 234 \mathrm{~K}$.

$T_{\lambda}$ is indicated by a change in the cross section.

The hyperfine constant shows a maximum at $\sim 238 \mathrm{~K}$.

$$
\begin{aligned}
& T_{\ell} \sim 234.4 \mathrm{~K} \\
& \Delta S \sim 0.34 \text { e.u } \\
& \Delta V \sim-0.16 \mathrm{~cm} \mathrm{~mol}^{-1}
\end{aligned}
$$

Effect of deuteration of $\mathrm{NH}_{4} \mathrm{Br}$ is discussed; $\Delta V$ values from the literature are compared and discussed.

Review of phase changes in $\mathrm{NH}_{4} \mathrm{Br}$ upto 1964.

$a_{1}=a_{2}=a_{3}$ for phase II

Transition is believed to be due to the change in the rotational motion of $\mathrm{NH}_{4}^{+}$ion.

[19].

[16].

Transformation is heterogeneous and is accompanied by a small hysteresis.

Transition is due to a change in motion of the $\mathrm{NH}_{4}^{+}$ion from torsional oscillation to relatively free rotation.

The maximum change at $\sim 238 \mathrm{~K}$ is due to the $\lambda$-change which occurs at $\sim 235 \mathrm{~K}$.

Reviews on phase changes in $\mathrm{NH}_{4} \mathrm{Br}$ upto 1964.
$[12,46 \mathrm{a}]$.

[15a].

[56].

$[11 \mathrm{a}, 24,47$, 52a].
[34].

$52 \mathrm{a}]$.

$[1] a, 24,47$, 


\begin{tabular}{|c|c|c|c|}
\hline $\begin{array}{l}\text { Substances and } \\
\text { measurement techniques }\end{array}$ & Data & Remarks & References \\
\hline & $P m 3 m-F m 3 m$ transition & & \\
\hline $\mathrm{X}$-ray diffraction. & $\begin{array}{l}T_{t} \sim 257 \mathrm{~K} \\
\quad \Delta V \sim 16.96 \% \\
\quad a=7.259 \AA \text { at } 295 \mathrm{~K}(\mathrm{Fm} 3 \mathrm{~m}) \\
\quad a=4.334 \AA \text { at } 252 \mathrm{~K}(\mathrm{Pm} 3 \mathrm{~m})\end{array}$ & $\begin{array}{l}\text { Effect of particle size on the time } \\
\text { for half-conversion in the transi- } \\
\text { tion is investigated. Below } T_{t} \text {, the } \\
\text { needed super-cooling increases } \\
\text { with decreasing particle size. }\end{array}$ & $\begin{array}{c}{[12 \mathrm{a}, 13} \\
46 \mathrm{a}]\end{array}$ \\
\hline Differential calorimetry & $\begin{array}{l}T_{t} \sim 257 \mathrm{~K} \\
\Delta H_{\mathrm{tr}} \sim 809 \mathrm{cal} \cdot \mathrm{mol}^{-1}\end{array}$ & $\begin{array}{l}\text { The method is applied for the first } \\
\text { time for the study of a transition } \\
\text { below } 273 \mathrm{~K} \text {. }\end{array}$ & {$[3]$} \\
\hline Thermal analysis & $T_{t} \sim 253$ to $259 \mathrm{~K}$ & Moisture affects the $T_{t}$. & {$[37]$} \\
\hline $\begin{array}{l}\text { IR investigation of } \mathrm{NH}_{4} \mathrm{I} \text { in } \\
\text { phase I. }\end{array}$ & $T_{t} \sim 255.4 \mathrm{~K}$ & $\begin{array}{l}\text { In phase } \mathrm{I} \text {, one hydrogen bond is } \\
\text { formed with } \mathrm{I}^{-} \text {and the } \mathrm{NH}_{4}^{+} \text {ion } \\
\text { rotates freely about this bond. }\end{array}$ & {$[30]$} \\
\hline Review articles & $\begin{array}{l}T_{t} \sim 258 \mathrm{~K} \\
\Delta V \sim 8.14 \mathrm{~cm}^{3} \mathrm{~mol}^{-1} \\
\lambda \text {-transition }\end{array}$ & Reviews upto 1964. & $\begin{array}{l}{[1 \mathrm{la}, 24,47} \\
52 \mathrm{a}]\end{array}$ \\
\hline $\mathrm{X}$-ray diffraction & $\begin{array}{l}a_{i}=4.3387+2.41 \times 10^{-4} t(i=1,2,3) \\
\left(a_{1}=a_{2}=a_{3} \text { for phase II }\right) \\
a_{i}=4.3439+2.28 \times 10^{-4} t(i=1,2) \\
a_{3}=4.2999-1.071 \times 10^{-3} t-6.41 \\
\quad \times 10^{-6} t^{2}\left(a_{1}=a_{2} \neq a_{3} \text { for phase }\right. \\
\text { III }) .\end{array}$ & $\begin{array}{l}\text { Molar volume changes are given as a } \\
\text { function of temperature. }\end{array}$ & {$[13]$} \\
\hline Differential thermal analysis. & $T_{\lambda} \sim 231.35 \mathrm{~K}$ & $\begin{array}{l}\text { Transition is likely to be associated } \\
\text { with a change in the } \mathrm{NH}_{4}^{+} \text {ion } \\
\text { rotation. }\end{array}$ & {$[19]$} \\
\hline $\begin{array}{l}\text { Molar volume as a function of } \\
\text { temperature. }\end{array}$ & $T_{\lambda} \sim 233$ to $213 \mathrm{~K}$. & $\begin{array}{l}\text { Above the } T_{\lambda} \text { the structure is regular } \\
\text { and below } T_{\lambda} \text { the structure is } \\
\text { tetragonal. }\end{array}$ & {$[44]$} \\
\hline $\begin{array}{l}\text { Dielectric constant }\left(\epsilon^{\prime} \text { and } \epsilon^{\prime \prime}\right) \\
\text { measurements. }\end{array}$ & $\begin{array}{l}\text { Two maxima between } 253 \text { and } 233 \mathrm{~K} \\
\text { are observed. }\end{array}$ & $\begin{array}{l}\text { The rotation of } \mathrm{NH}_{4}^{+} \text {ion along the } \\
\mathrm{N}-\mathrm{H} \text { axis cannot explain these } \\
\text { maxima. }\end{array}$ & {$[16,24]$} \\
\hline Review articles. & $\begin{array}{l}T_{\lambda} \sim 233 \mathrm{~K} \\
\quad \Delta S \sim 0.3 \mathrm{eu} \quad \Delta T \approx 0 . \\
\Delta V \sim-0.1 \mathrm{~cm}^{3} \mathrm{~mol}^{-1} .\end{array}$ & & $\begin{array}{l}{[11 \mathrm{a}, 24,47} \\
52 \mathrm{a}]\end{array}$ \\
\hline \multicolumn{4}{|l|}{$\begin{array}{l}\text { Deuteroammonium chloride, } \mathrm{ND}_{4} \mathrm{Cl} \\
(\mathrm{Pm} 3 \mathrm{~m}, a=3.8682 \AA \text { at } 291 \mathrm{~K})\end{array}$} \\
\hline $\mathrm{X}$-ray diffraction. & $\begin{array}{l}a_{\mathrm{Pm} 3 \mathrm{~m}}=3.8190 \AA \text { at } 88 \mathrm{~K} \\
a_{\mathrm{Pm} 3 \mathrm{~m}}=3.8682 \AA \text { at } 291 \mathrm{~K} . \\
T_{t} \sim 448 \mathrm{~K} \text { (for II-I transition). } \\
T_{\lambda} \sim 249.4 \mathrm{~K} .\end{array}$ & & {$[7,46 \mathrm{a}]$} \\
\hline Neutron diffraction. & $\begin{array}{l}\text { The nature of the } \mathrm{NH}_{4}^{+} \text {ion rotation } \\
\text { is examined. }\end{array}$ & $\begin{array}{l}\text { The neutron diffraction results are in } \\
\text { agreement with spectroscopic } \\
\text { results of Wagner and Hornig. }\end{array}$ & {$[22]$.} \\
\hline $\begin{array}{l}\text { IR spectra of their non-scattering } \\
\text { films at } 301.295 \text { and } 83 \mathrm{~K} \text {. }\end{array}$ & $\begin{array}{l}\text { The evidence for the order-disorder } \\
\text { nature of the second order } \\
\text { transition is confirmed. }\end{array}$ & $\begin{array}{l}\text { No evidence of fine structure due to } \\
\text { free rotation of } \mathrm{NH}_{4}^{+} \text {ion was found. } \\
\text { Evidence for the presence of a tor- } \\
\text { sional lattice mode involving the } \mathrm{NH}_{4}^{+} \\
\text {ion both above and below } \lambda \text {-point } \\
\text { was available. Low temperature } \\
\text { modification belongs to the } T_{d}^{\prime} \\
\text { symmetry in which the } \mathrm{NH}_{4}^{+} \text {ion } \\
\text { symmetry is } T_{d} \cdot \lambda \text {-point transitions } \\
\text { are probably order-disorder type. }\end{array}$ & {$[56]$.} \\
\hline
\end{tabular}




\begin{tabular}{c}
\hline $\begin{array}{c}\text { Substances and } \\
\text { measurement techniques }\end{array}$ \\
Review article. \\
$\begin{array}{c}\text { Deuteroammonium bromide, } \mathrm{ND}_{4} \mathrm{Br} \\
(\mathrm{Pm} 3 \mathrm{~m}, a=4.06 \AA \text { at } 299 \mathrm{~K})\end{array}$
\end{tabular}

$\mathrm{X}$-ray diffraction.

Neutron diffraction.

Heat capacity in the range 17 to $300 \mathrm{~K}$.

IR spectra of thin nonscattering films of $\mathrm{ND}_{4} \mathrm{Br}$ at 301,95 and $83 \mathrm{~K}$.

Spin-lattice relaxation and phase transition in $\mathrm{ND}_{4} \mathrm{Br}$, at $163.9 \mathrm{~K}$.

Neutron diffraction study of the $\mathrm{NaCl}$ phase.

Review articles.
$T_{t} \sim 448 \mathrm{~K}$ for Pm3m-Fm3m transition.

$T_{\text {入 }} \sim 249.3 \mathrm{~K}: \Delta V \sim 0.13 \mathrm{~cm} \mathrm{~mol}^{-1}$.

$\mathrm{T}_{t}, \mathrm{I} \rightarrow \mathrm{II} \sim 393 \mathrm{~K} ; \Delta V \sim 7.61 \mathrm{~cm}$ $\mathrm{mol}^{-1}$ at $398 \mathrm{~K}$ :

$T_{\lambda}$, II $\rightarrow$ III $\sim 215 \mathrm{~K} ; \Delta V \sim-0.293$

$\mathrm{cm} \cdot \mathrm{mol}^{-1}$ at $215 \mathrm{~K}$.

$\mathrm{III} \rightarrow \mathrm{IV} \sim 164 \mathrm{~K} ; \Delta V \sim 1.08$

$\mathrm{cm} \cdot \mathrm{mol}^{-1}$ at $164 \mathrm{~K}$.

\section{Lattice constants}

$a=6.889 \AA$ at $469 \mathrm{~K}$ (phase I)

$a=4.084 \AA$ at $385 \mathrm{~K}$ (phase II)

$a=4.047 \AA, c=4.062 \AA$ at $195 \mathrm{~K}$

(phase III); $a=4.016 \AA$ at $152 \mathrm{~K}$

(phase IV).

The nature of rotation of $\mathrm{NH}_{\xi}^{+}$ion is examined.

Two maxima in the $C_{p}$ versus $T$ curve are noted. The first maxima is associated with the polymorphic transition in the crystal lattice and the second one with the ordering of the $\mathrm{NH}_{\sharp}$ ion tetrahedra with respect to the two equilibrium positions in the unit cell. $T_{\lambda} \sim 215$ $\mathrm{K} ; \Delta H_{\lambda} \sim 307 \mathrm{cal} \cdot \mathrm{mol}^{-1} . T_{t} \sim 166$ $\mathrm{K} ; \Delta H_{\mathrm{tr}} \sim 340.5 \mathrm{cal} \cdot \mathrm{mol}^{-1} . \Delta H$ values are obtained from the integrated areas under the peaks.

The symmetry of $\mathrm{ND}_{4} \mathrm{Br}$ in Phase III is $\mathrm{D}_{\mathrm{h}}$, in accordance with $\mathrm{x}$-ray data.

In 99 percent of the sample, a hysteresis effect was observed. With a 94 percent $\mathrm{ND}_{4} \mathrm{Br}$ no such hysteresis effect was observed.

Four different models are considered to explain the experimentally observed phenomena of transition.

$T_{t} \sim 405 \mathrm{~K}(\mathrm{Pm} 3 \mathrm{~m}-\mathrm{Fm} 3 \mathrm{~m})$

$T_{\text {入 }} \sim 215 \mathrm{~K} ; \Delta V \sim-0.17 \mathrm{~cm} \mathrm{~mol}^{-1}$, $\Delta T \sim 0.06^{\circ}$.
Replacement of $\mathrm{H}$ by D lowers the $T_{t}$ while the volume changes, $\Delta V$, are not very much affected. In $\mathrm{ND}_{4} \mathrm{Br}$ some metastable states (with BCC structure) were observed in the range 408-399 K.

The freely rotating model is not tenable with the experimental results.

No evidence for free rotation at any temperature studied, was found. Below $173 \mathrm{~K}, \mathrm{ND}_{4} \mathrm{Br}$ transforms to phase IV where the symmetry is $T_{d}$ just as in $\mathrm{NH}_{4} \mathrm{Cl}$.

Assuming the activation energy for the transition to be a function only of the lattice type, the behavior of $99 \%$

$\mathrm{ND}_{4} \mathrm{Br}$ can be explained in terms of coexistence of two phases at $163.9 \mathrm{~K}$.

The freely rotating $\mathrm{ND}_{4}^{+}$ion model is not tenable, with the observed experimental situation. IR absorption data on thin films by Wagner and Hornig support a model involving a singleaxis rotation of $\mathrm{NH}_{4}^{+}$ion.
$[11 \mathrm{a}, 47]$.

$[14,46 a]$.
[56].

[58b].

[22].

[11a, 24, 47]. 


\begin{tabular}{c|}
\hline \hline $\begin{array}{c}\text { Substances and } \\
\text { measurement techniques }\end{array}$ \\
\hline $\begin{array}{c}\text { Pressure Transitions of Ammonium } \\
\text { Halides }\end{array}$ \\
Pressure transition in $\mathrm{NH}_{4} \mathrm{~F}$.
\end{tabular}

Pressure transition in $\mathrm{NH}_{4} \mathrm{~F}$.

$\mathrm{X}$-ray investigation of high pressure phases of $\mathrm{NH}_{4} \mathrm{~F}$ and $\mathrm{ND}_{4} \mathrm{~F}$, under purely hydrostatic conditions.

DTA study of pressure effects on $\lambda$ transition in $\mathrm{NH}_{4} \mathrm{Cl}$ and $\mathrm{ND}_{4} \mathrm{Cl}$ up to 2700 atmospheres.

Spectral investigation of the $\lambda$ transition in $\mathrm{NH}_{4} \mathrm{Cl}$ up to $23 \mathrm{kbar}$ pressure in the range $3000-7000$ $\mathrm{cm}^{-1}$.

Ultrasonic investigation of the high pressure transition in $\mathrm{NH}_{4} \mathrm{Br}$ single crystals.

DTA of ammonium halides up to $40 \mathrm{kbar}$; the pressure-temperature curves of the halides are given.

Volumetric study of the pressure transitions in $\mathrm{NH}_{4} \mathrm{Cl}$ and $\mathrm{NH}_{4} \mathrm{Br}$ up to $12000 \mathrm{Kg} \mathrm{cm}^{-2}$ between $273 \mathrm{~K}$ and $473 \mathrm{~K}$
$P_{T} \sim 3800$ atmospheres at room temperature; volume change is $28 \%$. The high pressure phase is FCC at this pressure. With still high pressures of $\sim 11 \mathrm{kbar}$ a BCC phase is obtained where the volume change is $\sim 11 \%$ of the zero pressure volume.

The high pressure phase in both the cases is likely to be tetragonal. The transitions are observed at 3.64 $\pm 0.02 \mathrm{kbar}$ in both fluorides.

Transition entropy and enthalpy decrease up to 1500 atmospheres and remain unchanged thereafter.

The $\lambda$-transition takes place around 13-15 kbar at room temperature. The transition was followed by noticing the change of the absorption band with pressure.

The adiabatic elastic constants of $\mathrm{NH}_{4} \mathrm{Br}$ crystals have been measured at $200 \mathrm{MHz}$ as a function of temperature and pressure in the ranges $180-240 \mathrm{~K}$ and $0-6$ kbar. A new high pressure ordered phase designated as $0_{\text {II }}$ was noticed in this range.

$\mathrm{NH}_{4} \mathrm{~F}$ has a triple point at 16.8 kbar and $582 \mathrm{~K}$. The melting curve of $\mathrm{NH}_{4} \mathrm{~F}$ shows an increase up to $706 \mathrm{~K}$ at $40 \mathrm{kbar}$.

$\Delta H_{\mathrm{tr}} \sim 100 \mathrm{cal} \cdot \mathrm{mol}^{-1}\left(\mathrm{NH}_{4} \mathrm{Cl}\right)$. $\Delta H_{\mathrm{tr}} \sim 160 \mathrm{cal} \cdot \mathrm{mol}^{-1}\left(\mathrm{NH}_{4} \mathrm{Br}\right)$.
The phase change occurs at a very high pressure at liquid nitrogen temperature. The recovery begins only when the pressure is completely removed. The phase change involves a collapse of the wurtzite structure into a cubic modification.

The fact that the entropy of transition is reduced by increased pressure, cannot be explained on the basis of an order-disorder theory which pictures the transition as due to a reorientation of $\mathrm{NH}_{4}^{+}$ion over two sites $(\Delta S=R \ln 2)$.

The change is associated with the suppression of the random orientation of the $\mathrm{NH}_{4}^{+}$ions, in the crystal lattice. Lattice vibration frequencies are affected to a greater extent than the intramolecular vibration frequencies by pressure.

The behavior of $\mathrm{NH}_{4} \mathrm{Br}$ is compared with that of $\mathrm{NH}_{4} \mathrm{Cl}$ near its orderdisorder phase transition.

The $\lambda$-changes in $\mathrm{NH}_{4} \mathrm{Cl}$ and $\mathrm{ND}_{4} \mathrm{Cl}$ possibly change to first order transitions above $30 \mathrm{kbar}$.

The $\Delta H_{\mathrm{tr}}$ in $\mathrm{NH}_{4} \mathrm{Cl}$ is independent of pressure. These anomalies may in part be explained with Pauling's suggestion that there is a change from torsional oscillation to rotational motion of $\mathrm{NH}_{4}^{+}$ions; further considerations may be necessary to account for the different behaviors of $\mathrm{NH}_{4} \mathrm{Cl}$ and $\mathrm{NH}_{4} \mathrm{Br}$.
$[10]$

$[48,50 \mathrm{a}]$

[24a]. 
Ammonium Halides - Continued

\begin{tabular}{|c|c|c|c|c|c|c|c|}
\hline $\begin{array}{l}\text { Substances and } \\
\text { measurement techniques }\end{array}$ & \multicolumn{5}{|c|}{ Data } & Remarks & References \\
\hline \multirow{9}{*}{$\begin{array}{l}\text { Piston displacement technique } \\
\text { down to liquid nitrogen tempera- } \\
\text { tures, on } \mathrm{NH}_{4} \mathrm{Cl}, \mathrm{NH}_{4} \mathrm{Br}, \mathrm{NH}_{4} \mathrm{I} \\
\text { and } \mathrm{ND}_{4} \mathrm{Cl}, \mathrm{ND}_{4} \mathrm{Br} \text { and } \mathrm{ND}_{4} \mathrm{I} \text {. }\end{array}$} & \multicolumn{5}{|c|}{ Transition temperature, $K$} & \multirow{9}{*}{$\begin{array}{l}\text { The Ammonium tetrahedra are } \\
\text { placed on the face of the cube as in } \\
\text { the } \alpha \text {-phase or at the center of the } \\
\text { cube for all the other phases. In } \\
\beta-, \gamma-\text {, and } \delta \text {-phases the } \mathrm{NH}_{4}^{+} \\
\text {tetrahedra are located at the } \\
\text { center of the cube formed by the } \\
\text { halide ions. The tetrahedra are } \\
\text { oriented in a parallel sense in } \\
\delta \text {-phase from cell to cell; in } \\
\gamma \text {-phase there is antiparallel } \\
\text { orientation while in the } \beta \text {-phase the } \\
\text { orientation is randomly. }\end{array}$} & \multirow[t]{9}{*}[49]{.} \\
\hline & & $\alpha-\beta$ & $\beta-\gamma$ & $\beta-\delta$ & $\gamma-\delta$ & & \\
\hline & $\mathrm{NH}_{4} \mathrm{Cl} \ldots \ldots$ & 458 & * & 243 & * & & \\
\hline & $\mathrm{ND}_{4} \mathrm{Cl} \ldots \ldots$ & - & * & 249 & * & & \\
\hline & $\mathrm{NH}_{4} \mathrm{Br} . . .$. & 411 & 235 & * & 100 & & \\
\hline & $\mathrm{ND}_{4} \mathrm{Br} . . .$. & 398 & 215 & * & 169 & & \\
\hline & $\mathrm{NH}_{4} \mathrm{I} \ldots \ldots$ & 257 & 231 & $*$ & * & & \\
\hline & $\mathrm{ND}_{4} \mathrm{I} \ldots \ldots .$. & 254 & 227 & * & & & \\
\hline & \multicolumn{5}{|c|}{$\begin{array}{l}{ }^{*} \text { No transition takes place at } \\
\text { atmospheric pressures. }\end{array}$} & & \\
\hline $\begin{array}{l}\text { Modified Bridgman's device with } \\
\text { diamond and beryllium anvils } \\
\text { employed to study pressure } \\
\text { changes up to } 20 \text { kbars, in } \mathrm{NH}_{4} \mathrm{I} \text {. }\end{array}$ & \multicolumn{5}{|c|}{$\begin{array}{l}\mathrm{NH}_{4} \mathrm{I} \text { which exists in } \mathrm{Fm} 3 \mathrm{~m} \\
\text { structure at room temperature } \\
\text { changes to } \mathrm{Pm} 3 \mathrm{~m} \text { at } \sim 500 \text { bars. }\end{array}$} & $\begin{array}{l}\text { The transition conforms to first } \\
\text { order at the start but second order } \\
\text { effects are prominent diring the } \\
\text { major interval of the change. }\end{array}$ & [1]. \\
\hline
\end{tabular}

\section{References}

[1] Adams, L. H., and Davis, B. L., Am. J. Sci. 263, 359 (1965).

[2] Arell, A.. Ann. Acad. Fennicae. Ser. A VI 57 (1960).

[3] Arell, A., and Alare, O., Phys. Kondens. Materie 2, 423 (1964).

[4] Arell, A., Ann. Acad. Fennicae, Ser. A VI' 204,5 (1966).

[5] Ayant, Y., and Soutif, M., Compt. rend. 232, 639 (1951).

[6] Birge. P., and G. Blanc. J. Phys. Kadium 21, Suppl. 141 A$145 \mathrm{~A}(1960)$.

[7] Boiko, A. A., Kristallografiya 14,639 (1969).

[7a] Bridyman, P. W., Phys. Rev. 38, 182 (1931).

[7b] Crystal Data, ACA Monograph. No. 5. Eds. J. D. H. Donnay and G. Donnay, American Crystallographic Association (1963).

[8] Erofeev, B. V.. and Mendeleev, L. T., Vesti. Akad. Navuk. Belarus, S.S.R. Ser. Fiz. Tech. Navuk 57 (1957).

[8a] Frenkel, J., Acta. Physicochim, U.R.S.S. 3, 23 (1935).

[9] Garland, C. W., and Young. R. A., J. Chem. Phys. 48, 146 (1968).

[9a] Garland, C. W., and Jones, J. S., Bull. Am. Phys. Soc. Ser. 2, 8, 354 (1963).

[10] Garland, C. W.. and Robert, R. A., J. Chem. Phys. 49, 5282 (1968).

[i0a] Gutoswsky, H. S., Pake, G. E., and Bersohn, R., J. Chem. Phys. 22,643 (1954).

[11] Hovi, V., and Varteva, M., Phys. Kondens. Materie 3, 305 (1964).

[1la] Hovi, V., Proc. Intern Conf. Sci \& Tech. of Non-metallic Crystals (New Delhi India) (1969).

[12] Hovi. V.. Heiskanen. K., and Varteva. M., Ann. Acad. Sci. Fennicae, Ser. A. 144, 12 (1964).

[12a] Hovi, V., Paavola, K., and Nurmi. E., Ann. Acad. Sci. Fennicae A, 328 (1969).

[13] Hovi, V., and Lainio. J., Ann. Acad. Sci. Fennicae. Ser. A, 215, 1 (1966).

[14] Hovi, V.. Paavola, K., and Urvas, O., Helv. Phys. Acta. 41, 938 (1968); Ann. Acad. Sci. Fennicae, Ser. A. 291 (1968).

[15] Itoh, J., Kusaka, R., and Saito, Y., J. Phys. Soc. (Japan), 17, 463 (1962).

[15a] Jaakkola, S., Pöyhonen. J.. and Simola. K: Ann. Acad. Sci. Fennicae, A, 295 (i968).

[16] Kamiyoshi, K; Sci. Repts, A8, 252 (1956).

[17] Klynev, Yu. A., Soviet Physics-Solid State 8, 322 (1966).

[18] Klug, H. P., Northwest Sci. 10, 13 (1936); 1 1, 36 (1937).

[19] Klug, H. P., and Johnson, W. W., J. Am. Chem. Soc. 59, 2061 (1937).
[20] Kuroda, N., Kawamori, A., and Mito, E.. J. Phys. Soc. (Japan), 26, 868 (1969)

[21] Kuzmin, S. V., Rab. Fiz. Tverd. Tela 2, 155 (1967).

[22] Levy, H. A.. and Peterson. L. W., J. Chem. Phys. 21, 366 (1953); Phys. Rev. 83, 1270 (1951): 86, 766 (1952).

[23] Leung, P. S., Taylor, T. I., and Havens, W. W. Jr., J. Chem. Phys. 48, 4912 (1968).

[24] Meinnel, J., Bull. Soc. Sci. Bretagne 39, 31 (1964).

[24a] Morosin, B., and Shirber, J. E., J. Chem. Phys. 42, 1389 (1965).

[25] Nagamiya, T., Proc. Phys. Math. Soc. Japan 24, 137 (1942).

[26] Nagamiya, T.. Proc. Phys. Math. Soc. Japan 25, 540 (1943).

[27] Nagamiya, T., compt. rend. 251 (1952).

[28] Narayana, P. A., and Venkateswarlu, P., J. Chem. Phys. 52, 5159 (1970).

[28a] Pauling. L., Phys. Rev. 36, 430 (1930).

[29] Pistorius. C. W. F. T., J. Chem. Phys. 50, 1436 (1969)

[30] Plumb, R. C.. and Hornig. D. F.. J. Chem. Phys. 21, 366 (1953).

[31] Pöyhönen, J., Ann. Acad. Sci. Fennicae. Ser. A. 58, 52 (1960).

[32] Pöyhönen, J., Mansikka, K., and Heiskanen, K., Ann. Acad. Sci. Fennicae, Ser. A., 168, 8 (1964).

[32a] Rao. K. J., and Rao. C. N. R.. J. Materials. Sci. 1, 268 (1966).

[33] Renard, R., and Garland, C. W., J. Chem. Phys. 45, 763 (1966).

[34] Sastry. M. D., and Venkateswarlu, P.. Proc. Ind. Acad. Sci. A66, 208 (1967).

[35] Sastry. M. D., and Venkateswarlu. P., Molecular Physics 13, 161 (1967).

[36] Sato, Y., J. Phys. Soc., Japan 20(12), 2304 (1965).

[37] Scheffer, F. E. C., Proc. Akad. Wetenschappen 18, 446 (1915): 1498 (1916): Proc. Akad. Sci. Amsterdam, 19, 798 (1917).

[38] Sharma, M. N., and Madan, M. P., Ind. J. Phys. 38, 305 (1964).

[39] Shustin, O. A., Yakovlev, I. A., and Velichkina, T. S., JETP Letters 5, 3 (1967).

[40] Sonin, A. S., Kristallografiya 6(1), 137 (1961).

[41] Smits, A., and Eastlack, H. E., J. Am. Chem. Soc. 38, 1261 (1916).

[42] Smits, A., Eastlack, H. E., and Scatchard, G., J. Am. Chem. Soc. 41, 1961 (1919).

[43] Smits, A., and Mac Gillavry, C. H., Z. physik. Chem. A166, 97 (1933). 
[44] Smits, A., Ketelaar, J. A. A., and Muller, G. J., Z. physik. Chem. Al 75, 359 (1936).

[45] Smits, A., and Muller, G. J., Z. physik. Chem. B36, 140 (1937).

[46] Stammler, M., Orcutt, D., and Colondy, P. C., Advan. X-ray Anal. 6, 202 (1962).

[46a] Stammler, M., J. Inorg. Nucl. Chem. 29, 2203 (1967).

[47] Staveley, L. A. K., Quart. Rev. 3, 64 (1949).

[48] Stevenson, R., J. Chem. Phys. 34, 346 (1961).

[49] Stevenson, R., J. Chem. Phys. 34, 1757 (1961)

[50] Stephenson, C. C., and Karo, A. M., J. Chem. Phys. 48, 104 (1968).

[50a] Swenson, C. A., and Tedeschi, J. R., J. Chem. Phys. 40, 1141 (1964).

[51] Thomas, D. G., Staveley, L. A. K., and Cullis, A. F., J. Chem. Soc. 1727 (1952).
[52] Trappeniers, N. J., and Van der Molen, Th. J., Physica 32, 1161 (1966).

[52a] Ubbelohde, A. R., Quart. Rev. 11 , 246 (1957).

[53] Urbakh, V. Yu., Zhur. Fiz. Khim. 30, 217 (1956).

[54] Vedder, W., U.S. Dept. of Com. Office Tech. Serv. PB Rept., $143-474,96$ p. (1958).

[55] Venkataraman, G., Deniz, K. U., Iyengar, P. K., Roy, A. P., and Vijayaraghavan, P. R., J. Phys. Chem. Solids. 27, 1103 (1966).

[55a] Voronel, A. V., and Garber, S. R., Zh. Eksp. Teor. Fiz. 52(6), 1464 (1967)

[56] Wagner, E. L., and Hornig, D. F., J. Chem. Phys. 18, 296, 305 (1950).

[57] Wallace, R. C., Cent. Min. 33 (1910).

[58] Woessner, D. E., and Snowden, B. S., J. Phys. Chem. 7 1(4), 952 (1967); J. Chem. Phys. 47(7), 2361 (1967).

\section{Alkaline Earth (Group IIA) Halides}

\section{Substances and measurement techniques \\ Beryllium fluoride, $\mathrm{BeF}_{2}$ \\ (Tetragonal, $a=6.60 \AA$ and $c=6.74 \AA$ )}

X-ray diffraction and DTA.

High pressure transitions up to $873 \mathrm{~K}$ and $60 \mathrm{kbar}$.

Beryllium chloride, $\mathrm{BeCl}_{2}$ (orthorhombic. Ibam, $a=5.36 \AA$, $b=9.86 \AA$ and $c=5.26 \AA$ )

X-ray diffraction and DTA.

Heat capacity in the range 13 to $715 \mathrm{~K}$.

Beryllium iodide, $\mathrm{BeI}_{2}$

(Tetragonal, $\mathrm{P} 4 / \mathrm{nmm}$.

$a=6.12 \pm 0.01 \AA$ and

$c=10.6 .3 \pm 0.04 \AA$ )

Two forms of $\mathrm{BeI}_{2}$ are known with a transition at $623 \mathrm{~K}$.
Three DTA peaks are observed at 308,673 and $818 \mathrm{~K}$. The transition at $308 \mathrm{~K}$ is a change from tetragonal to cubic structure, with $a=6.78 \AA$; this is an edge centered cubic structure. ( 8 molecules in the unit cell].

At $773^{\circ}, \mathrm{BeF}_{2}$ transforms from the quartz form to the coesite form, under pressure. At room temperature transition occurs at $\sim 15.5$ kbar.

On cooling the melt rapidly, the $\alpha^{\prime}$ phase is obtained. The structure of $\alpha^{\prime}-\mathrm{BeCl}_{2}$ is similar to $\mathrm{SiS}$. The $\alpha^{\prime}$-phase on heating to $523 \mathrm{~K}$ gives a cubic modification $\left(\beta^{\prime}\right)$. The $\beta^{\prime}$ form on further heating to $613 \mathrm{~K}$ produces the stable $\beta$ form. If, however, the melt is allowed to slow equilibrium cooling the $\alpha$ form is encountered at $\sim 698 \mathrm{~K}$ and further to $\beta$ form at $\sim 678 \mathrm{~K}$.

$T_{\imath}$ is $\sim 676 \mathrm{~K}$ for the $\alpha-\beta$ transition; $\Delta H_{\mathrm{tr}} \sim 1495 \pm 50 \mathrm{cal} \mathrm{mol}^{-1}$.

Form I is tetragonal; this transforms to Form II (orthorhombic) above $623 \mathrm{~K}$. The lattice constants of Form II are: $a=16.48 \pm 0.02 \AA$, $b=16.702 \pm 0.01 \AA$ and $c=11.629 \pm$ $\pm 0.01 \AA . \Delta V \approx 0$.
The peak at $673 \mathrm{~K}$ does not produce any new form. The products after heating in the range 673 to $803 \mathrm{~K}$ showed $x$-ray patterns of cubic form only.

Some high pressure phases are also produced by grinding.

$[5,8 \mathrm{a}]$

[1 to 4]

$[6,9]$.

Thermodynamic properties for $\mathrm{BeCl}_{2}$ are tabulated for the range $0-750 \mathrm{~K}$.

The number of molecules per unit cell is 4 in the low temperature phase, while there are 32 molecules in the high temperature phase.

$[1$ to 4$]$

[8].
Reterences 
Alkaline Earth (Group IIA) Halides - Continued

\begin{tabular}{|c|c|c|c|}
\hline $\begin{array}{l}\text { Substances and } \\
\text { measurement techniques }\end{array}$ & Data & Remarks & References \\
\hline \multicolumn{4}{|l|}{$\begin{array}{l}\text { Fluorides of calcium, Magnesium } \\
\text { Strontium and Barium }\end{array}$} \\
\hline $\begin{array}{l}\text { Changes in lattice spacings of } \\
\mathrm{CaF}_{2} . \mathrm{SrF}_{2} . \text { and } \mathrm{BaF}_{2} \text { investigated by } \\
\text { x-ray diffraction at pressures up to } \\
65 \text { kbar in a tetrahedral anvil press. }\end{array}$ & $\begin{array}{l}\text { Transitions to structures of lower } \\
\text { symmetry take place at } \sim 30 \mathrm{kbar} \\
\text { in } \mathrm{BaF}_{2} \text { and at } \sim 60 \mathrm{kbar} \text { in } \mathrm{SrF}_{2} \text {. }\end{array}$ & $\begin{array}{l}\text { The dependence of the repulsive } \\
\text { potential on interionic distances is } \\
\text { estimated. Various alternative } \\
\text { assignments of repulsive parameters } \\
b \text { and } \rho \text { for the individual ion-ion } \\
\text { interactions are discussed in the light } \\
\text { of the Born model. The repulsive } \\
\text { parameters appropriate to alkali } \\
\text { halides are insufficient to provide the } \\
\text { observed repulsion energy. }\end{array}$ & {$[10]$.} \\
\hline$X$-ray studies up to $160 \mathrm{kbar}$. & 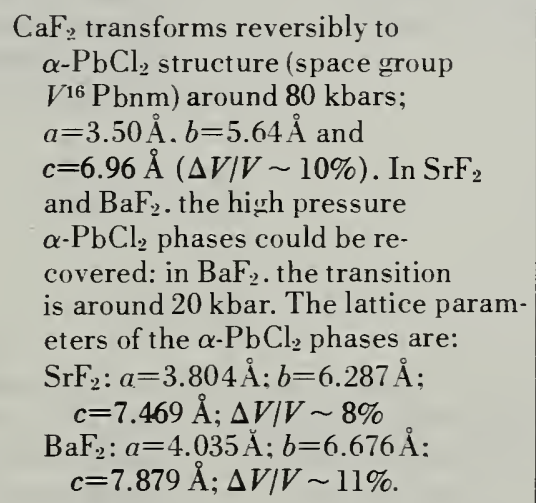 & $\begin{array}{l}\mathrm{MgF} \mathrm{F}_{2} \text { reveals no transformation up to } \\
160 \text { kbar. }\end{array}$ & {$[2 \mathrm{a}]$.} \\
\hline
\end{tabular}

\section{References}

[1] Dachille, F., and Roy, R., Z. Krist. 111, 451 (1959).

[2] Dachille. F., and Roy. R., Nature 186, 34 (1960).

[2a] Dandekar, D. P., and Jamieson, J. C.. personal communication (1971).

[3] Douglas, T. B., STAR, 2, 1348A (1964).

[4] Kirkina, D. F., Novoselova, A. V., and Simanov, Yu. P.. Proc. Akad. Sci., U.S.S.R., Sect. Chem. 107, 201 (1956).

[5] Kirkina. D. F., Novoselova, A. V.. and Simanov. Yu. P. Doklady Akad. Nauk. S.S S.R. 107, 837 (1956).

[6] Kuvyrkin. O. N., Breusov, O. N., Novoselova. A. V.. and Semenenko. K. N.. Zhur. Fiz. Khim. 34, 343 (1960).
[7] Johnson, R. E., Staritzky, E., and Douglass, R. M., J. Am. Chem. Soc. 79, 2037 (1957).

[8] McDonald, R. A., and Oetting, F. L., J. Phys. Chem. 69 (11), 3839 (1965).

[8a] Novoselova, A. V., and Simanov, Yu. P., Uchenye Zapiski, Moskov Gosudarst. Univ. im. M. V. Lomonosova No. 174, 7 (1955).

[9] Rundle, R. E., and Lewis, P. H., J. Chem. Phys. 20, 132 (1952).

[10] Smith, H. I., and Chen, J. H., Bull. Am. Phys. Soc. 11, 414 (1966).

\section{Group IIIA Halides}

There are no data available regarding the phase transitions of the halides of boron and gallium. $\mathrm{AlF}_{3}$ is known to exist in two polymorphic forms, $\alpha$ and $\beta[7 \mathrm{a}]$. NQR investigations have shown that $\mathrm{InI}_{3}$ undergoes a sluggish transformation under pressure at low temperatures [4a]. There are, however, a few reports on the phase transitions of thallium halides. TIF is orthorhombic [8] and undergoes a phase change at $\sim 354 \mathrm{~K}$ to a tetragonal structure [10]. TlCl $[5,9,15], \operatorname{TlBr}[15,16]$ and TII [11] which crystallize in the $\mathrm{CsCl}$ structure transform to the $\mathrm{NaCl}$ structure when evaporated into thin films on suitable substrates at low temperatures $[3,7,12,13]$. The abnormal $\mathrm{NaCl}$ structures have been examined by electron diffraction as well as x-ray diffraction techniques. Lattice energies of the thallium halides have been calculated by Mayer [8a]. Altshuller [1] as well as Sharma and Madan [14]. No pressure transformation is known in $\mathrm{TlCl}$ or $\mathrm{TlBr}$ up to $500 \mathrm{kbar}$ [1la]; three high pressure polymorphs of TIF are known [10]. 


Substances and
measurement techniques

Heat capacity as a function of temperature.

Indium triiodide, $\mathrm{InI}_{3}$

NQR investigations and pressuredependence studies.

\section{Thallium fluoride, TlF}

(orthorhombic $\mathrm{D}_{2 h}^{23}-\mathrm{Fmmm}$, $a=5.495 \AA, b=6.08 \AA$ and $c=5.18 \AA$ at $298 \mathrm{~K}$ )

X-ray and DTA investigation of high temperature and high pressure transitions.

Thallium chloride, TICl

(Pm3m, $a=3.8427 \AA$ at $298 \mathrm{~K}$ )

Thin films of $\mathrm{TlCl}$ evaporated on to amorphous bases at low temperatures and investigated by electron and $\mathrm{x}$-ray diffraction.

\section{Thallium bromide, TIBr}

(Pm3m, $a=3.9588 \AA$ at $298 \mathrm{~K}$ )

Thin films of TIBr evaporated on to amorphous bases and investigated by electron and $\mathrm{x}$-ray diffraction.

Thallium iodide, TlI

(orthorhombic, $\mathrm{D}_{2 h}^{17}-\mathrm{Cmcm}$, $a=4.582 \AA, b=12.92 \AA$ and $c=2.251 \AA$ at $298 \mathrm{~K}$ )

Thin layers of TlI evaporated on to amorphous bases (or ionic crystals) and examined by electron and $\mathrm{x}$-ray diffraction.
$T_{t} \sim 718 \mathrm{~K}$

$\Delta H_{\mathrm{tr}} \sim 160 \mathrm{cal} \cdot \mathrm{mol}^{-1}$.

The sample changes from normal yellow to brick red color at low temperatures, indicating a sluggish transition, under pressure.

$T_{t} \sim 354 \mathrm{~K}$. The space group of the tetragonal structure $(\mathrm{I})$ is $\mathrm{D}_{4 h^{17}}^{17}$ $\mathrm{mmm} ; a=3.771 \AA$ and $c=6.115 \AA$ at $408 \mathrm{~K}, z=2$. A high pressure transition is observed at $\sim 12.6$ kbars and $128.5 \mathrm{~K}$. TIF(II) is orthorhombic with $\mathrm{D}_{2 h}^{23}$.Fmmm; $a=5.18 \AA, b=5.495 \AA, c=6.08 \AA$; $z=4$.

Abnormal $\mathrm{NaCl}$ structure was observed with $a=6.30-6.37 \AA$ around $208 \mathrm{~K}$.

$a_{\mathrm{Fm} 3 \mathrm{~m}}=6.58-6.63 \AA$ around $213 \mathrm{~K}$.

The $\mathrm{CsCl}$ type structure of TII has $a_{\mathrm{pm} 3 \mathrm{~m}}=4.205 \AA$ at $288 \mathrm{~K}$.

$a_{\mathrm{Fm} 3 \mathrm{~m}}=6.94 \AA$ (on LiF substrate).
Extrapolation of data seems to suggest that the transition may be feasible around $200 \mathrm{~K}$ at atmospheric pressure. Earlier observations indicated a transition around $77 \mathrm{~K}$, at atmospheric pressures.

The orthorhombic to tetragonal transition is accompanied by a decrease in density. Pressuretemperature curves of $\mathrm{TlCl}, \mathrm{TlBr}$ and TII are also presented.

The stability of the $\mathrm{NaCl}$ phase is influenced by the base and the temperature.

The $\mathrm{NaCl}$ structure disappears with increase in temperature.

The $\mathrm{CsCl}$ structure passes onto the orthorhombic structure near room temperature. It is interesting that TII deposited on $\mathrm{LiF}$ has the $\mathrm{NaCl}$ structure. [7a].

$[4 a, 13 a]$.

[10].

[3. 7, 12, 13].

$[3,7,12,13]$.

$[3,5 \mathrm{a}, 7,12$

13]. 


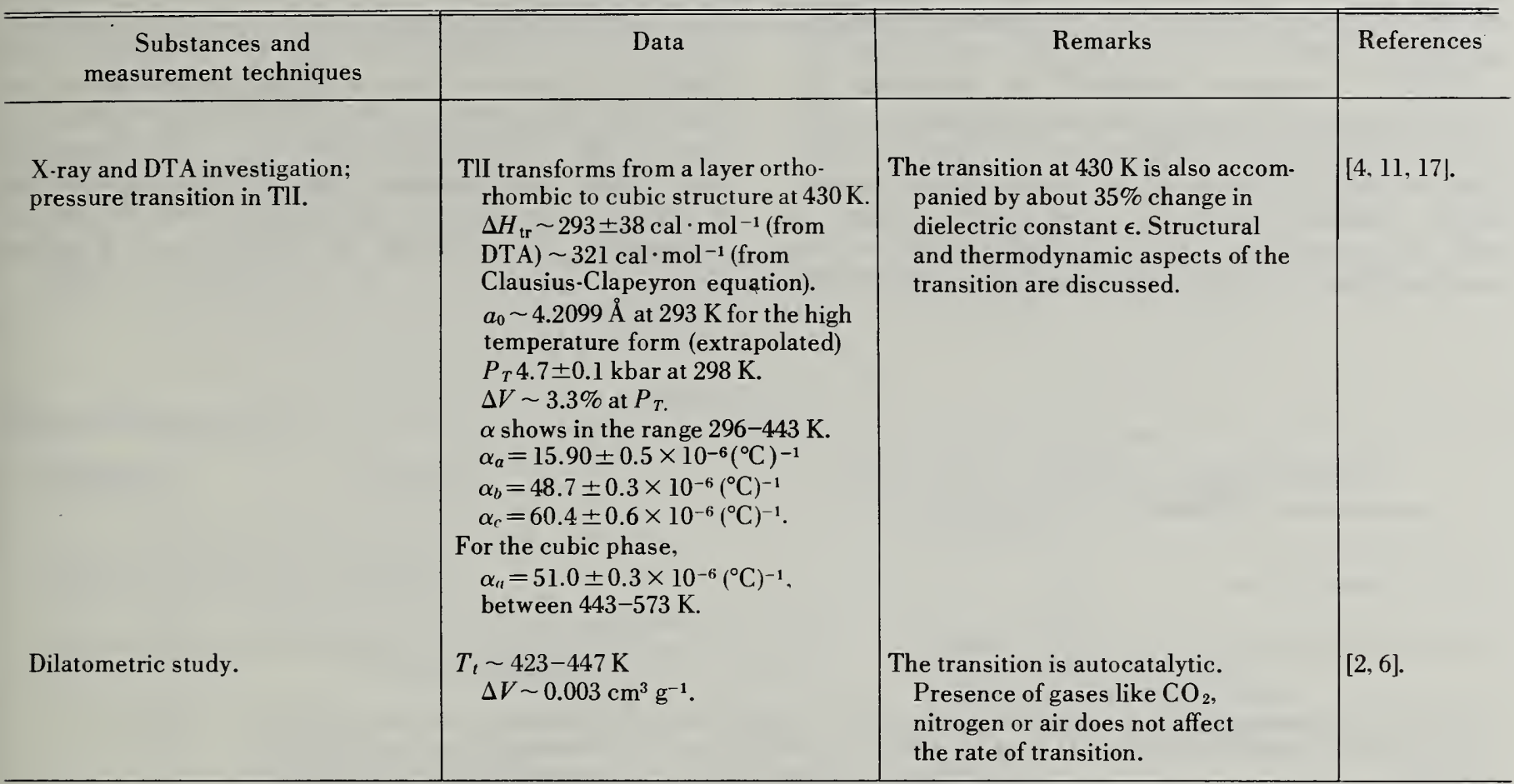

\section{References}

[1] Altshuller, A. P., J. Chem. Phys. 22, 1136 (1954).

[2] Benton, A. F., and Cool, R. D., J. Phys. Chem. 35, 1762 (1931).

[3] Blackman, M., and Kahn, I. H., Proc. Phys. Soc. 77, 471 (1961).

[4] Bradley, R. S., Grace, J. D., and Munro, D. C., Z. Krist. 120,349 (1964).

[4a] Brooker, H. R., and Scott, T. A., J. Chem. Phys. 41, 475 (1964).

[5] Hambling, P. G., Acta. Cryst. 6, 98 (1953).

[5a] Helmholtz, L., Z. Krist. 95, 129 (1936).

[6] Ishikawa, F., and Sato, Y., J. Chem. Soc. Japan 55, 930 (1934).

[7] Kahn. I. H., Proc. Phys. Soc. (London), 76, 507 (1960).

[7a] Kirk-Othmer, Encyclopedia' of Chemical Technology, 2nd Edition, Vol. 9, p. 529 (John Wiley \& Sons., New York, 1966).

[8] Ketelaar, J. A. A., Z. Krist. 92,30 (1935).

[8a] Mayer, J. E., J. Chem. Phuss. 1, 327 (1933).
[9] Meyerhoff, V. K. Acta. Cryst. 12,330 (1959).').

[10] Pistorius, C. W. F. T., and Clark, I. B., Phys. Rev. 173, 692 (1968).

[11] Samara, G. A., Walters, L. C., and Northrop, D. A., J. Phys. Chem. Solids 28, 1875 (1967).

[1la] Samara, G. A., and Drickamer, H. G., J. Chem. Phys. 37, 408 (1962).

[12] Schulz, L. G., J. Chem. Phys. 18, 996 (1950).

[13] Schulz, L. G., Acta Cryst. 4, 487 (1951).

[13a] Segel, S. E., and Barnes, R. G., J. Chem. Phys. 25, 578 (1956).

[14] Sharma, M. N., and Madan, M. P., Ind. J. Phys. 38, 305 (1964).

[15] Smakula, A., and Kalanajs, J., Phys. Rev. 99, 1737 (1955).

[16] Westman, S., and Magneli, A., Acta. Chem. Scand. 11, 1587 (1957).

[17] Zahner, J. C., and Drickamer, H. G., J. Phys. Chem. Solids 1 1, 92 (1959).

\section{Group IVA Halides}

Carbon tetrafluoride exhibits a first order thermal transformation at $\sim 76.2 \mathrm{~K}$ and atmospheric pressure [6]; the transformation shows no hysteresis. Stewart [21] observed a volume change of about 1.8 $\mathrm{cm}^{3} \mathrm{~mol}^{-1}$ at $\sim 89 \mathrm{~K}$. The transition temperature for $\mathrm{CF}_{4}$ observed by Stewart is, however, higher than that mentioned in the previous report. $\mathrm{CCl}_{4}$ when cooled below its freezing point undergoes a transformation at $\sim 225 \mathrm{~K}[11,14]$; the transition is accompanied by a change from the cubic to the monoclinic structure. The large enthalpy $(\sim 1080$ $\mathrm{cal} \mathrm{mol}^{-1}$ ) suggests the transition to be of first order. $\mathrm{CBr}_{4}$ exhibits a similar transformation from a cubic to a monoclinic structure [10].

Bridgman [3] observed three solid forms of $\mathrm{CCl}_{4}$ in the range $253-473 \mathrm{~K}$ and up to $12 \mathrm{kbar}$; Kleiss and co-workers [12] have reported two pressure transitions in $\mathrm{CCl}_{4}$ at $\sim 4 \mathrm{kbar}(\mathrm{I}-\mathrm{II})$ and at $\sim 7 \mathrm{kbar}$ (II-III). Bridgman [4, 5] reports pressure transitions in $\mathrm{CBr}_{4}$. $\mathrm{SiF}_{4}$ undergoes a pressure transition 
from a BCC structure to a close-packed structure in the region 5-20 kbar [21]. A pressure transition occurs at $\sim 94.3 \mathrm{~K}$ in $\mathrm{SiF}_{6}$ [6]. $\mathrm{SiCl}_{4}$ is reported to undergo a pressure transition by Bridgman [3]. $\mathrm{GeI}_{2}$ exists in two hexagonal modifications as evidenced by electron diffraction studies on thin films of $\mathrm{GeI}_{2}$ [1]. Electrical resistance measurements under pressure indicate a polymorphic change in $\mathrm{SnI}_{4}$ to a metallic state [17]. $\mathrm{PbF}_{2}$ exists in two modifications [2] while $\mathrm{PbI}_{2}$ exhibits polytypism
$[7,9]$. An x-ray study of over 600 crystals of $\mathrm{PbI}_{2}$ [8] has revealed some important facts for the formula. tion of a satisfactory theory of polytypism [9]. Phase changes in $\mathrm{PbI}_{2}$ have been investigated by the Hahn emanation method of following the emanation of the ${ }^{135} \mathrm{Xe}$ from $\mathrm{Pb}^{135} \mathrm{I}_{2}$ [15]. The theory of polytypism has been discussed by Schneer [19]; a systematic account of polytypism with literature references is furnished by Verma and Krishna [22].

Group IVA Halides

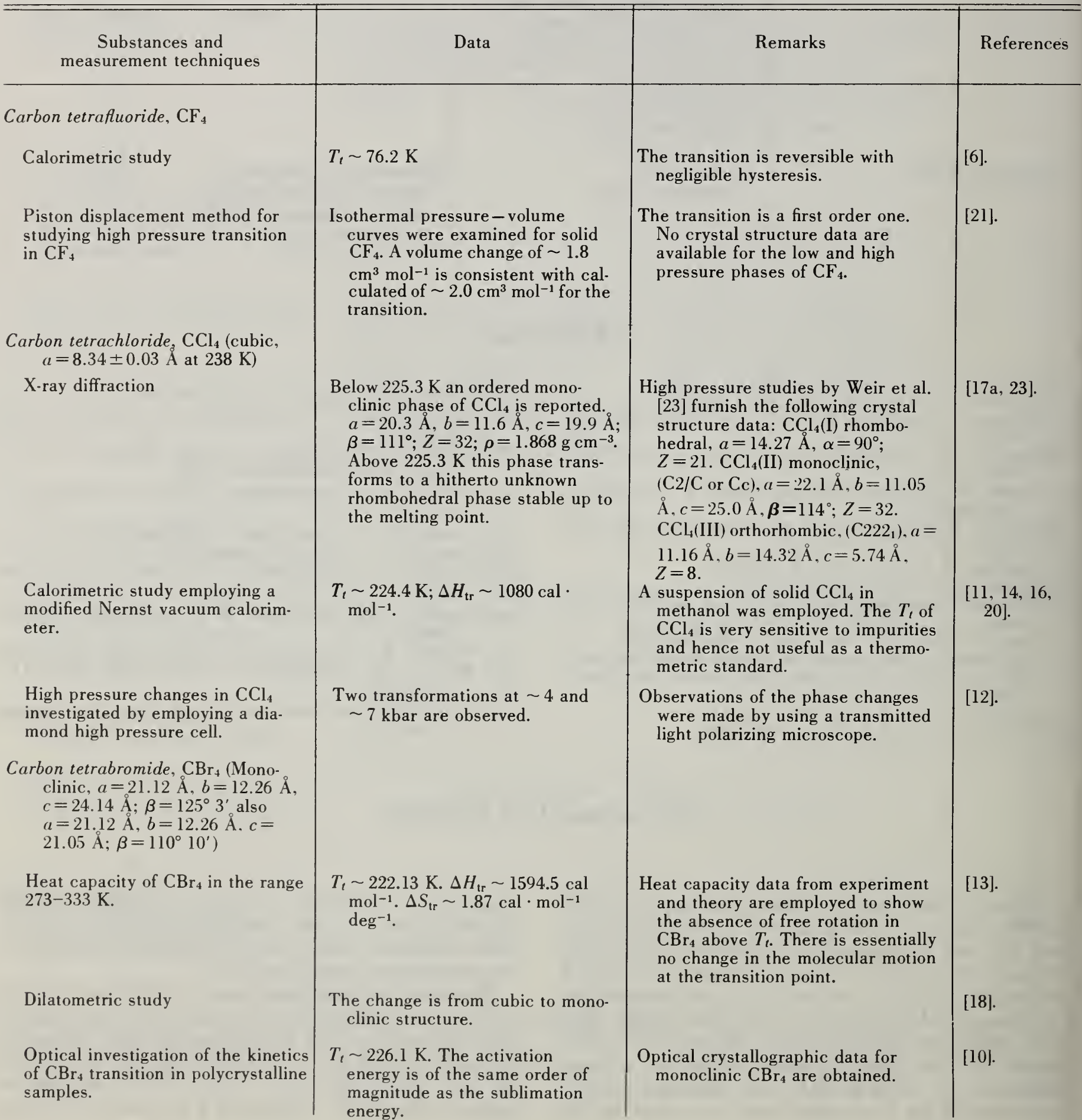




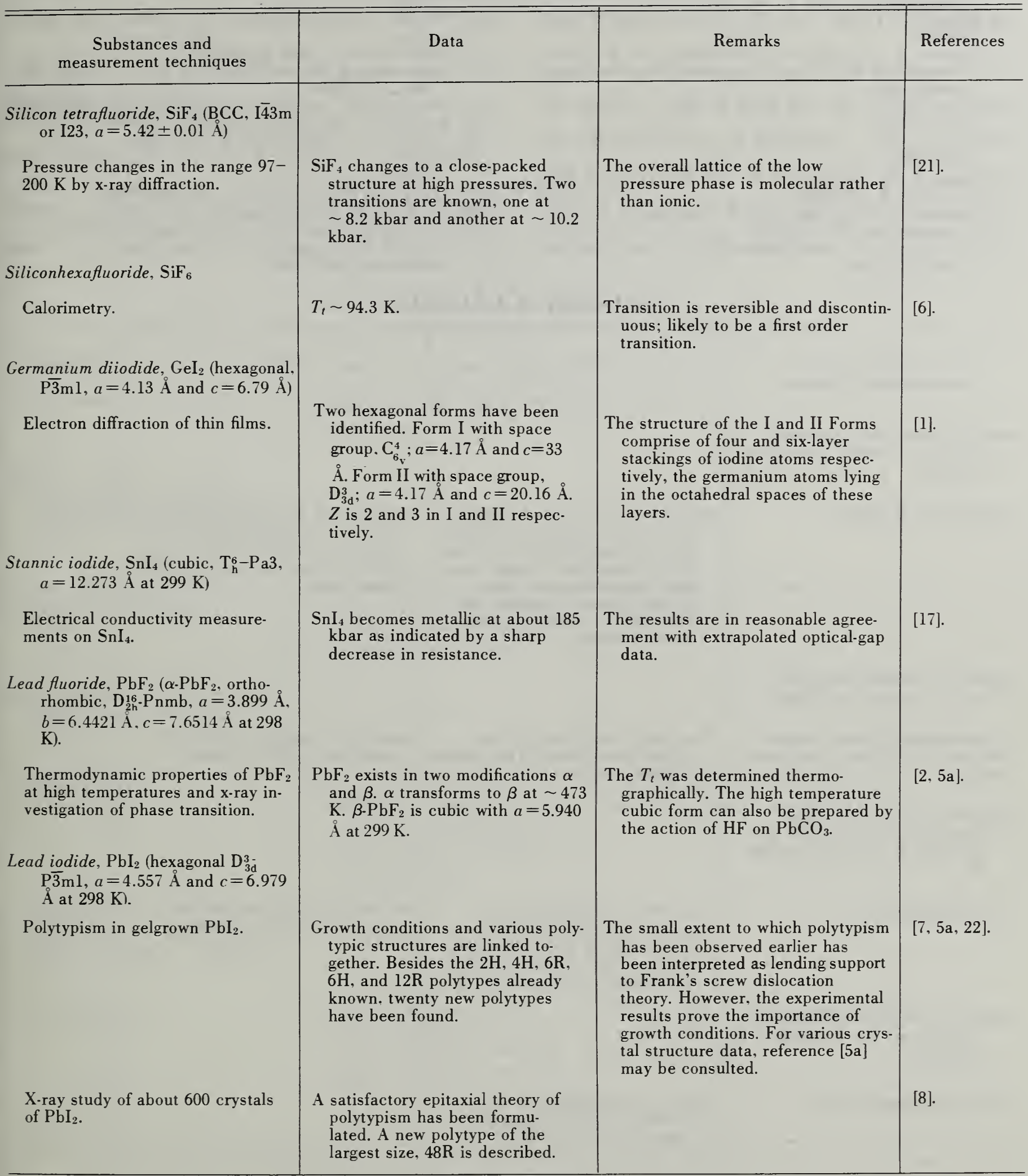

\section{References}

[1] Avilov, A. S., and Imanov, R. M., Sov. Phys-Cryst. 13, 52 (1968):

[2] Banashek, E. I., Patsukova, N. N., and Rassonskaya. I. S., Neorg. Khim Acad. Nauk. S.S.S.R. 27, 223 (1956).

[3] Bridgman, P. W., Phys. Rev. 3, 153 (1914); ibid., 6, 1 (1915).
[4] Bridgman, P. W., Proc. Am. Acad. Arts Sci. 52, 57 (1916).

[5] Bridgman, P. W., Proc. Am. Acad. Arts Sci. 72, 227 (1938).

[5a] Crystal Data, ACA Monograph, No. 5, Ed. J. D. H. Donnay, and Donnay, G., American Crystallographic Association (1963).

[6] Eucken, A., and Schroder, E., Math-Physik. Klasse, and Donnay, G., Fachgruppe II, 3, 65 (1938). 
[7] Hanoka. J. I., Vedam. K., and Henisch, H. K., J. Phys. Chem. Solids, Suppl. 1, 369 (1967).

[8] Hanoka, J. I., and Vand, V., J. Appl. Phys. 39, 5288 (1968).

[9] Hanoka, J. I., Vedam, K., and Henisch, H. K., Crystal Growth, Ed. H. S. Peiser (Pergamon Press, Inc. Oxford, 1967) p. 369.

[10] Hartshorne. N. H., and Swift, P. McL., J. Chem. Soc. 3705 (1955).

[11] Johnston, H. L., and Long, E. A., J. Am. Chem. Soc. 56, 31 (1934).

[12] Kleiss, R. M., Nourbakhsh, M., and Alder, P. N., J. Materials Sci. 3, 657 (1968).

[13] Marshall, J. G., Staveley, L. A. K., and Hart, K. R., Trans. Faraday Soc. 52, 19 (1956).

[14] McCullough, J. C., and Phipps, H. E., J. Am. Chem. Soc. 50, 2213 (1928).
[15] Narang, V. P., and Yaffe, L., Canadian J. Chem. 46, 491 (1968).

[16] Phipps, H. E., and Reedy, J. H., J. Phys. Chem. 40, 89 (1936).

[16a] Post, B., Acta. Cryst. 12, 349 (1959)

[17] Rigglemann, B. M., and Drickamer, H. G., J. Chem. Phys. 38, 2721 (1963).

[17a] Rudman, R., and Post, B., Science 154, 1009 (1966).

[18] Sakovich, G. V., Zhur. Fiz. Khim. 34, 2808 (1960).

[19] Schneer, C. J., Acta. Cryst. 8, 279 (1955).

[20] Skau, E. L., and Meier. H. F., J. Am. Chem. Soc., 5 1, 3517 (1929).

[21] Stewart, J. W., J. Chem. Phys. 33, 128 (1960).

[22] Verma, A. R., and Krishna, P., in Polymorphism and Polytypism in Crystals (John Wiley, New York, 1966).

[23] Weir, C. E., Piermarini, G. J., and Block, S., J. Chem. Phys. 50, 2089 (1969).

\section{Group VA Halides}

\section{Substances and
measurement techniques at $298 \mathrm{~K})$.}

Polymorphism in $\mathrm{AsI}_{3}$.

Antimony trichloride, $\mathrm{SbCl}_{3}$ and Antimony tribromide, $\mathrm{SbBr}_{3}$.

Investigation of phase changes in the range 273 to $450 \mathrm{~K}$ and up to 30 kbar.

Bismuth trifluoride, $\mathrm{BiF}_{3}$ orthorhombic, Pnma, $a=6.563 \AA$, $b=7.021 \AA, c=4.845 \AA$ at 298 $\mathrm{K})$.

Polymorphism in $\mathrm{BiF}_{3}$.

Bismuth triiodide, $\mathrm{BiI}_{3}$ (Trigonal, $\mathrm{C}_{31}^{2}$ - R $\overline{3}, a=7.522 \AA, c=20.73 \AA$ at $298 \mathrm{~K}$ ).

Two new forms of $\mathrm{BiI}_{3}$.
Two polymorphic forms are known. An yellow (metastable accicular) form is obtained by rapid cooling of a hot benzene or toluene solution. On standing, the yellow crystals change to a stable red form. The conversion becomes faster on heating.

Two new forms for each of the halides were noticed. Their phase diagrams are similar.
Two other modifications are reported in the literature. An $\alpha$ form stable up to $473 \mathrm{~K}$ is cubic $(\mathrm{Fm} 3 \mathrm{~m})$, with $a=5.865 \pm 0.06 \AA$. $\alpha$-changes to $\beta$-form above 473 $\mathrm{K}$.
No conversion was observed when the samples were carefully dried and stored at room temperature in the absence of air, even after a period of one month.

Study on $\mathrm{SbI}_{3}$ and $\mathrm{BiI}_{3}$ showed no transitions in either of them.

For various crystal structure data reference 2 must be consulted.
References

$[3,4]$.

$[1,4 \mathrm{a}, 5]$.

[2].

Form I, hexagonal, R $\overline{3}$, with $a=7.5$ $\AA$ and $c=20.65 \AA$. Form II cubic, with $a=20.676 \AA$.

\section{References}

[1] Aurivillius, B., and Lindqvist, T., Acta. Chem. Scand. 9, 1209 (1955)

[1a] Bowles, B. F., Scott. G. J., and Bable, S. E., Jr., J. Chem. Phys. 39, 831 (1963)

[2] Crystal Data, ACA Monograph, No. 5, Ed. J. D. H. Donnay, anc Donnay. G., American Crystallowraphic Association (1963).
[3] Hass, D., Z. anorg. allgem. chem. 327, 84 (1964).

[4] Heyworth, D., Phys. Rev. 38, 351 (1931).

[4a] Kirk-Othmer, Encyclopedia of Chemical Technology, 2nd Edition, Vol. 3, p. 539 (John Wiley \& Sons., New York, 1964).

[5] Zalkin, A., and Templeton, D. H., J. Am. Chem. Soc. 75 , 2453 (1953). 
8. 3d Transition Metal Halides

Substances and
measurement techniques

$\mathrm{X}$-ray diffraction

Chromium chloride, $\mathrm{CrCl}_{3}$ (Monoclinic, C2 $/ \mathrm{m} ; a=5.959 \AA, b=$ $10.321 \AA, c=6.114 \AA ; \beta=$ $108.49^{\circ}$ )

\section{X-ray diffraction and NQR $\left({ }^{35} \mathrm{Cl}\right)$ with $\mathrm{CrCl}_{3}$ single crystals.}

Ferrous bromide, $\mathrm{FeBr}_{2}$ (hexagonal, $\mathrm{P} \overline{3} \mathrm{ml}, a=3.74 \pm 0.05 \AA, c=$ $6.171 \AA$ А.)

X-ray diffraction

Ferric fluoride, $\mathrm{FeF}_{3}$ (hexagonal, $\mathrm{R} \overline{3} \mathrm{c}, a=5.20 \AA, c=13.40 \AA$ at $291 \mathrm{~K}$ )

$\mathrm{X}$-ray diffraction
$\mathrm{TiCl}_{4}$ on reduction with hydrogen at 1070 to $1173 \mathrm{~K}$ gives $\alpha-\mathrm{TiCl}_{3}$; this is bidimensional and belongs to rhombohedral symmetry, $R_{3}$. The coordinates of $\mathrm{Ti}$ are: 0,0 $1 / 3$; chlorine atoms are at, $1 / 3,0$, $0.079 . \mathrm{TiCl}_{4}$ on reduction with aluminum alkyls give $\beta$-form of $\mathrm{TiCl}_{3}$; this is a linear polymer. This has a hexagonal structure with $a=b=6.27 \AA, c=5.82 \AA$. $\beta$ form on heating to about $\sim 573 \mathrm{~K}$ passes on to a new $(\gamma)$ modification.

$T_{t} \sim 240 \mathrm{~K}$. The monoclinic structure transforms to a rhombohedral structure with $\bar{R} \overline{3}$ symmetry; $a=5.942 \AA, c=17.333 \AA$.

$\mathrm{FeBr}_{2}$ undergoes a cooperative second-order transformation at $\sim 673 \mathrm{~K}$. The high-temperature phase is different from hcp or random-packed-layer structure of the $\mathrm{Cd}(\mathrm{OH})_{2}$ type.

$\mathrm{FeF}_{3}$ grown by sublimation of anhydrous crystals has a cubic symmetry. At $683 \mathrm{~K}$, transition to a rhombohedral structure takes place.
The transformation seems to be a first order one.

$T_{t}$ is markedly affected by the pres ence of moisture in the sample.

For other data on the hexagonal crystal structure, reference should be made to $[4 \mathrm{a}]$.
References

[13]. 
$3 d$ Transition Metal Halides - Continued.

\section{Substances and
measurement techniques} $\mathrm{P} 4 / \mathrm{mnm}, a=13.59 \pm 0.05 \AA$,
$c=3.3099 \pm 0.05 \AA$ at $298 \mathrm{~K})$

X-ray investigation of high pressure transitions up to $160 \mathrm{kbar}$ and at $298 \mathrm{~K}$.

Pressure transitions of $\mathrm{CoF}_{2}$,

$\mathrm{NiF}_{2}$, and $\mathrm{ZnF}_{2}$

$\mathrm{X}$-ray investigation of high pressure changes in $\mathrm{CoF}_{2}$, $\mathrm{NiF}_{2}$ and $\mathrm{ZnF}_{2}$ upto 160 kbar at $298 \mathrm{~K}$.

Copper (I) Chloride CuCl ( $\mathrm{T}_{\overline{\mathrm{d}}}^{-2}-\overline{\mathrm{F}}_{4} 3 \mathrm{~m}$ : $a=5.416 \AA$ at $299 \mathrm{~K}$ )

$\mathrm{X}$-ray powder pattern of $\mathrm{CuCl}$ at high temperatures.
At $33 \pm 4$ kbars, $\mathrm{MnF}_{2}$ (I) (rutile type) transforms to $\mathrm{MnF}_{2}$ (II) (a distorted $\mathrm{CaF}_{2}$ type) with $a=b=$ $5.03 \AA, c=5.28 \AA$; density, $\rho=$ $4.62 \mathrm{~g} \mathrm{~cm}^{-3}$ at $80 \mathrm{kbar}$. At higher pressures (150 kbar) a third phase, III, is formed ( $a=$ $3.25 \AA, b=5.54 \AA, c=6.88 \AA$; $\left.\rho=4.98 \mathrm{~g} \mathrm{~cm}^{-3}\right)$. A metastable phase, IV, is obtained on removing the pressure.

The phase changes occur from the low pressure rutile phase to the distorted fluorite structure. The lattice constants and densities are given below:

\section{High pressure phase}

\begin{tabular}{c|c|c}
\hline & $a, \AA$ & $\rho, \mathrm{g} \mathrm{cm}^{-3}$ \\
\hline $\mathrm{CoF}_{2} \ldots \ldots \ldots \ldots \ldots \ldots$ & 4.91 & 5.44 \\
$\mathrm{NiF}_{2} \ldots \ldots \ldots \ldots \ldots \ldots$ & 4.84 & 5.66 \\
$\mathrm{ZnF}_{2} \ldots \ldots \ldots \ldots \ldots \ldots$ & 4.82 & 6.13 \\
\hline
\end{tabular}

Low pressure phase

\begin{tabular}{l|c|c|c}
\hline & $a, \AA$ & $c, \AA$ & $\rho, \mathrm{g} \mathrm{cm}^{-3}$ \\
\hline $\mathrm{CoF}_{2} \ldots \ldots \ldots$ & 4.54 & 3.32 & 4.70 \\
$\mathrm{NiF}_{2} \ldots \ldots \ldots .$. & 4.51 & 3.30 & 4.78 \\
$\mathrm{ZnF}_{2} \ldots \ldots \ldots$ & 4.41 & 3.27 & 5.40 \\
\hline
\end{tabular}

$T_{\imath} \sim 683 \mathrm{~K}$. The low temperature phase of $\mathrm{CuCl}$ is FCC $(\mathrm{ZnS})$ with $a=5.4057 \AA$. The high temperature form has the hexagonal structure $(a=3.91 \AA$ and $c=6.42$ A).
A triclinic form of $\mathrm{MnF}_{2}$ with 1 point group has been mentioned in the literature and referred to in "Crystal Data" [4a]. The lattice constants are:

$a=5.13 \AA, b=5.31 \AA, c=5.07 \AA$, $\alpha=180^{\circ} 30^{\prime}, \beta=119^{\circ} 35^{\prime}$ and $\gamma=88^{\circ} 33^{\prime}$, Dandek ar and Jamieson [4b] suggest that the rutile phase transforms to a new tetragonal phase which then transforms reversibly to the $\alpha \cdot \mathrm{PbCl}_{2}$ form $(a=3.323 \AA, b=5.560 \AA, c=$ $6.454 \AA ; \Delta V / V=10 \%$ ).

These data have been obtained in $130-150 \mathrm{~kb}$ ar region at $298 \mathrm{~K}$. Xray diffraction patterns of these fluorides indicate the presence of a mixture of the high and low pressure phases under these conditions. Dandek ar and Jamieson [4b] sug. gest that the initial rutile structure transforms to another tetragonal structure (starting around 30 kbar) with $a=4.908 \AA$ and $c=$ $4.658 \AA$ (at $25 \mathrm{kbar}$ ); release of pressure yields a mixture of the two phases. There is no further change in structure up to 120 kbar.

The high temperature phase may be similar to wurtzite
$[1,4 b, 7,17]$.

$[4 b, 7]$.

[10]. 
$3 d$ Transition Metal Halides-Continued Substances and
measurement techniques tivity and TEP measurements in the $370-670 \mathrm{~K}$ and $10-55$ kbar.

\section{Copper (II) chloride, $\mathrm{CuCl}_{2}$ (Mono-} clinic, $\mathrm{I} 2 / \mathrm{m}, a=6.70 \AA, b=3.30$ $\AA, c=6.67 \AA ; \beta=118^{\circ} 23^{\prime}$ )

$\mathrm{X}$-ray investigation of polymorphisn in $\mathrm{CuCl}_{2}$.

Copper (I) bromide, CuBr $\left(\mathrm{T}_{\mathrm{d}}^{2}-\mathrm{F} \overline{4} 3 \mathrm{~m}\right.$, $a=5.6905 \AA)$

Calorimetric and x-ray investigation.

Microcalorimetric studies (employ. ing DTA)

\section{Copper (I) iodide, CuI (cubic $\mathrm{T}_{\mathrm{d}}^{2}$}

$\mathrm{F} \overline{4} 3 \mathrm{~m}, \gamma$-form, $a=6.0507 \AA$ )

DTA and TGA studies on $\mathrm{CuI}_{2}$ and CuI.

Investigation of $\mathrm{CuI}$ by $\mathrm{x}$-ray diffraction, heat capacity, etc.

High pressure polymorphism in $\mathrm{CuBr}$ and CuI, by DTA and $\mathrm{x}$-rays.
A phase diagram has been constructed indicating the stability range of various high pressure phases. The stability of phase I is in a small range of $673-683 \mathrm{~K}$ and below 5 kbar. Phase II is stable in the range up to $600 \mathrm{~K}$ and 40 kbar. Between 40 and 60 kbar a new phase IIa is reported. IV and $\mathrm{V}$ are stable above $60 \mathrm{kbar}$ up to $140 \mathrm{kbar}$ and below $673 \mathrm{~K}$.

There are two polymorphic forms $\alpha$ and $\beta$ with a $T_{t} \sim 761 \mathrm{~K}$.

$\gamma-\mathrm{CuBr}$ is FCC with $a=5.6794 \AA$ at $293 \mathrm{~K}$. This is $\mathrm{ZnS}$ type and is like $\mathrm{CuI}$. $\beta$ - $\mathrm{CuBr}$ is hexagonal, $\mathrm{C}_{6 \mathrm{v}}^{4}$ $a=4.04 \AA, c=6.58 \AA$ at $\sim 703 \mathrm{~K}$. $\alpha-\mathrm{CuBr}$ is BCC and is similar to $\alpha$-AgI. $a=4.53 \AA$ at $\sim 753 \mathrm{~K}$. $\Delta H_{\gamma-\beta}=1400 \mathrm{cal} \cdot \mathrm{mol}^{-1}$ $\Delta S_{\gamma-\beta}=2.1$ e.u. $\mathrm{mol}^{-1}$ $\Delta H_{\beta-\alpha}=700 \mathrm{cal} \cdot \mathrm{mol}^{-1}$ $\Delta S_{\beta-\alpha}=0.9$ e.u. $\mathrm{mol}^{-1}$ $\beta$ and $\alpha$ are only average structures.

$\mathrm{CuBr}$ (obtained from $\mathrm{CuBr}_{2}$ dissociation at $\sim 453 \mathrm{~K}$ ) exhibits the $\gamma \rightarrow \beta \rightarrow \alpha$ transitions by DTA anomalies.

$\mathrm{CuI}_{2}$ readily loses iodine and transforms to the $\beta$ form at $\sim 648 \mathrm{~K}$ and finally to the $\alpha$ form at $\sim 785$ $\mathrm{K}$. The solid melts at $\sim 873 \mathrm{~K}, \alpha$ is cubic, $\beta$ is hexagonal $(\mathrm{ZnO}$ type) and $\gamma$ is of $\mathrm{ZnS}$ type structure.

$T_{t}, \gamma \rightarrow \beta, 642 \mathrm{~K}$ $\beta \rightarrow \alpha, 680 \mathrm{~K}$.

In CuI, six phases have been reported: $\alpha$ (FCC phase) $\beta$ (wurtzite) $\gamma$ (zinc blende) as well as $h_{1}$, $h_{2}$, and $h_{3}$ phases are known. $\gamma \rightarrow h_{1}$ transition is at $4 \mathrm{kbar}$, $h_{1} \rightarrow h_{2}$ at 5 kbar and $h_{2} \rightarrow h_{3}$ at $\sim 15$ kbar.

In the case of $\mathrm{CuBr}, \alpha$ (BCC), $\beta$ (wurtzite) and $\gamma$ (zinc blende) are all stable below $40 \mathrm{kbar}$ and $\sim 800 \mathrm{~K}$.
Phase I is wurtzite type and phase II is zinc blende type structure. DTA diagrams are given for various phases and their mutual transitions.

$[2,16]$.

Immediately after the $\alpha$-form is formed, $\mathrm{CuBr}$ starts melting at $\sim 770 \mathrm{~K}$

The high temperature forms ( $\beta$ and $\alpha)$ are average structures.

For both $\mathrm{CuBr}$ and $\mathrm{CuI}$ phase diagrams are given.

$[9,15]$.
[8].

[6].

References

$[9,18]$

[12].

$[3,11,12$, 16]. 
$3 d$ Transition Metal Halides - Continued

\begin{tabular}{c|c|c|c}
\hline \hline $\begin{array}{c}\text { Substances and } \\
\text { measurement techniques }\end{array}$ & Data & Remarks \\
\hline Dinc chloride, $\mathrm{ZnCl}_{2}$ & $\begin{array}{c}\text { The glass transition temperature } \\
\text { was determined by dilatometric } \\
\text { and linear expansion coefficient } \\
\text { methods. }\end{array}$ & $\begin{array}{c}\text { The rate of crystallization was also } \\
\text { measured dilatometrically and } \\
\text { results are presented in detail. } \\
\text { There are three forms of } \mathrm{ZnCl}_{2} \\
\text { known, } \alpha, \beta \text { and } \gamma . \text { For the various } \\
\text { structural data reference should be } \\
\text { made to [4a]. }\end{array}$ \\
\hline
\end{tabular}

Polymorphic Phases of Copper Halides

\begin{tabular}{|c|c|c|c|}
\hline & Designation & Structure & Range of stability \\
\hline $\mathrm{CuCl}$ & $\begin{array}{r}\text { I } \\
\text { II } \\
\text { III }\end{array}$ & $\begin{array}{l}\text { wurtzite } \\
\text { zinc blende } \\
\mathrm{BCC} \text { (similar to } \alpha-\mathrm{AgI})\end{array}$ & $\begin{array}{l}\text { Between } 650-700 \mathrm{~K} \text { and below } 5 \text { kbar. } \\
\text { Below } 650 \mathrm{~K} \text { and } \sim 30 \mathrm{~kb} \text { ar. } \\
\text { Above } 700 \mathrm{~K} \text { and } 10 \mathrm{kbar} \text {. }\end{array}$ \\
\hline $\mathrm{CuBr}$ & $\begin{array}{r}\text { I } \\
\text { II } \\
\text { III }\end{array}$ & $\begin{array}{l}\text { BCC (similar to } \alpha-\mathrm{AgI} \text { ) } \\
\text { wurtzite } \\
\text { zinc blende }\end{array}$ & $\begin{array}{l}\text { Above } 800 \mathrm{~K} \text { and } \sim 10 \mathrm{kbar} \text {. } \\
\text { Between } 600-700 \mathrm{~K} \text { and below } \sim 8 \mathrm{kbar} \text {. } \\
\text { Below } 600 \mathrm{~K} \text { and up to } \sim 30 \mathrm{kbar} \text {. }\end{array}$ \\
\hline $\mathrm{CuI}$ & $\begin{array}{r}\text { I } \\
\text { II } \\
\text { III } \\
\text { IV } \\
\text { V } \\
\text { VI } \\
\text { VII }\end{array}$ & $\begin{array}{l}\begin{array}{l}\text { FCC (disordered zinc blende) } \\
\text { wurtzite } \\
\text { zinc blende }\end{array} \\
\ldots \ldots \ldots \ldots \ldots \ldots \ldots \ldots \ldots \ldots \\
\ldots \ldots \ldots\end{array}$ & $\begin{array}{l}\text { Between } 675-1000 \mathrm{~K} \text { and up to } 30 \mathrm{kbar} \text {. } \\
\text { Between } 575-675 \mathrm{~K} \text { and below } \sim 5 \mathrm{~kb} \text { ar. } \\
\text { Below } 575 \mathrm{~K} \text { and } \sim 12 \mathrm{kbar} \text {. } \\
\text { Below } \sim 600 \mathrm{~K} \text { and above } \sim 10 \mathrm{kbar} \text {. } \\
\text { Above } 20 \mathrm{~kb} \text { and } \sim 600 \mathrm{~K} . \\
\text { Above } 30 \mathrm{kbar} \text { and around } 800 \mathrm{~K} . \\
\text { Above } 900 \mathrm{~K} \text { and } \sim 10 \mathrm{kbar} \text {. }\end{array}$ \\
\hline
\end{tabular}

\section{References}

[1] Azzaria, L. M., and Dachille, F., J. Phys. Chem. 65, $88^{\circ}$ (1961).

[2] Bradley, R. S., Munro, D. C., and Spencer, P. N., Trans. Faraday Soc., 65, 1912 (1969).

[3] Bridgman, P. W., Proc. Am. Acad. Arts Sci. 52, 91 (1916); Proc. Nat. Acad. Sci. 1, 513 (1915).

[3a] Cras, J. A., Nature 194, 678 (1962).

[4] Croft, W. J., and Kestigian, M., J. Electrochem. Soc. 115, 674 (1968).

[4a] Crystal Data, ACA Monograph, No. 5, Ed. J. D. H. Donnay, and Donnay G., American Crystallographic Association (1963).

[4b] Dandekar, D. P., and Jamieson, J. C., personal communication (1971).

[4c] Eisenberg, A., and Hilemen, B. J., U.S. Gov. Res. Rep. 39, 108A (1964).

[5] Gregory, N. W., and O'Neal, H. E., J. Am. Chem. Soc. 81, 2649 (1959).

[6] Hoshino, S., J. Phys. Soc. Japan 7, 560 (1952).

[7] Kabalkina, S. S., Vereshchagin, L. F., and Lityagina, L. M., Sov. Phys. Solid State 11, 847 (1969).

[8] Korzhukov, N. G., and Psalidas, V. S., Vestn. Mork. Univ. Khim. 23, 54 (1968).
[9] Le-Van-My, Perinet, G., and Bianco, P., Bull. Soc. Chim. France 12, 3651 (1965).

[10] Lorenz, M. R., and Prener, J. S., Acta. Cryst. 9, 538 (1956).

[11] Mao-Chia, Y. W., Schwartz, L. H., and La Mori, P. N., J. Phys. Chem. Solids 29, 1633 (1968).

[12] Miyake, S., Hoshino, S., and Takenaka, T., J. Phys. Soc. Japan 7, 19 (1952).

[13] Morrison, B., and Narath, A., J. Chem. Phys. 40, 1958 (1964).

[14] Natta, G., Corrodini, P., Bassi, I. W., and Porri, L., Atti. 'acad. nazl. Lincei, Rend. 24, 121 (1951).

[15] Pechkovskii, V. V., and Sofronova, A. V., Zh. Neorgan. Khim. 10, 1513 (1965).

[16] Rapoport, E., and Pistorius, C. W. F. T., Phys. Rev. 172, 838 (1968).

[17] Vereshchagin, L. F., Kabalkina, S. S., and Kotilevets, A. A., Sov. Phys. JETP 22, 1181 (1966).

[18] Winkler, H. G. F., Z. anorg. u. allgem. chem. 276, 169 (1954).

\section{Ad Transition Metal Halides}

$\mathrm{ZrF}_{4}$ exists in two polymorphic forms [13a, 42a]. A transition in $\mathrm{MoF}_{6}$ has been reported from NMR studies [la].
AgF undergoes a pressure transformation from $\mathrm{NaCl}$ to the $\mathrm{CsCl}$ structure [18b]. There is no thermal transition in $\mathrm{AgCl}$ or $\mathrm{AgBr}$. AgI, which usually 
exists in the $\mathrm{B} 4$ or wurtzite form (hexagonal $\mathrm{P}_{3}$ mc; $a=4.592 \AA, c=7.510 \AA$ ) and in the B3 or sphalerite form 1 (low cubic, F43m, $a=6.495 \AA$ ) both of which undergo a thermal transformation at $418 \mathrm{~K}$ to the B23 (high cubic) phase. The transformation is reversible and is associated with large $\Delta H$ as well as considerable thermal hysteresis, $\Delta T$ and volume change, $\Delta V$; the transformation is likely to be of first order [39].

The existence of the low-cubic (sphalerite or B3-form) AgI was questioned by Majumdar and Roy [29]. Burley [12], however, reports the kinetics of the B3 $\rightarrow$ B4 transition in AgI by x-ray diffractometry at high temperature. The structure of the B23 (high-cubic) AgI has also been a subject of interest [22]. Statistical models have been employed to explain the type of one-dimensional polymorphism (polytypism) in AgI [44]. Accordingly, $\mathrm{B} 3$ and $\mathrm{B} 4$ are polytypes of $\mathrm{AgI}$. $\mathrm{CdI}_{2}$ is another example of polytypism.

$\mathrm{AgBr}$ enters into solid solution with $\mathrm{AgI}$ and the structures of the specific phases depend on the composition and temperature $[3,4]$. The solid solutions of $\mathrm{AgI}$ and $\mathrm{AgBr}$ have the $\mathrm{B} 3$ and/or B4 structure up to $\sim 10$ percent $\mathrm{AgBr}$, and with higher percent of $\mathrm{AgBr}$ the $\mathrm{NaCl}$ type of structure (Bl phase) is formed [16, 39]. About 25 percent of AgI seems to enter into solid solution with $\mathrm{AgBr}$ in the Bl-phase. However, the literature data available on the solid solution limits and the range of stability of specific phases are widely different.

Pressure transitions of silver halides with Blstructure have been studied in detail, but there appears to be some uncertainty regarding the exact structures. The most commonly postulated high pressure structure is the $\mathrm{CsCl}$ type (B2) structure $[2,9]$, essentially because of its higher anion-cation coordination. X-ray studies have revealed this to be the case with ionic solids like rubidium and potassium halides. However, with more covalent solids this is not the case. It has been shown by $\mathrm{x}$-ray studies that $\mathrm{AgCl}$ and $\mathrm{AgBr}$ under pressure transform to a cinnabar type of structure (B9) i.e., a tetragonal one [26, 47]. The different phases of $\mathrm{AgI}$ encountered in the high pressure transitions have different structures and ranges of stability $[1,5]$. In the following table the high pressure phases of $\mathrm{AgI}$ are listed along with their structures and stability ranges.

Structure and Stability of Silver Iodide in the High Pressure Area

\begin{tabular}{|c|c|c|c|}
\hline Designation & Structure & Lattice constants & Range of stability \\
\hline I & B23, high cubic & $a=5.074 \AA$ at $443 \mathrm{~K}$ & Stable above $\sim 419 \mathrm{~K}$ and up to $\sim 80 \mathrm{kbar}$. \\
\hline II & B4, wurtzite & $\begin{array}{l}a=4.591 \AA, c=7.498 \AA \\
\quad \text { at } 298 \mathrm{~K} .\end{array}$ & Stable up to $\sim 419 \mathrm{~K}$ and below $\sim 2$ kbar. \\
\hline $\mathrm{II}^{\prime}$ & B3, sphalerite & $a=6.495 \AA$ at $298 \mathrm{~K}$ & Stable below $\sim 413 \mathrm{~K}$ and below $\sim 2 \mathrm{kbar}$. \\
\hline III & $\mathrm{Bl}, \mathrm{NaCl}$ type & $a=6.07$ at $298 \mathrm{~K}$ & Stable up to $\sim 419 \mathrm{~K}$ and above $3-4 \mathrm{kbar}$. \\
\hline IV & Orthorhombic & & Stable below $\sim 320 \mathrm{~K}$ and between $2-4 \mathrm{~kb}$ ar. \\
\hline V & B2. CsCl type & & Stable above $95 \mathrm{kbar}$. \\
\hline
\end{tabular}

Lattice energies of silver halides have been calculated by Mayer [31], Huggins [23], Ladd and Lee [27], Sharma and Madan [45] and recently by Natarajan and Rao [39]. Most of these workers have employed the Born model. Lattice energy calculations have enabled a study of the relative stabilities of the various structures of silver halides and some of their solid solutions [39]. Born model has been employed to explain the pressure transitions in silver halides as well as the thermal transition in silver iodide [39]. Transition pressures have been theoretically determined by Jacob [24] employing the Born model.

Polytypism of Cadmium halides. Both $\mathrm{CdBr}_{2}$ [8] and $\mathrm{CdI}_{2}$ [18a] are known to exhibit polytypism $[32,35,37,44,57$ a]. Single crystal x-ray studies on $\mathrm{CdBr}_{2}$ grown from solution have shown that $6 \mathrm{R}$ is by far the most common polytype of $\mathrm{CdBr}_{2}$.
There are as many as 130 structures for the $\mathrm{CdBr}_{2}$ polytypes [36]; 92 of these belong to the $6 \mathrm{R}$ type; sublimation of $\mathrm{CdBr}_{2}$ also yields the 6R type.

Polytypism in $\mathrm{CdI}_{2}$ has been found to be due to screw dislocations [32]. X-ray diffraction studies show the existence of many polytypes with different stacking sequences [31]. The entire "22 . . . 11" series of structures could be generated by spiral growth from single nonintegral screw dislocations in an "ideal" $4 \mathrm{H}$ structure $[33,34]$. Other known structures not belonging to the "22 ... 11" series could be generated by assuming the presence of two or more cooperative dislocations. These considerations suggest that polytypism is not expected in certain substances because of the nature of their ideal structures. A detailed discussion on polytypism is furnished by Verma and Krishna [57a]. 


\begin{tabular}{|c|}
\hline $\begin{array}{l}\text { Substances and } \\
\text { measurement techniques }\end{array}$ \\
\hline $\begin{array}{l}\text { Zirconium tetrafluoride, } \mathrm{ZrF}_{4} \text { (Mono- } \\
\text { clinic, } \mathrm{C}_{2 \mathrm{~h}}^{6}, a=11.69 \AA, b= \\
9.87 \AA, c=7.64 \AA ; \beta= \\
126^{\circ} 9^{\prime} \text { at } 298 \mathrm{~K} \text { ) }\end{array}$ \\
\hline
\end{tabular}

DTA and heat capacity

\section{Molybdenum hexafluoride, $\mathrm{MoF}_{6}$}

NMR investigations of phase change in $\mathrm{MoF}_{6}$ (temperature dependence of half width of the ${ }^{19} \mathrm{~F}$ line).

Silver Fluoride, $\mathrm{AgF}$ (Fm3m, $a=$ $4.932 \pm 0.003 \AA$ at $295 \mathrm{~K}$ )

$\mathrm{X}$-ray studies at different pressures.

Silver iodide, AgI (B3-AgI, $\mathrm{F} \overline{4} 3 \mathrm{~m}, a=6.495 \AA$ at $298 \mathrm{~K}$; B4-AgI, $\mathrm{P6}_{3} \mathrm{mc}, a=4.592 \AA$, $c=7.510 \AA$ at $298 \mathrm{~K}$ )

Structure of various polymorphs of $\mathrm{AgI}$ by x-ray diffraction.

AgI polymorphism with

DTA, X-ray etc.
$\mathrm{ZrF}_{4}$ undergoes a phase transition at $\sim 680 \mathrm{~K}$. The high temperature form is cubic $(\mathrm{Fm} 3 \mathrm{~m})$ with $a=7.88 \AA$.

Two jumps in half-line-width at $\sim 263 \mathrm{~K}$ and at $\sim 219 \mathrm{~K}$ are ob. served. The jump at $263 \mathrm{~K}$ is due to the phase transition in $\mathrm{MoF}_{6}$ at $\sim 263 \mathrm{~K}$.

Transforms to a new structure (probably B2 or $\mathrm{CsCl}$ ) at $\sim 26$ kbar with $\Delta V=1.64 \mathrm{~cm}^{3} \mathrm{~mol}$; $\Delta S \approx 4.2-5.1$ Joule/mole-deg.

Three modifications of $\mathrm{AgI}$ are known; a low cubic-sphalerite (B3) phase stable upto $410 \mathrm{~K}$, a hexagonal-wurtzite (B4 phase) which is formed when the AgI melt is cooled and a hot cubic (B23) form stable above $420 \mathrm{~K}$. The hot cubic phase has a space centred lattice of I atoms, with $a=5.04 \AA$; Ag ions are distributed over the 30 largest gaps in the I structure.

Sphalerite to wurtzite transformation probably takes place over a wide temperature interval. The transition is associated with a

$\Delta H_{\mathrm{tr}} \sim 100 \mathrm{cal} \cdot \mathrm{mol}^{-1}$. The energy of activation is $\sim 10.3 \pm$ $0.8 \mathrm{kcal} \cdot \mathrm{mol}^{-1}$. The low temperature phases of AgI transform to the B23 phase at $\sim 420$ $\mathrm{K}$ with a $\Delta H_{\text {tr }}$ of about 1600 $\mathrm{cal} \cdot \mathrm{mol}^{-1}$.
Heat capacity measurements in the range 5-307 $\mathrm{K}$ do not indicate any anomaly. DTA indicates a transition at $\sim 680 \mathrm{~K}$.

The spectra of the two modifications of $\mathrm{MoF}_{6}$ are discussed in relation to the different types of Mo-F bonds and other symmetry considerations.

The lattice parameter of the B2 phase (extrapolated to $l \mathrm{bar}$ ) is $2.99 \AA$.

The structure of B23-AgI was suggested to be tetragonal, but later work confirmed that the structure is an average between two structures of space groups $\operatorname{Im} 3 \mathrm{~m}$ and $I \overline{4} \mathrm{~m} 2$. The structure of AgI precipitated from solution depends on the presence of excess of $\mathrm{I}^{-}$or $\mathrm{Ag}^{+}$as well as the rate of precipitation.

The sphalerite-wurtzite transition is more likely to be an athermal higher order transition. Burley's [12] observation, however, suggests that the transition is a firstorder one. Presence of iodine vapor seems to facilitate the B3 $\rightarrow$ B4 change at $\sim 393 \mathrm{~K}$. The $T_{t}$ of $\mathrm{B} 3 /$ $\mathrm{B} 4 \rightarrow \mathrm{B} 23$ transition also depends on the partial pressure of iodine. $\mathrm{B} 3 \rightarrow \mathrm{B} 4$ transition is not seen by $\mathrm{x}$-ray diffraction or DTA when small heating rates are employed. The $\mathrm{B} 3 / \mathrm{B} 4 \rightarrow \mathrm{B} 23$ transition is a well defined first order transition.
$[13 \mathrm{a}, 42 \mathrm{a}$, 58a].

[1].

[18b].

$[6,7,10,19$, $21,22,28$, $52,60]$.

$[11,12,22$, $29,30,39$, $43,58,59$ 54]. 
4d Transition Metal Halides - Continued

\begin{tabular}{|c|c|c|c|}
\hline $\begin{array}{l}\text { Substances and } \\
\text { measurement techniques }\end{array}$ & Data & Remarks & References \\
\hline $\begin{array}{l}\text { B3/B4 } \rightarrow \text { B23 transition inves- } \\
\text { tigated by emf method. }\end{array}$ & $\begin{array}{l}\text { The emf of the cell, } \\
\qquad \mathrm{Ag}(\mathrm{s})|\mathrm{AgI}(\mathrm{s})| \begin{array}{l}\mathrm{CaCl}_{2} \cdot 6 \mathrm{H}_{2} \mathrm{O} \mid \mathrm{Pb}(\mathrm{s}) \\
\mathrm{AgI}\left(\mathrm{C}_{1}\right) \\
\mathrm{PbI}\left(\mathrm{C}_{2}\right)\end{array} \mid\end{array}$ & & {$[14,15]$} \\
\hline Electrical Conductivity & The high ionic conductivity of the & The $\sigma$ versus $1 / T$ plots seem to sug- & {$[20,38$. } \\
\hline
\end{tabular}

hot cubic (B23) phase above (420

$\mathrm{K})$ of $\mathrm{AgI}$ is in accordance with a random orientation of silver ions in the lattice. $E_{\text {u }}$ for conduction in B3 and B4 phases are $\sim 0.2$ and $\sim 0.6 \mathrm{eV}$ respectively.

X-ray and DTA study of the effect of $\mathrm{AgBr}$ on the $\mathrm{AgI}$ transition.

Silver chloride, AgCl (Fm3m, $a=$ $5.5491 \AA$ at $299 \mathrm{~K})$ and Silver bromide $\mathrm{AgBr}(\mathrm{Fm} 3 \mathrm{~m}, a=5.7745$ $\AA$ at $299 \mathrm{~K}$ ).

$\mathrm{X}$-ray diffraction of $\mathrm{AgCl}$ supported in amorphous boron vessel and subjected to quasi-hydrostatic pressures up to 150 kbar.

X-ray diffraction

Volumetric method

Optical observation on single crystals.

Pressure-temperature curves for $\mathrm{AgCl}$ and $\mathrm{AgBr}$ upto $60 \mathrm{kbar}$ and $1073 \mathrm{~K}$.

\section{Pressure transitions in AgI:}

High pressure transition in AgI investigated by $x$-rays.

High pressure transition of AgI upto $60 \mathrm{kbar}$ and $\mathrm{x}$-ray investi‡ation.
AgBr lowers the $T_{t}$ to $\sim 493 \mathrm{~K}$ at $\sim 10 \% \mathrm{AgBr}$. This seems to be the solid solution limit in the low and high temperature phases. The specific phases of the solid solutions depend on the temperature as well as composition.

At $\sim 25$ kbar, $\Delta V$ is $\sim-0.9 V_{0}$ where $V_{0}$ is the volume at $298 \mathrm{~K}$ and $1 \mathrm{~atm}$. At higher pressures, the structure is shown to be that of $\mathrm{Hg}_{2} \mathrm{Cl}_{2} ; a=3.92 \AA, c=9.03 \AA$

Both $\mathrm{AgCl}$ and $\mathrm{AgBr}$ do not transform to a B2 or CsCl-type structure. The high pressure phase in both the cases is of B9 type. For $\mathrm{AgCl}, a=4.06 \AA, c=7.02 \AA$; $c / a=1.73 . \Delta V / V_{0} \sim 8 \%$ at the transition. For $\mathrm{AgBr}, a=4.0 \AA$, $c=7.15 \AA ; c / a=1.77$.

$P_{T} \sim 88 \mathrm{kbar}$ for $\mathrm{AgCl} ; P_{T} \sim 84$ kbar for $\mathrm{AgBr}$.

$P_{T} \sim 90 \mathrm{kbar}$ for $\mathrm{AgCl}, P_{T} \sim 86$ kbar for $\mathrm{AgBr}$.

No change was observed in both the halides.

At $\sim 3$ kbar the cell symmetry seem to belony to orthorhombic one. Moore and Kasper [37], however, consider the 3 kbar phase as tetragonal or pseudotetragonal.

At $\sim 60 \mathrm{kbar}, \mathrm{AgI}$ has the $\mathrm{NaCl}(\mathrm{Bl})$ structure with $a=6.067 \AA$. and $c / a=2.30$. gest the transition of $\mathrm{B} 3 \rightarrow \mathrm{B} 4$ to occur at $\sim 410 \mathrm{~K}$.

$39,53]$.

$\mathrm{AgBr}$ and $\mathrm{AgI}$ form an eutectic at $\sim 68 \% \mathrm{AgBr}$ with a eutectic temperature of $\sim 613 \mathrm{~K}$.

$[3,4,16$,

$39,51,55]$.
This is the first experimental evidence where a tetragonal structure is assigned to the $\mathrm{AgCl}$ high pressure phase.

The tetragonal structure is stabilized due to overlap of electron orbitals resulting in the formation of two highly covalent collinear bonds. The $\mathrm{Hg}_{2} \mathrm{Cl}_{2}$ type structure assigned to $\mathrm{AgCl}$ at high pressure is questioned.

The high pressure phases were con. sidered to be of B2 structure.

The pressure was not enough to detect the appearance of the high pressure phases.

Stability range of six polymorphs is indicated in a $P-T$ diagram. The phase at $3 \mathrm{kbar}$ is likely to be related to the $\mathrm{NaCl}$ structure, according to Moore and Kasper. 
4d Transition Metal Halides - Continued

\begin{tabular}{c}
\hline \hline $\begin{array}{c}\text { Substances and } \\
\text { measurement techniques }\end{array}$ \\
\hline High pressure transition in AgI up
\end{tabular}

High pressure transition in $\mathrm{AgI}$ up to $\sim 120$ kbar; examination by microscopic and $\mathrm{x}$-ray diffraction techniques.

High pressure transformation in AgI up to $100 \mathrm{kbar}$, and $\mathrm{x}$-ray investigation.

High pressure transition in AgI by electrical conductivity measurements as a function of pressure up to $100 \mathrm{kbar}$.

Cadmium fluoride, $\mathrm{CdF}_{2}$

X-ray study up to $160 \mathrm{kbar}$
Cadmium bromide, $\mathrm{CdBr}_{2}$ (hexa- gonal, $\mathrm{R} \overline{3} \mathrm{~m}, a=3.957 \AA$, $c=18.668 \AA$ )

$\mathrm{X}$-ray study of $\mathrm{CdBr}$ 2 polytypic structures.

Cadmium iodide, $\mathrm{CdI}_{2}$ (hexagonal,

$$
\mathrm{P} \overline{3} \mathrm{ml}, a=4.24 \AA, c=6.835 \AA \text { ) }
$$

$\mathrm{X}$-ray and interferometric studies of $\mathrm{CdI}_{2}$ polytypism in relation to crystal growth.
Conductivity increases with pressure in the low pressure phase (stable upto $2.5 \mathrm{kbar}$ ) and then decreases in the two high pressure phases. The increase in the low pressure phase is in accordance with - ve thermal expansion. A reversal of the slope above $45 \mathrm{kbar}$ in the $(\mathrm{NaCl}$ type) cubic phase is explained in terms of the formation of $\mathrm{I}_{3}$ ions.

$\mathrm{CdF}_{2}$ transforms to the $\alpha-\mathrm{PbCl}_{2}$ structure reversibly around 60 kbar; $a=3.368 \AA ; b=5.690 \AA$, $c=6.730 \AA$ (at 120 kbar?).

An x-ray study of solution grown $\mathrm{CdBr}_{2}$ crystals has revealed that $6 \mathrm{R}$ is by far the most common polytype. Other structures encountered include, $4 \mathrm{H}, 12 \mathrm{H}$ (or $12 \mathrm{R}$ ), $4 \mathrm{OH}$ (or $\sim 12 \mathrm{OR}$ ) and some disordered structures.

A combined optical and $x$-ray diffraction study was made of polytypism of $\mathrm{CdI}_{2}$ which grow by a dislocation mechanism. For the $2 \mathrm{H}$ and $4 \mathrm{H}$ structure types, a correlation between spiral step height and $x$-ray unit cell is found; with larger unit-cells no such correlation was observed. This is contrary to expectations on the basis of Frank's theory and can not be fully explained.

\begin{tabular}{|c|c|c}
\hline \multicolumn{1}{|c|}{ Remarks } & References \\
\hline $\begin{array}{c}\text { alectrical conductivity measure- } \\
\text { ments suggest that the transition } \\
\text { involves a significant change to } \\
\text { more covalent bonding. }\end{array}$ & {$[2,47]$.} \\
2 &
\end{tabular}

The $3 \mathrm{kbar}$ phase is yet to be identified exactly. There is a possible mutual transformation between B3, B4 and the ' 3 kbar' phases by a displacive mechanism rather than a reconstructive mechanism. This immediately suggests that B3, B4 and the $3 \mathrm{kbar}$ phases are polytypes of $\mathrm{AgI}$ and should be very similar to each other energywise and structurewise.

Riggleman and Drickamer [42]

however find a large increase in conductivity at $\sim 97 \mathrm{kbar}$ indicating a transformation.
Sublimation of $\mathrm{CdBr}_{2}$ does not produce any polytype other than $6 \mathrm{R}$. The relation between screw dislocations and polytypism is discussed.

Thirteen new polytypes of $\mathrm{CdI}_{2}$ are described. This number probably may be eighteen. In addition, several crystals resembling $2 \mathrm{H}$ and $4 \mathrm{H}$ types are also reported. [15a]. 
$4 d$ Transition Metal Halides - Continued

\begin{tabular}{|c|c|c|c|}
\hline $\begin{array}{l}\text { Substances and } \\
\text { measurement techniques }\end{array}$ & Data & Remarks & References \\
\hline $\begin{array}{l}\text { Investigation of the rhombohedral } \\
\text { polytypes of } \mathrm{CdI}_{2} \text { and the trans- } \\
\text { formation to hexagonal polytypes. }\end{array}$ & $\begin{array}{l}\text { Two rhombohedral polytypes of } \\
\text { CdI } \mathrm{I}_{2}, 30 \mathrm{R} \text { and } 42 \mathrm{R} \text {, grown from } \\
\text { vapour phase are reported. Their } \\
\text { complete structures are }(221212)_{3} \\
\text { and }(22221212)_{3} \text { respectively. }\end{array}$ & $\begin{array}{l}\text { Each of these polytypes occurs in } \\
\text { syntactic coalescence with a hexa- } \\
\text { gonal polytype having the same cell } \\
\text { dimensions as the rhombohedral } \\
\text { one showing that the lattice was } \\
\text { transformed from hexagonal to } \\
\text { rhombohedral or vice versa during } \\
\text { crystal growth. }\end{array}$ & [13]. \\
\hline New polytypes of $\mathrm{CdI}_{2}$ & $\begin{array}{l}\text { A } 28 \text { layered new polytype of } \mathrm{CdI}_{2} \text {, } \\
\text { designated as } 28 \mathrm{Hc} \text { with unit } \\
\text { cell dimensions, } a=4.24 \AA \text {, } \\
c=95.69 \AA \text { has been described. } \\
\text { The detailed atomic structure has } \\
\text { been worked out and its zig zag } \\
\text { sequence is found to be } \\
2222222222221111 \text {. Another } \\
\text { anomalous polytype of } \mathrm{CdI}_{2} \text { is } \\
26 \mathrm{Hc} \text {. }\end{array}$ & 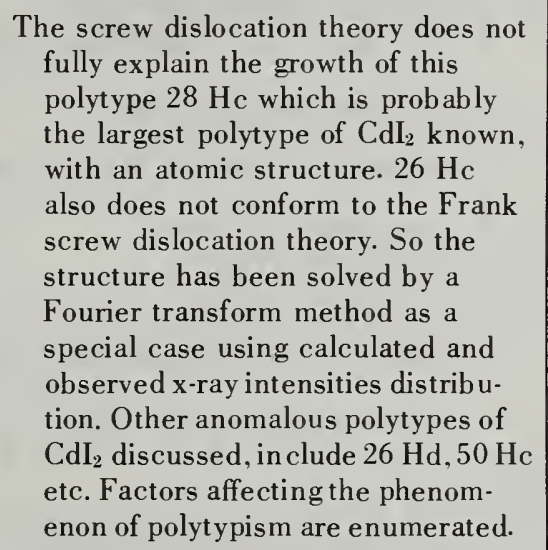 & {$[48,49,50]$. } \\
\hline $\begin{array}{l}\text { X-ray investigation of polytypism as } \\
\text { a higher order transformation. }\end{array}$ & $\begin{array}{l}\text { Interaction energies for the known } \\
\text { polytypic structures are calculated } \\
\text { for } \mathrm{CdI}_{2} \text { on the basis of Schneer's } \\
\text { theory of polytypism. Almost } \\
\text { all polytypes are characterised by } \\
\text { a maximum number of unlike } \\
\text { interaction contacts. }\end{array}$ & $\begin{array}{l}\text { This aspect was confirmed, experimen- } \\
\text { tally by } \mathrm{x} \text {-rays, which suggests a } \\
\text { gradual transition from } 3 \mathrm{C} \text { to } 2 \mathrm{H} \\
\text { structures. }\end{array}$ & {$[41]$} \\
\hline $\begin{array}{l}\text { X-ray study of the phenomenon of } \\
\text { polytypism in } \mathrm{CdI}_{2} \text {. }\end{array}$ & $\begin{array}{l}\text { X-ray oscillation photographs of } \\
\mathrm{CdI}_{2} \text { crystals reveal the existence } \\
\text { of two different structures in } \\
\text { parallel orientation on the same } \\
\text { face of a crystal. This helped in } \\
\text { understanding the frequent obser- } \\
\text { vation of the syntactic coalescence } \\
\text { of two more polytypes in the same } \\
\text { crystal as a phenomenon of } \\
\text { epitaxial growth. }\end{array}$ & $\begin{array}{l}\text { Prolonged microscopic observations } \\
\text { have shown that } 3 \text {-dimensional } \\
\text { nuclei keep on forming at preferred } \\
\text { sites during the growth of crystals. } \\
\text { Subsequent } x \text {-ray investigation shows } \\
\text { that it leads to the formation of a new } \\
\text { polytypic structure of lower free- } \\
\text { energy. }\end{array}$ & {$[25]$.} \\
\hline
\end{tabular}

\section{References}

[1] Adams, L. H., and Davis, B. L., Am. J. Sci. 263, 359 (1965).

[1a] Afanasév. M. L.. Gabuda, S. P., Lundin, A. G.. Opalovskii, A. A., and Khaldoyanidi. K. A., Izv. Sib. Otd. Akad. Nauk. SSSR, Ser. khim. Nauk. 4, 18 (1968).

[2] van Valkenberær, Alvin, Jr., Rev. Sci, Instruments, 33, 1462 (1962).

[3] Barth, T., and Lunde, G., Norsk. Geol. Tids. 8, 293 (1925).

[4] Barth, T., and Lunde, G., Z. Physik. Chem. 122, 293 (1926).

[5] Bassett. W. A., and Takahashi, T.. Am. Mineralogist 50 (10), 1576 (1965).

[6] Berry, C. R.. Phys. Rev. 161, 848 (1967).

[7] Bijvoet, J. M.. and Nieuwenkamp, W., Z. Krist. 86, 466 (1933).

[8] Blocw, R., and Möller, H., Z. Physik. Chem. Vol A, 152, 245 (1931).

[9] Bridgman, P. W., Proc. Am. Acad. Arts. Sci. 1, 76 (1945).

[10] Burley G.. J. Chem. Phys. 38. 2807 (1963).

[11] Burley. G., Am. Mineralogist 48, 1266 (1963).
[12] Burley, G.. J. Phys. Chem. 68, 1111 (1964).

[13] Chada, G. K., and Trigunayat, G. C., Acta. Cryst. 22, 573 (1967).

[13a] Chŕetien, A., and Gaudreau, B.. Compt. rend. 246, 2266 (1958).

[14] Cohen. E., and Joss, E. J., J. Am. Chem. Soc. 50, 727 (1928).

[15] Cohen, E., and Joss, E. J., Verslag Akad. Wetenschappen Amsterdam, 36,980 (1927).

[15a] Dandekar, D. P.. and Jamieson, J. C.. personal communication (1971).

[16] de Cugnac, A., Chateau, H.. and Pouradier, J., Compt. rend. Acad. Sci., Paris, Ser. C 14, 264 (1967).

[17] Davis. B. L., and Adams, L. H.. Science 146, 519 (1964).

[18] Deaton, D. C.. J. Appl. Phys. 36 (4), 1500 (1965).

[18a] Forty. A. J., Phil. Mag. 43, 377 (1952).

[18b] Halleck, P. M., Jamieson. J. C. and Pistorius, C. W. F. T. personal communication (1971); J. Phys. Chem. Solids (in print). 
[19] Helmholtz. L.. J. Chem. Phys, 3, 740 (1935).

[20] Hevesy, G. V., Z. Physik. Chem. 127, 401 (1927).

[21] Hoshino. S., and Miyake, S., Science et. inds. phot. 25, 154 (1954).

[22] Hoshino. S., J. Phys. Soc. Japan 12, 315 (1957).

[23] Hugrins, M. L.. in Phase Transformations in Solids, Ed. R. Smoluchovski (John Wiley \& Sons., Inc., New York, 1951).

[24] Jacobs, R: B., Phys. Rev. 54, 468 (1938).

[25] Jain, R. K., and Triqunayat, G. C., J. Cryst. Growth 2 (5), 267 (1968).

[26] Jamieson, J. C., and Lawson. A. W.. J. Appl. Phys. 33; 776 (1962)

[27] Ladd. M. F. C.. and Lee. W. H., J. Inorg. and Nuclear Chem. 11, 264 (1959).

[28] Livitzkii. V., Ukrain. Khem. Zhur 10, 283 (1935).

[29] Majumdar. A. J., and Roy. R., J. Phys. Chem. 63, 1858 (1959).

[30] Manson. J. E.. J. Phys. Chem. 60,806 (1956).

[31] Mayer. J. E.. J. Chem. Phys. 1, 327 (1933).

[32] Mitchell, R. S., Phil. Mag. 45, 1093 (1954); ibid. 46, 1141 (1955).

[33] Mitchell, R. S.. Z. Krist. 108, 296 (1956).

[34] Mitchell. R. S. Z. Krist. 108, 341 (1957).

[35] Mitchell, R. S. Nature 182, 337 (1958).

[36] Mitchell. R. S. Z. Krist. 11 7,309 (1962).

[37] Moore, M. J.. and Kasper, J. S.. J. Chem. Phys. 48, 2446 (1968).

[38] Mrqudich, J. N.. J. Electrochem. Soc. 107, 475 (1960).

[39] Natarajan, M., and Rao. C. N. R., J. Chem. Soc. (London), A, 3087 (1970).

[40] Piermarini, G. J., and Weir, C. E., J. Res. Nat. Bur. Stand. (U.S.) A66, (Phys. and Chem.), No. 4, 325 (1962).

[41] Rai, K. N., and Krishna, P., Indian J. Pure and Appl. Phys. 6, 118 (1968).

[42] Rixgleman, B. M., and Drickamer, H. G., J. Chem. Phys. 38, 2721 (1963). [42a] Robbins, G. D., Thoma, R. E., and Insley, H., J. Inorg. Nucl. Chem. 27,559 (1965).

[43] Schneer, C. J., and Whiting, W., Jr., Am. Mineralogist 4.8, $737(1963)$.

[44] Schneer, C. J., Acta. Cryst. 8, 279 (1955).

[45] Sharma, M. N., and Madan, M. P., Indian J. Physics 38. 305 (1964).

[46] Shock R. N., and Katz, S., J. Chem. Phys. 48, 2094 (1968).

[47] Shock, R. N., and Jamieson, J. C., J. Phys. Chem. Solids 30, 1527 (1969).

[48] Srivastava, O. N., and Verma, A. R., Proc. Nucl. Phys. Solid State Symp., Chandigarh, India, Part B, 362 (1964).

[49] Srivastava, O. N., and Verma, A. R., Acta. Cryst. 17, 260 (1964).

[50] Srivastava, O. N., and Verma, A. R., Acta. Cryst. 19, 56 (1965).

[51] Stasiw O., and Teltow, J., Z. anorg. Chem. 259, 143 (1949).

[52] Strock, L. W., Z. physik. chem. B25, 441 (1934).

[53] Takahashi, T., Katusmi, K., and Osamu, Y., J. Electrochem. Soc., 116,357 (1969).

[54] Tamman, G..,Z. Physik. chem. 75, 733 (through Chemical Abstracts, 5, 1219).

[55] Tamman, G., Z. anorg. chem. 91, 263 (1915).

[56] Trigunayat, G. C., and Verma, A. R., Acta. Cryst. 15, 499 (1962)

[57] Verma, A. R., J. Sci. Ind. Res. 25, 487 (1966).

[57a] Verma, A. R., and Krishna, P., Polymorphism and Polytypism in Crystals (John Wiley, 1966).

[58] Weiss, K., and Vermaas, P. A., Z. physik. chem. 44, 372 (1965).

[58a] Westrum, E. F., Jr., J. Chem. Eng. Data 10, 140 (1965).

[59] Winkler, H. G. F., Z. anorg. u. allgem. chem. 276, 169 (1954).

[60] Yamada, K., Bull. Soc. Sci. Phot. Japan No. 11, 1 (1961).

\section{5d Transition Metal Halides}

$\mathrm{OsCl}_{4}$ is known to exist in two polymorphic forms [15]. Transitions in mercury halides are also known. Both mercuric chloride and mercuric bromide are orthorhombic at room temperature. No detailed phase transformation data are available for these two halides. Some information regarding the isomorphic relations of these halides as well as their mixed salts are available [11, 12].

Red mercuric iodide is tetragonal and is the stable phase at room temperature. The change of red $\mathrm{HgI}_{2}$ to the orthorhombic yellow variety takes place reversibly at $\sim 403 \mathrm{~K}$. The effect of state of aggregation [1], heating rate $[3,5]$ and the presence of other halides [10] on the $T_{t}$ have been studied. The theory of dynamic allotropy has been found to be applicable to the $\mathrm{HgI}_{2}$ transition [5].
The kinetics of the tetragonal-orthorhombic transition in $\mathrm{HgI}_{2}$ has been studied by Baram [2] and others $[3,6]$. The mechanism of the transition [14] has been discussed by Johansson [7], from considerations of the structures of the two modifications. The $\mathrm{HgI}_{2}$ transition has been considered as an example of a topochemical reaction which takes place in the inner or outer fields of force of the crystalline matter $[8,9]$. The high temperature yellow $\mathrm{HgI}_{2}$ could be stabilized on $\mathrm{Al}_{2} \mathrm{O}_{3}$ base provided the sample is free from moisture [17]. Recently, the $\mathrm{HgI}_{2}$ transition has been studied with low frequency laser excited Raman spectroscopy [13]. A third variety of $\mathrm{HgI}_{2}$ has been reported [16]. A pressure transition in $\mathrm{HgI}_{2}$ was reported by Bridgman [4]. 


\begin{tabular}{|c|c|c|c|}
\hline $\begin{array}{l}\text { Substances and measurement } \\
\text { techniques }\end{array}$ & Data & Remarks & References \\
\hline \multicolumn{4}{|l|}{$\begin{array}{l}\text { Osmium tetrachloride. } \mathrm{OsCl}_{4} \\
\quad \text { (cubic. } a=9.5 \AA \text { at } 298 \mathrm{~K} \text { ) }\end{array}$} \\
\hline X-ray and marnetic measurements & $\begin{array}{l}\text { A solution of } \mathrm{OsO}_{4} \text { when refluxed } \\
\text { with } \mathrm{SOCl}_{4} \text { yields the cubic form. } \\
\text { This is a dark-brown solid. It } \\
\text { belongs to the space-yroup } \\
\mathrm{O}^{6}-\mathrm{P}_{4}[32] \text { or } \mathrm{O}^{7}-\mathrm{P}_{4}[32] \text {. } \\
\mathrm{OsO}_{4} \text { and } \mathrm{CCl}_{4} \text { when reacted in a } \\
\text { sealed tube at } \sim 743 \mathrm{~K} \text {. yield the } \\
\text { hish temperature orthorhombic } \\
\text { form }(a=12.08 \AA . b=11.96 \AA \\
\text { and } c=11.68 \AA) \text {. }\end{array}$ & $\begin{array}{l}\text { Both the low and high temperature } \\
\text { forms are paramagnetic and display } \\
\text { magnetic susceptibilities as a result } \\
\text { of strong spin-orbit coupling: the } \\
\text { high temperature form exhibits the } \\
\text { temperature dependent magnetic } \\
\text { susceptibility. }\end{array}$ & {$[15]$} \\
\hline \multicolumn{4}{|l|}{$\begin{array}{l}\text { Mercuric iodide. } \mathrm{H}_{\longleftarrow} \mathrm{I}_{2} \text { (Tetragonal. } \\
\qquad a=4.39 \AA . c=12.38 \AA \text { at } 296 \mathrm{~K} \text { ). }\end{array}$} \\
\hline Factors affecting the $T_{t}$ of $\mathrm{HgI}_{2}$ & $\begin{array}{l}\text { A freshly prepared sol. of } \mathrm{HgI}_{2} \\
\text { transforms at a lower tempera- } \\
\text { ture. The } T_{t} \text { increases as precipit- } \\
\text { ation continues. } T_{t} \text { is also affected } \\
\text { by other halides such as } \mathrm{HgCl}_{2}, \\
\mathrm{H} \mathrm{Br} \text { etc. }\end{array}$ & $\begin{array}{l}\text { The yellow sol. when dried is covered } \\
\text { with a red layer which disappears } \\
\text { slowly. }\end{array}$ & {$[1,10]$. } \\
\hline Dilatometry and kinetics & $\begin{array}{l}\text { The transition from red to yellow } \\
\text { variety takes place at } \sim 400 \mathrm{~K} \text {. } \\
\text { The dilatometric studies indicate } \\
\text { that the transition is autocata- } \\
\text { lytic in both the directions. } \\
\text { Quenching experiments indicate } \\
\text { that the theory of dynamic allo- } \\
\text { tropy is applicable to } \mathrm{H}_{\leftarrow} \mathrm{I}_{2} \\
\text { transition. } \\
\Delta V \sim 0.0028 \mathrm{~cm}^{3} \mathrm{~g}^{-1} \text {. }\end{array}$ & $\begin{array}{l}\text { Transition rates in the range } 400- \\
406 \mathrm{~K} \text { are almost the same in the } \\
\text { presence of air, } \mathrm{CO}_{2} \text { or nitrogen. } \\
\text { However, presence of hydrogren or } \\
\text { oxygen has a definite effect on the } \\
\text { speed of the conversion of yellow to } \\
\text { red form. An inconclusive evidence } \\
\text { for a white modification of } \mathrm{HgI}_{2} \text { is } \\
\text { also mentioned. }\end{array}$ & {$[2,3,5,6,8,9]$. } \\
\hline $\begin{array}{l}\text { Low frequency laser Raman } \\
\text { spectra. }\end{array}$ & $\begin{array}{l}\text { Raman bands for red } \mathrm{HgI}_{2} \text { are at } \\
17.5 .29 \text { and } 114 \mathrm{~cm}^{-1} \text { : in addition. } \\
\text { weaker bands are seen at } 46,142, \\
\text { and } 246 \mathrm{~cm}^{-1} \text {. For yellow } \mathrm{HgI} \text {, } \\
\text { stronger bands are at } 37,41 \text {, and } \\
138 \mathrm{~cm}^{-1} \text { : a weaker band is seen } \\
\text { at } \sim 278 \mathrm{~cm}^{-1} \text {. }\end{array}$ & $\begin{array}{l}\text { Marked changes in the spectra were } \\
\text { attributed to changes in crystal } \\
\text { structure. }\end{array}$ & [13]. \\
\hline
\end{tabular}

\section{References}

[1] Balarev, D., Chemie 47, 27 (1952).

[2] Baram, O. M., ukrain. khim. Zhur. 22, 137 (1956).

[3] Benton, A. F., and Cool, R. D., J. Phys. Chem. 35, 1762 (1931).

[4] Bridgman, P. W., Proc. Am. Acad. Arts Sci. 51, 55 (1915).

[5] Damiens, A., compt. rend. 177, 816 (1923).

[6] Eade, D. G., and Hartshorne, N. H., J. Chem. Soc. 1636 (1938).

[7] Johansson, G., Arkiv Kemi 8, 153 (1955).

[8] Kohlscüutter, H. W., kolloid chem. Beihefte 24, 319 (1927).

[9] Kohlscüutter, V., kolloid-Z 42, 254 (1927).

[10] Losana, L., Gazz. Chim. ital. 56, 301 (1926).
[11] Luczizkii, W., Mem. Soc. Nat. Kiew. 20, 191 (through Chemical Abstracts. 1, 2849²).

[12] Luczizkii, V. I., Z. Krist. Min. 46, 297 (through Chemical Abstracts, 6, $57^{9}$ ).

[13] Melveger, A. J., Khanna, R. K.. Guscott, B. R., and Lippincott, E. R., Inorg. Chem. 7, 1630 (1968).

[14] Newkirk, J. B., Acta. Met. 4, 316 (1956).

[15] Paul, M., Z. Naturforsch 24, 200 (1969).

[16] Seiskind, M., Michel, P., and Grun, J. B., J. Chim. Phys. 56, 858 (1959).

[17] Zeitlin, H., and Goya, H., Nature 183, 1041 (1959).

\section{Rare-Earth Trifluorides}

The crystal structures of some of the rare-earth fluorides like $\mathrm{SmF}_{3}, \mathrm{EuF}_{3}, \mathrm{HoF}_{3}$, and $\mathrm{TmF}_{3}$ depend on the method of preparation [2]. The fluorides can thus exist in a hexagonal structure or an orthorhombic one. $\mathrm{YF}_{3}$ is orthorhombic at room temperature. A cubic modification of $\mathrm{YF}_{3}$ reported by 
Nowachi [1] has not been reprodıcible. The preparation of the various fluorides and their crystal dimensions have been reported by Zalkin and Templeton [2].

The hexagonal trifluoride seems to be the only stable form for elements from lanthanum to neodymium. It is likely that it can be produced under proper conditions for the rest of the rare-earth elements and also yttrium, although this has not been achieved in several cases. The data on $\mathrm{LnF}_{3}$ structures are best understood if only the hexagonal form is stable at elevated temperatures even though it may be precipitated from solution under certain conditions because of greater ease of crystal nucleation and growth.

\section{References}

[1] Nowacki. W.. Z. krist. 100, 242 (1938).

[2] Zalkin, A., and Templeton, D. H., J. Am. Chem. Soc. 75, 2453 (1953).

\section{Inert Gas Halides}

Xenon fluorides $\left(\mathrm{XeF}_{2}, \mathrm{XeF}_{4}, \mathrm{XeF}_{6}\right.$, etc.) have been well characterized in the literature. Two forms of $\mathrm{XeF}_{4}$ have been reported from $\mathrm{x}$-ray studies. $\mathrm{XeF}_{6}$ has been found to exhibit interesting thermal properties [3]. Heat capacity measurements have indicated the existence of two phase transitions [3], in the range 200-300 K. The crystal structures of $\mathrm{t}$ wo $\mathrm{XeF}_{6}$ phases have been reported [1].

Inert Gas Halides

\begin{tabular}{|c|c|c|c|}
\hline $\begin{array}{c}\text { Substances and measurement } \\
\text { techniques }\end{array}$ & Data & Remarks & References \\
\hline \multicolumn{4}{|l|}{ Xenon tetrafluoride, $\mathrm{XeF}_{4}$} \\
\hline \multicolumn{4}{|l|}{ Xenon hexafluoride, $\mathrm{XeF}_{6}$} \\
\hline Calorimetry & $\begin{array}{l}\text { Very larige specific heat anomalies } \\
\text { are observed in the regions } \\
241-261 \mathrm{~K} \text { and } 288-297 \mathrm{~K} \text {. }\end{array}$ & $\begin{array}{l}\text { The anomalies are probably due to } \\
\text { slow phase transitions. }\end{array}$ & {$[3]$.} \\
\hline
\end{tabular}

\section{References}

[1] Agron, P. A.. Johnson. C. K.. and I.evy. H. A., Inore. Nucl. Chem. Letters 1, 145 (1965).

[2] Burns. J. H.. J. Phys. Chem. 67, 536 (1963).

[3] Malm. J. G.. Schreiner. F.. and Osborne, D. W.. Inorer. Nucl. Chem. Letters 1, 97 (1965).
[4] Siegrel. S., and Gerbert, E., J. Am. Chem. Soc. 85, 240 (1963).

[5] Templeton, D. H., Zalkin, A., Forrester, J. D.. and Willianson. S. M., J. Am. Chem. Soc. 85, 242 (1963). 


\section{Halogens}

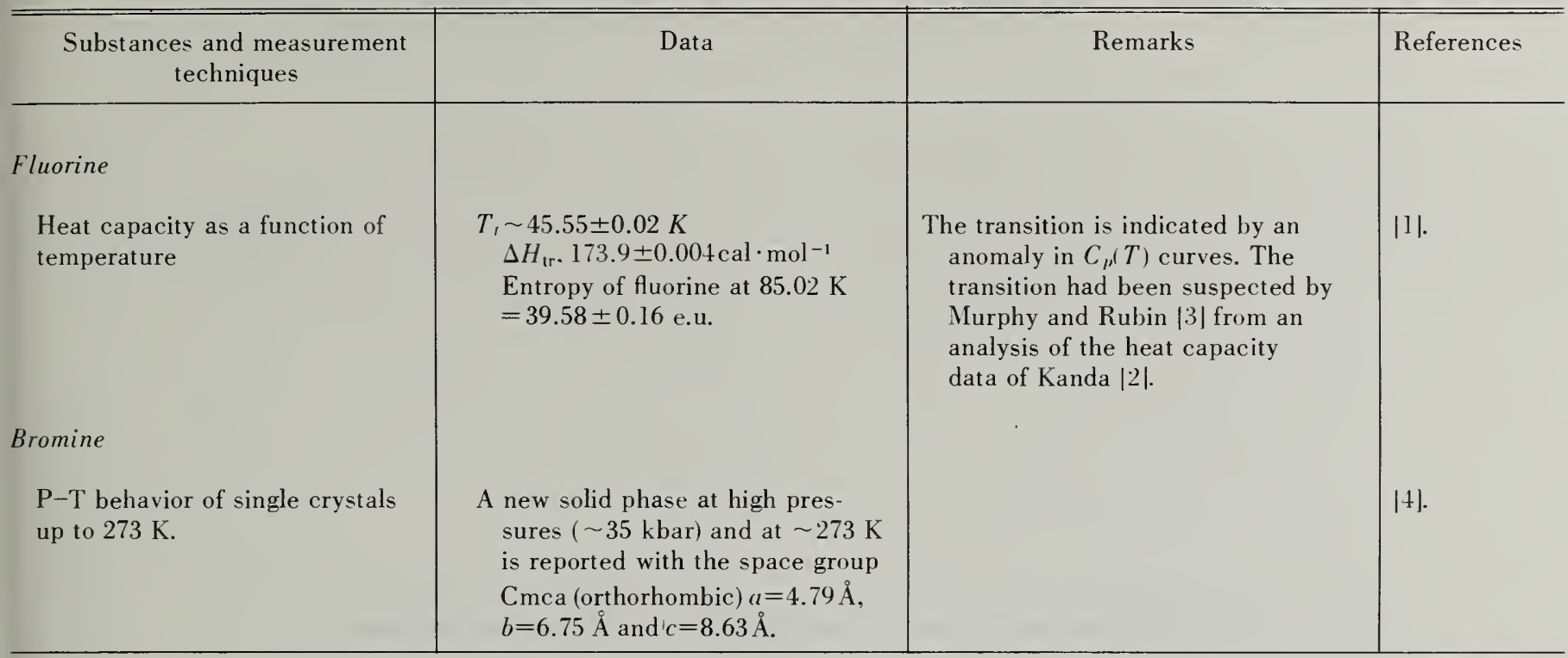

\section{References}

[1] Hu, J. H., White, D., and Johnston, H. L., J. Am. Chem. Soc. 75, 5642 (1953).

[2] Kanda, E.. Bull. Chem. Soc. Japan, 12,473 (1937).
[3] Murphy, G. M., and Rubin, E., J. Chem. Phys. 20, 1179 (1952).

14] Wier. C. E.. Piermarini, G. J., and Block. S., J. Chem. Phys. 50. 2089 (1969). 



\section{Announcement of New Publications on Standard Reference Data}

Superintendent of Documents.

Government Printing Office,

Wa shington, D.C. 20402

Dear Sir:

Please add my name to the announcement list of new publications to be issued in the series: National Standard Reference Data Series - National Bureau of Standards.

Name

Company

Address:

City_ State___ Zip Code

(Notification Key N337) 



\section{Publications in the National Standard Reference Data Series National Bureau of Standards}

You may use this listing as your order form by checking the proper box of the publication(s) you desire or by providing the full identification of the publication you wish to purchase. The full letter symbols with each publication number and full title of the publication and author must be given in your order, e.g. NSRDS - NBS - 21, Kinetic Data on Gas Phase Unimolecular Reactions, by S. W. Benson and H. E. O’Neal.

Pay for publications by check, money order, or Superintendent of Documents coupons or deposit account. Make checks and money orders payable to Superintendent of Documents. Foreign remittances should be

NSRDS-NBS 1, National Standard Reference Data System-Plan of Operation, by E. L. Brady and M. B. Wallenstein, 1964 (15 cents), SD Catalog No. C13.48:1.

NSRDS-NBS 2, Thermal Properties of Aqueous Uni-univalent Electrolytes, by V. B. Parker, 1965 (45 cents), SD Catalog No. C13.48:2. NSRDS-NBS 3, Sec. 1, Selected Tables of Atomic Spectra, Atomic Energy Levels and Multiplet Tables, Si II, Si III, Si IV, by C. E. Moore, 1965 (35 cents), SD Catalog No. C13.48:3/Sec.1.

NSRDS-NBS 3, Sec. 2, Selected Tables of Atomic Spectra, Atomic Energy Levels and Multiplet Tables, Si I, by C. E. Moore, 1967 (20 cents), SD Catalog No. C13.48:3/Sec.2.

NSRDS-NBS 3, Sec. 3, Selected Tab!es of Atomic Spectra, Atomic Energy Levels and Multiplet 'Tables, C I, C II, C III, C IV, C V, C vi, by C. E. Moore, 1970 (\$1), SD Catalog No. C13.48:3/Sec.3.

NSRDS-NBS 3, Sec. 4, Selected Tables of Atomic Spectra, Atomic Energy Levels and Multiplet Tables, $\mathbf{N}$ IV, $\mathbf{N}$ v, $\mathbf{N}$ vi, $\mathbf{N}$ vII, by made either by international money order or draft on an American bank. Postage stamps are not acceptable.

No charge is made for postage to destinations in the United States and possessions, Canada, Mexico, and certain Central and South American countries. To other countries, payments for documents must cover postage. Therefore, one-fourth of the price of the publication should be added for postage.

Send your order together with remittance to Superintendent of Documents, Government Printing Office, Washington, D.C. 20402.

C. E. Moore, 1971 (55 cents), SD Catalog No. C13.48:3/Sec.4.

NSRDS-NBS 3, Sec. 6, Selected Tables of Atomic Spectra, Atomic Energy Levels and Multiplet Tables, HI , D, T, by C. E. Moore, 1971 (In press), SD Catalog No. C13.48:3/Sec. 6. NSRDS-NBS 4, Atomic Transition Probabilities, Vol. i, Hydrogen Through Neon, by W. L. Wiese, M. W. Smith, and B. Mi. Glennon, 1966 (\$2.50), SD Catalog No. C13.48:4/Vol. I.

NSRDS-NBS 5, The Band Spectrum of Carbon Monoxide, by P. H. Krupenie, 1966 (70 cents), SD Catalog No. C13.48:5.

NSRDS-NBS 6, Tables of Molecular Vibrational Frequencies, Part 1 , by T. Shimanouchi, 1967 (40 cents), SD Catalog No. C13.48:6/Pt.1. Superseded by NSRDS-NBS 39. NSRDS-NBS 7, High Temperature Properties and Decomposition of Inorganic Salts, Part 1. Sulfates, by K. H. Stern and E. L. Weise, 1966 (35 cents), SD Catalog No. C13.48:7/Pt.1.

NSRDS-NBS 8, Thermal Conductivity of Selected Materials, by R. W. Powell, C. Y. Ho, 
and P. E. Liley, 1966 (\$3). PB189698*

NSRDS-NBS 9, Tables of Bimolecular Gas Reactions, by A. F. Trotman-Dickenson and G. S. Milne, 1967 (\$2), SD Catalog No. C13.48:9. NSRDS-NBS 10, Selected Values of Electric Dipole Moments for Molecules in the Gas Phase, by R. D. Nelson, Jr., D. R. Lide, Jr., and A. A. Maryott, 1967 (40 cents), SD Catalog No. C13.48: 10 .

NSRDS-NBS 11, Tables of Molecular Vibrational Frequencies, Part 2, by T. Shimanouchi, 1967 (30 cents), SD Catalog No. C13.48:11/Pt.2. Superseded by NSRDS-NBS 39. NSRDS-NBS 12, Tables for the Rigid Asymmetric Rotor: Transformation Coefficients from Symmetric to Asymmetric Bases and Expectation Values of $\mathbf{P}_{z}^{2}, \mathbf{P}_{z}^{4}$ and $\mathbf{P}_{z}^{6}$, by R. H. Schwendeman, 1968 (60 cents), SD Cata$\log$ No. C13.48:12.

NSRDS-NBS 13, Hydrogenation of Ethylene on Metallic Catalysts, by J. Horiuti and K. Miyahara, 1968 (\$1), SD Catalog No. C13.48:13.

NSRDS-NBS 14 , X-Ray Wavelengths and $\mathbf{X}$ Ray Atomic Energy Levels, by J. A. Bearden, 1967 (40 cents), SD Catalog No. C13.48:14.

NSRDS-NBS 15, Molten Salts: Vol. 1, Electrical Conductance, Density, and Viscosity Data, by G. J. Janz, F. W. Dampier, G. R. Lakshminarayanan, P. K. Lorenz, and R. P. T. Tomkins, 1968 (\$3), SD Catalog No. C13.48:15/Vol.1.

NSRDS-NBS 16, Thermal Conductivity of Selected Materials, Part 2, by C. Y. Ho, R. W. Powell, and P. E. Liley, 1968 (\$2), SD Catalog No. C13.48:16/Pt.2.

NSRDS-NBS 17, Tables of Molecular Vibrational Frequencies, Part 3 , by $T$. Shimanouchi, 1968 (30 cents), SD Catalog No. C13.48:17/Pt.3. Superseded by NSRDS-NBS 39 . NSRDS-NBS 18, Critical Analysis of the HeatCapacity Data of the Literature and Evaluation of Thermodynamic Properties of Copper, Silver, and Gold from 0 to $300 \mathrm{~K}$, by G. T. Furukawa, W. G. Saba, and M. L. Reilly, 1968 (40 cents), SD Catalog No. C13.48:18.

NSRDS-NBS 19, Thermodynamic Properties of Ammonia as an Ideal Gas, by L. Haar, 1968 (20 cents), SD Catalog No. C13.48:19.

NSRDS-NBS 20, Gas Phase Reaction Kinetics of Neutral Oxygen Species, by H. S.

*Available from National Technical Information Service, Springfield, Virginia 22151
Johnston, 1968 (45 cents), SD Catalog No. C13.48:20.

NSRDS-NBS 21, Kinetic Data on Gas Phase Unimolecular Reactions, by S. W. Benson and H. E. O'Neal, 1970 (\$7), SD Catalog No. C13.48:21.

NSRDS-NBS 22, Atomic Transition Probabilities, Vol. II, Sodium Through Calcium, A Critical Data Compilation, by W. L. Wiese, M. W. Smith, and B. M. Miles, 1969 (\$4.50), SD Catalog No. C13.48:22/Vol.II.

NSRDS-NBS 23, Partial Grotrian Diagrams of Astrophysical Interest, by C. E. Moore and P. W. Merrill, 1968 (55 cents), SD Catalog No. C13.48:23.

NSRDS-NBS 24, Theoretical Mean Activity Coefficients of Strong Electrolytes in Aqueous Solutions from 0 to $100{ }^{\circ} \mathrm{C}$, by Walter J. Hamer, 1968 (\$4.25), SD Catalog No. C13.48:24.

NSRDS-NBS 25, Electron Impact Excitation of Atoms, by B. L. Moiseiwitsch and S. J. Smith, 1968 (\$2), SD Catalog No. C13.48:25.

NSRDS-NBS 26, Ionization Potentials, Appearance Potentials, and Heats of Formation of Gaseous Positive Ions, by J. L. Franklin, J. G. Dillard, H. M. Rosenstock, J. T. Herron, K. Draxl, and F. H. Field, 1969 (\$4), SD Catalog No. C13.48:26.

NSRDS-NBS 27, Thermodynamic Properties of Argon from the Triple Point to $300 \mathrm{~K}$ at Pressures to 1000 Atmospheres, by A. L. Gosman, R. D. McCarty, and J. G. Hust, 1969 (\$1.25), SD Catalog No. C13.48:27.

NSRDS-NBS 28, Molten Salts: Vol. 2, Section 1. Electrochemistry of Molten Salts: Gibbs Free Energies and Excess Free Energies from Equilibrium-Type Cells, by G. J. Janz and C. G. M. Dijkhuis; Section 2. Surface Tension Data, by G. J. Janz, G. R. Lakshminarayanan, R. P. T. Tomkins, and J. Wong, 1969 (\$2.75), SD Catalog No. C13.48:28/Vol.2.

NSRDS-NBS 29, Photon Cross Sections, Attenuation Coefficients, and Energy Absorption Coefficients from $10 \mathrm{keV}$ to $100 \mathrm{GeV}$, by J. H. Hubbell, 1969 (75 cents), SD Catalog No. C13.48:29.

NSRDS-NBS 30, High Temperature Properties and Decomposition of Inorganic Salts, Part 2. Carbonates, by K. H. Stern and E. L. Weise, 1969 (45 cents), SD Catalog No. C13.48:30/Pt.2.

NSRDS-NBS 31, Bond Dissociation Energies 
in Simple Molecules, by B. deB. Darwent, 1970 (55 cents), SD Catalog No. C13.48:31.

NSRDS-NBS 32, Phase Behavior in Binary and Multicomponent Systems at Elevated Pressures: $n$-Pentane and Methane- $n$-Pentane, by V. M. Berry and B. H. Sage, 1970 (70 cents), SD Catalog No. C13.48:32.

NSRDS-NBS 33, Electrolytic Conductance and the Conductances of the Halogen Acids in Water, by W. J. Hamer and H. J. DeWane, 1970 (50 cents), SD Catalog No. C13.48:33.

NSRDS-NBS 34, Ionization Potentials and Ionization Limits Derived from the Analyses of Optical Spectra, by C. E. Moore, 1970 (75 cents), SD Catalog No. C13.48:34.

NSRDS-NBS 35, Atomic Energy Levels as Derived from the Analyses of Optical Spectra, Vol. I, ${ }^{1} \mathrm{H}$ to ${ }^{23} \mathrm{~V}$; Vol. II, ${ }^{24} \mathrm{Cr}$ to ${ }^{41} \mathrm{Nb}$; Vol. III, ${ }^{42} \mathrm{Mo}$ to ${ }^{57} \mathrm{La}_{2}{ }^{72} \mathrm{Hf}$ to ${ }^{89} \mathrm{Ac}$, by C. E. Moore, 1971 (Vol. I, \$5; Vol. II, \$4.25; Vol. I!I, $\$ 4.50)$, SD Catalog No. C13.48:35/Vols. I, II, and III.

NSRDS-NBS 36, Critical Micelle Concentrations of Aqueous Surfactant Systems, by P. Mukerjee and K. J. Mysels, 1971 (\$3.75), SD Catalog No. C13.48:36.

NSRDS-NBS 37 , JANAF Thermochemical Tables, 2d Edition, by D. R. Stull, H. Prophet, et al., 1971 (\$9.75), SD Catalog No. C13.48:37.
NSRDS-NBS 38, Critical Review of Ultraviolet Photoabsorption Cross Sections for Molecules of Astrophysical and Aeronomic Interest, by R. D. Hudson, 1971 (\$1), SD Catalog No. C13.48:38.

NSRDS-NBS 39, Tables of Molecular Vibrational Frequencies, Consolidated Tables, by T. Shimanouchi, 1972 (In press), SD Catalog No. C13.48:39.

NSRDS-NBS 40, A Multiplet Table of Astrophysical Interest (Reprint of 1945 Edition), by C. E. Moore, 1972 (\$2), SD Catalog No. C13.48:40. NSRDS-NBS 41, Crystal Structure Transformations in Binary Halides, by C. N. R. Rao, 1972 (In press), SD Catalog No. C13.48:41. NSRDS-NBS 42, Selected Specific Rates of Reactions of the Solvated Electron in Alcohols, by E. Watson, Jr., and S. Roy, 1972 (In press), SD Catalog No. C13.48:42.

NSRDS-NBS 43, Selected Specific Rates of Reactions of Transients from Water in Aqueous Solution, by M. Anbar, M. Bambenek, and A. B. Ross, 1972 (In press), SD Catalog No. C13.48:43.

NSRDS-NBS 44, The Radiation Chemistry of Gaseous Ammonia, by D. B. Peterson, 1972 (In press), SD Catalog No. C13.48:44. 


\begin{tabular}{|c|c|c|c|}
\hline $\begin{array}{l}\text { U.S. DEPT. OF COMM. } \\
\text { BIBLIOGRAPHIC DATA } \\
\text { SHEET }\end{array}$ & $\begin{array}{l}\text { 1. PUBLICATION OR REPORT NO. } \\
\text { NBS-NSR DS-41 }\end{array}$ & $\begin{array}{l}\text { 2. Gov't Accession } \\
\text { No. }\end{array}$ & 3. Recipient's Accession No. \\
\hline \multicolumn{3}{|l|}{ 4. TIT LE AND SUBTITLE } & $\begin{array}{l}\text { 5. Publication Date } \\
\text { July } 1972\end{array}$ \\
\hline \multicolumn{3}{|c|}{ Crystal Structure Transformations in Einary Halides } & 6. Performing Organization Code \\
\hline \multicolumn{3}{|c|}{$\begin{array}{l}\text { 7. AUTHOR(S) } \\
\text { C.:?R. Rao and M. Natarajan }\end{array}$} & 8. Performing Organization \\
\hline \multicolumn{3}{|c|}{ 9. PERF ORMING ORGANIZATION NAME AND ADDRESS } & 10. Project/Task/Work Unit No. \\
\hline \multicolumn{3}{|c|}{$\begin{array}{l}\text { NAT IONAL BUREAU OF ST AND ARDS } \\
\text { DEPARTMENT OF COMMERCE } \\
\text { WASHINGTON, D.C. } 20234\end{array}$} & 11. Contract/Grant No. \\
\hline \multirow{2}{*}{\multicolumn{3}{|c|}{ 12. Sponsoring Organization Name and Address }} & $\begin{array}{l}\text { 13. Type of Report \& Period } \\
\text { Covered }\end{array}$ \\
\hline & & & 14. Sponsoring Agency Code \\
\hline
\end{tabular}

\section{SUPPLEMENTARY NOTES}

16. ABSTRACT (A 200-word or less factual summary of most significant information. If document includes a significant bibliography or literature survey, mention it here.)

A critical survey of the data describing crystal structure transformations in binary halides is compiled. Data on themodynamic, crystallographic, spectroscopic and electronic properties are given for each transformation. Experimental techniques used to obtain the data are named and comments on the data are included in the tables The literature is surveyed up to 1970. References have heen selected on the basis of their pertinence to the data which are cited and do not represent all the available literature.

17. KEY WORDS (Alphabetical order, separated by semicolons)

Pinary halides; Crystal structure transformation; Electronic data; Phase transformation; Spectroscopic data; Thermodynamic data; X-ray diffraction data. 18. AVAILABILITY STATEMENT

$X$ UNLIMITED.

FOR OFFICIAL DISTRIBUTION. DO NOT RELEASE TO NTIS.

19. SECURITY CLASS (THIS REPURT)

UNCL ASSIF IED

20. SECURITY CLASS

(THIS PAGE)

UNCL ASSIFIED
21. NO. OF PAGES

\section{3}

22. Price

55 Cents 
PERIODICALS

JOURNAL OF RESEARCH reports National Bureau of Standards research and development in physics, mathematics, and chemistry. Comprehensive scientific papers give complete details of the work, including laboratory data, experimental procedures, and theoretical and mathematical analyses. Illustrated with photographs, drawings, and charts. Includes listings of other NBS papers as issued.

Published in two sections, available separately:

\section{- Physics and Chemistry}

Papers of interest primarily to scientists working in these fields. This section covers a broad range of physical and chemical research, with major emphasis on standards of physical measurement, fundamental constants, and properties of matter. Issued six times a vear. Annual subscription: Domestic, $\$ 9.50 ; \$ 2.25$ additional for foreign mailing.

\section{- Mathematical Sciences}

Studies and compilations designed mainly for the mathematician and theoretical physicist. Topics in mathematical statistics, theory of experiment design, numerical analysis, theoretical physics and chemistry; logical design and programming of computers and computer systems. Short numerical tables. Issued quarterly. Annual subscription: Domestic, $\$ 5.00$; $\$ 1.25$ additional for foreign mailing.

\section{TECHNICAL NEWS BULLETIN}

The best single source of information concerning the Bureau's measurement, research, developmental, cooperative, and publication activities, this monthly publication is designed for the industry-oriented individual whose daily work involves intimate contact with science and technology-for engineers, chemists, physicists, research managers, product-development managers, and company executives. Includes listing of all NBS papers as issued. Annual subscription: Domestic, $\$ 3.00 ; \$ 1.00$ additional for foreign mailing.

\section{Bibliographic Subscription Services}

The following current-awareness and literaturesurvey bibliographies are issued periodically by the Bureau: Cryogenic Data Center Current Awareness Service (weekly), Liquefied Natural Gas (quarterly), Superconducting Devices and Materials (quarterly), and Electromagnetic Metrology Current Awareness Service (monthly). Available only from NBS Boulder Laboratories. Ordering and cost information may be obtained from the Program Information Office. National Bureau of Standards, Boulder, Colorado 80302 .

\section{NONPERIODICALS}

Applied Mathematics Series. Mathematical tables, manuals, and studies.

Building Science Series. Research results, test methods, and performance criteria of building materials, components, systems, and structures.

Handbooks. Recommended codes of engineering and industrial practice (including safety codes) developed in cooperation with interested industries, professional organizations, and regulatory bodies.

Special Publications. Proceedings of NBS conferences, bibliographies, annual reports, wall charts, pamphlets, etc.

Monographs. Major contributions to the technical literature on various subjects related to the Bureau's scientific and technical activities.

\section{National Standard Reference Data Series.} NSRDS provides quantitative data on the physical and chemical properties of materials, compiled from the world's literature and critically evaluated.

Product Standards. Provide requirements for sizes, types, quality, and methods for testing various industrial products. These standards are developed cooperatively with interested Government and industry groups and provide the basis for common understanding of product charateristics for both buyers and sellers. Their use is voluntary.

Technical Notes. This series consists of communications and reports / covering both other-agency and NBS-sponsored work) of limited or transitory interest.

Federal Information Processing Standards Publications. This series is the official publication within the Federal Government for information on standards adopted and promulgated under the Public Law 89-306, and Bureau of the Budget Circular A-86 entitled, Standardization of Data Elements and Codes in Data Systems.

Consumer Information Series. Practical information, based on NBS research and experience, covering areas of interest to the consumer. Easily understandable language and illustrations provide useful background knowledge for shopping in today's technological marketplace.

\section{CATALOGS OF NBS PUBLIICATIONS}

NBS Special Publication 305, Publications of the NBS. 1966-1967. When ordering, include Catalog No. C13.10:305. Price $\$ 2.00 ; 50$ cents additional for foreign mailing.

NBS Special Publication 305, Supplement 1, Publications of the NBS, 1968-1969. When ordering, include Catalog No. C13.10:305/Suppl. 1. Price $\$ 4.50$; $\$ 1.25$ additional for foreign mailing.

NBS Special Publication 305, Supplement 2, Publications of the NBS, 1970. When ordering, include Catalog No. C13.10:305/Suppl. 2. Price $\$ 3.25$; 85 cents additional for foreign mailing.

Order NBS publications (except Bibliographic Suliseription Services

from: Superintendent of Documents. Government Printiner Office, Wash-

ington, D.C. 20402. 
U.S. DEPARTMENT OF COMMERCE

National Bureau of Standards

Washington, D.C. 20234

OFFICIAL BUSINESS

POSTAGE AND FEES PAIO

U.S. OEPARTMEN

215

Penalty for Private Use, $\$ 300$ 